\title{
HYPOXIA-SELECTIVE ANTITUMOR PRODRUGS AND FLUORESCENT PROBES
}

A Dissertation
Presented to
the Faculty of the Graduate School
at the University of Missouri-Columbia
In Partial Fulfillment
of the Requirements for the Degree
Doctor of Philosophy
Xiulong Shen
becember 2016 Kent Gates, Dissertation Supervisor
Decer


The undersigned, appointed by the dean of the Graduate School, have examined the dissertation entitled

\title{
HYPOXIA-SELECTIVE ANTITUMOR PRODRUGS AND
}

FLUORESCENT PROBES

\author{
Presented by Xiulong Shen, \\ A candidate for the degree of doctor of philosophy, \\ And hereby certify that, in their opinion, it is worthy of acceptance.
}

Professor Kent S. Gates

Professor Timothy E. Glass

Professor Gary A. Baker

Professor Lixin Ma 


\section{ACKNOWLEDGEMENTS}

First I would like to thank my advisor, Professor Kent S. Gates, for his support throughout my Ph.D. career. I'm grateful for the opportunity to work in your group. You teach me how to become an independent researcher, from critical thinking to scientific manners. I could not image to have a better advisor than you.

Then, I also would like to thank my committee members, Professors Timothy E. Glass, Professor Gary A. Baker and Professor Lixin Ma for your help and valuable suggestions during my Ph.D. career.

I want to thank my colleagues in Gates research group, past and present. I would like to convey my special thanks to Dr. Anuruddha Rajapakse for his patient guide when I just joined the group. I also want to thank Dr. Fabio Gallazzi for his support and kind help in LC-MS.

Finally, I dedicate this thesis to my parents Mr. Wenxing Shen and Mrs. Chunxiang Du, as well as my girlfriend Hui Wang. Thank you for being the warm haven in my life. Without your love and support, I could not accomplish this much. 


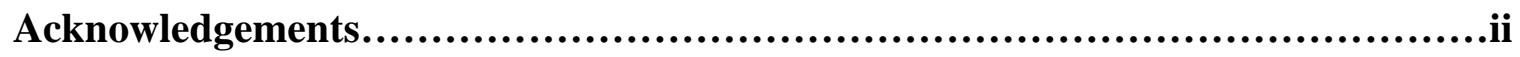

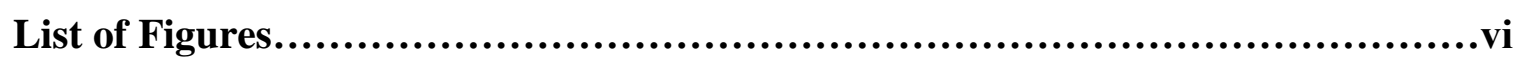

List of Schemes.........................................................................

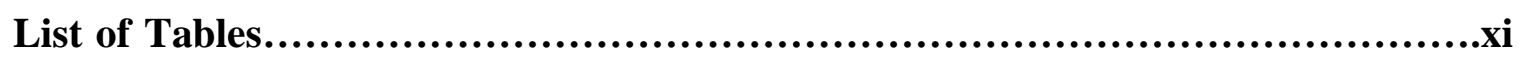

List of Abbreviations...................................................................ii

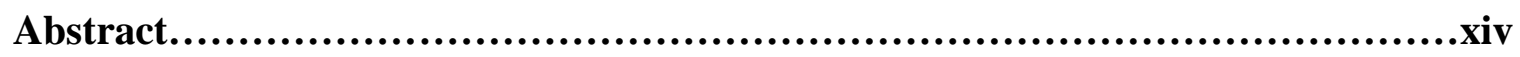

\section{Chapter 1. Introduction}

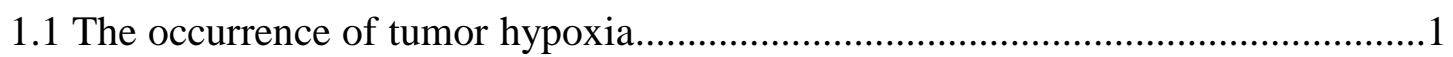

1.2 Therapeutic importance of tumor hypoxia...........................................................

1.3 Hypoxia-selective antitumor prodrug .............................................................

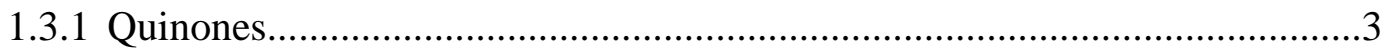

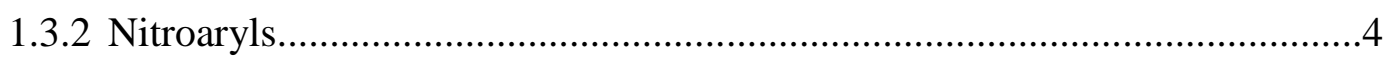

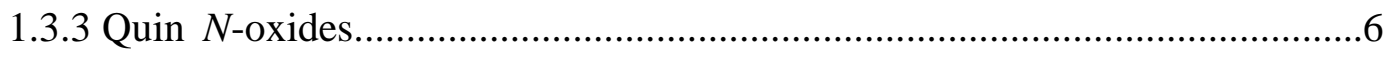

1.3.4 Metal complexes................................................................................

1.4 Probes for the detection of hypoxia and drug-related reductive enzymes................8

1.4.1 Reductase involved in bioactivation of hypoxia-selective prodrugs............8

1.4.2 Approaches for the evaluation of tumor hypoxia...........................................

1.4.3Fluorescent probes for the detection of hypoxia and drug-related

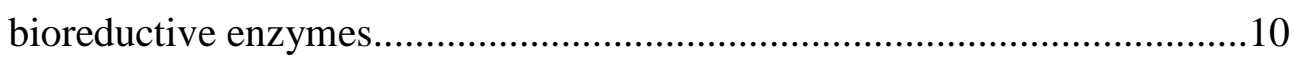

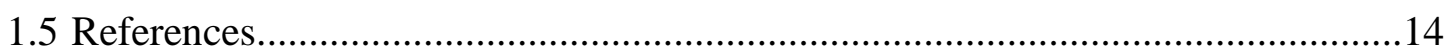


Chapter 2. Mechanistic study of DNA strand cleavage by 1,2,4-benzotriazine-1,4-di$N$-oxide

2.1 Introduction .29

2.2 Bioreductively-activated, hypoxia-selective DNA strand cleavage by compound $1 \mathrm{~b}$ .31

2.3 In vitro bioreductive metabolism of $\mathbf{1} \mathbf{b}$. .38

2.4 In vitro bioreductive metabolism of $\mathbf{1 b}$ in phosphate-buffered $\mathrm{D}_{2} \mathrm{O}$-methanol$d 4$. .41

2.5 In vitro bioreductive metabolism of the deuterium-labeled analog $\mathbf{1 c}$ .42

2.6 In vitro bioreductive metabolism of $\mathbf{1 b}$ in phosphate-buffered $\mathrm{D}_{2} \mathrm{O}$-methanol- $d_{4}$ with removal all exchangeable protium sources.

2.7 Conclusion .45

2.8 Experimental section and NMRs .45

2.9 References. .55

Chapter 3. TPZ mono- $N$-oxides as the pro-fluorescent substrates for bioredcutive enzymes

3.1 Introduction. .63

3.2 Synthesis and preliminary screening of 1,2,4-benzotriazine 1-oxides by

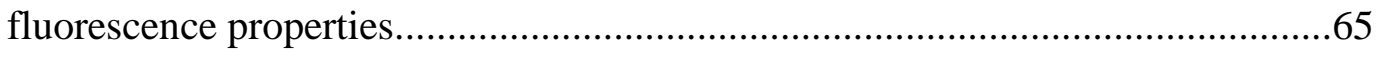

3.3 Static photophysical properties of 1,2,4-benzotriazine oxides...............................68

3.4 LC-MS analysis of hypoxia-selective in vitro metabolic conversion of dioxides (1d-e) to the corresponding mono-N-oxides (3d-e) .72 
3.5 Fluorimetric analysis of hypoxia-selective in vitro metabolic conversion of 1d-e into 3d-e .79

3.6 Effects of exogenous protein and cell extracts on the potential applications of the probes

3.7 Potential quantitative application of $1 \mathrm{~d}$ as pro-fluorescent probes to measure the total reductive enzyme activity .83

3.8 Conclusions .85

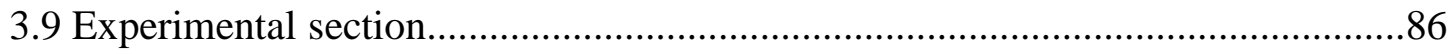

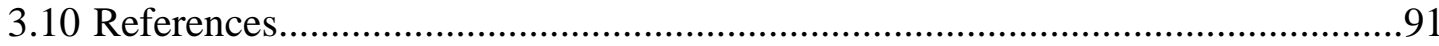

\section{Chapter 4. Mechanistic study of DNA strand cleavage by ${ }^{18} \mathrm{O}$-labeled tirapazamine}

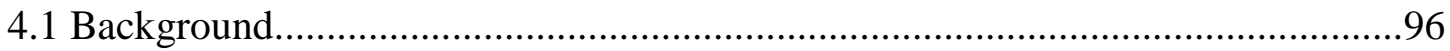

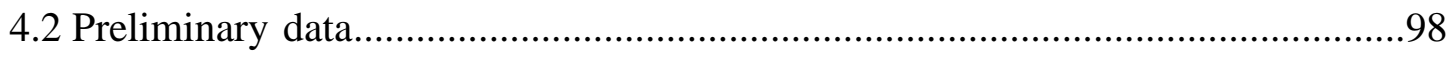

4.2.1 Synthesis of authentic diazosulfones 8a-b.........................................98

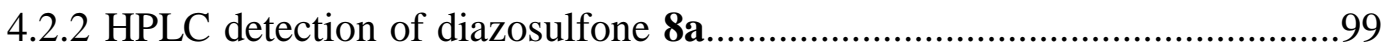

4.2.3 DMSO tolerance of in-vitro hypoxic enzymatic assays of 1a..................100

4.2.4 MS characterization of the authentic diazosulfones 8a-b.......................102

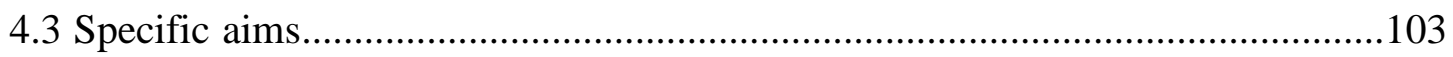

4.3.1 Estimation of the yield of 8a-b in enzymatic metabolism of 1a...............103

4.3.2 MS analysis of 8a-b generated in enzymatic assay of 1a and 1f..............104

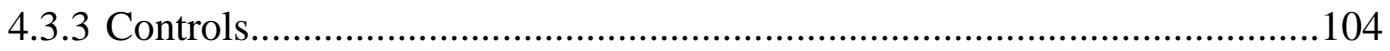

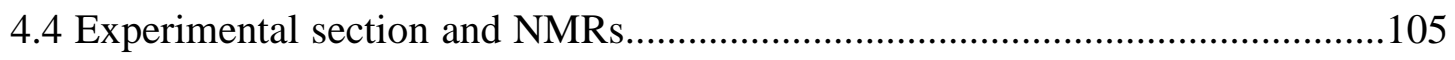

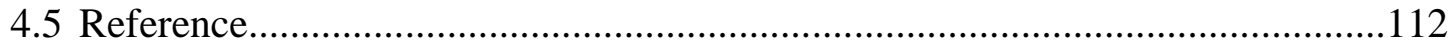

VITA 


\section{LIST OF FIGURES}

\section{Chapter 2}

Figure 2.1. Cleavage of supercoiled plasmid DNA by TPZ $(1 \mathrm{a}, 50-100 \mu \mathrm{M})$ in the presence of NADPH:cytochrome $\mathrm{P} 450$ reductase in phosphate-buffered $\mathrm{H}_{2} \mathrm{O} / \mathrm{CH}_{3} \mathrm{OH}$

Figure 2.2. Cleavage of supercoiled plasmid DNA by desamino TPZ (1b, 50-100 $\mu \mathrm{M})$ in the presence of NADPH:cytochrome P450 reductase as an activating system in

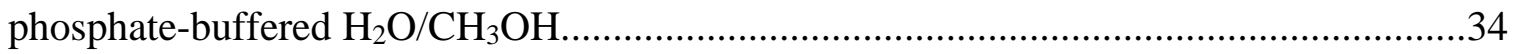

Figure 2.3. Cleavage of supercoiled plasmid DNA by TPZ $(1 \mathbf{a}, 50-100 \mu \mathrm{M})$ in the presence of NADPH:cytochrome P450 reductase as an activating system phosphate-

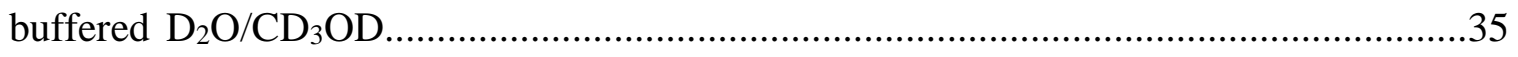

Figure 2.4. Gel and bar graph showing cleavage of supercoiled plasmid DNA by desamino TPZ (1b, 50-100 $\mu \mathrm{M})$ in the presence of the NADPH:cytochrome P450

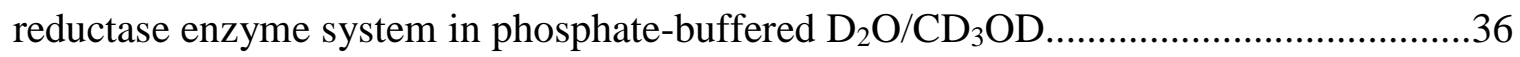

Figure 2.5. Control reactions relevant to DNA strand cleavage by $\mathbf{1 b} \ldots \ldots \ldots \ldots \ldots \ldots \ldots \ldots \ldots \ldots . . . . . .37$

Figure 2.6. Reverse-phase HPLC chromatogram (UV $240 \mathrm{~nm}$ ) of the products generated by in vitro hypoxic metabolism of $\mathbf{1 b}$ in buffered $\mathrm{H}_{2} \mathrm{O} / \mathrm{CH}_{3} \mathrm{OH}$...................................38

Figure 2.7. Reverse-phase HPLC chromatogram (UV $240 \mathrm{~nm}$ ) of the products generated

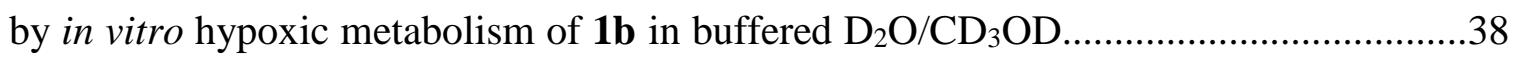

Figure 2.8. MS/MS spectra of the metabolite 7 generated................................................40

Figure 2.9. Hypoxic metabolism of $\mathbf{1 b}$ in phosphate-buffered $\mathrm{D}_{2} \mathrm{O} / \mathrm{CD}_{3} \mathrm{OD}$ does not lead to incorporation of deuterium into the metabolite 3 . 
Figure 2.10. MS of 1c and 3c present in the mixture generated by hypoxic metabolism of 1c by NADPH:cytochrome $\mathrm{P} 450$ reductase in buffered $\mathrm{H}_{2} \mathrm{O} / \mathrm{CH}_{3} \mathrm{OH}$

Figure 2.11. LC-MS of metabolites $\mathbf{6}$ and $\mathbf{3}$ generated by hypoxic metabolism of $\mathbf{1 b}$ by NADPH:cytochrome P450 reductase in "completely deuterated" $\mathrm{D}_{2} \mathrm{O} / \mathrm{CD}_{3} \mathrm{OD}$ buffer described below

\section{Chapter 3}

Figure 3.1. Normalized excitation and emission spectra of BTO dioxides (1d-1e) and mono- $N$-oxides (3d-3e) in $18 \mathrm{M} \Omega \mathrm{H}_{2} \mathrm{O}$. .71

Figure 3.2. A. Solvent dependent emission spectra of 3d at an exication of $450 \mathrm{~nm}$. B. $\mathrm{E}_{\mathrm{T}}(30)$-Emission maximum curve of $\mathbf{3 d}$ in twelve solvents. .73

Figure 3.3. A. Solvent dependent emission spectra of $\mathbf{3 e}$ at an exication of $450 \mathrm{~nm}$. B. $\mathrm{E}_{\mathrm{T}}(30)$-Emission maximum curve of $\mathbf{3 e}$ in twelve solvents.

Figure 3.4. LC-MS analysis of the in vitro hypoxic metabolism of $\mathbf{1 d}$ in

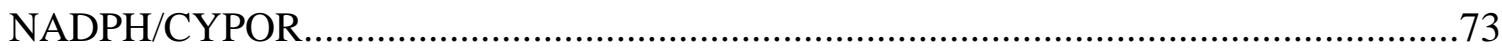

Figure 3.5. LC-MS analysis of the in vitro hypoxic metabolism of $1 \mathbf{e}$ in

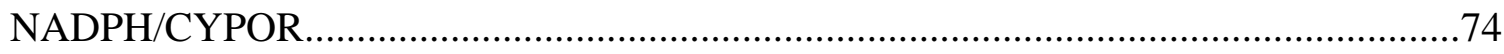

Figure 3.6. LC-MS analysis of the in vitro hypoxic metabolism of $\mathbf{1 a}$ in

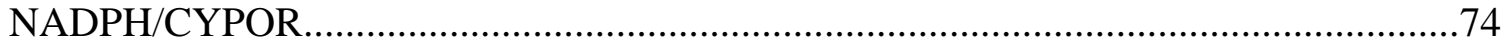

Figure 3.7. HPLC calibration curves of BTO mono- $N$-oxides with different concentrations. .75

Figure 3.8. HPLC calibration curves of quinones with different concentration. .77 Figure 3.9. 1,4-Naphthoquinone (NQ) and 2,3-Dimethyl-1,4-naphthoquinone (DMNQ) as the positive control of the enzymatic function of DT-Diaphorase. .78 
Figure 3.10. Fluorimetric analysis of metabolites in ethyl acetate extract generated in the aerobic and hypoxic metabolism of 1a, 1d, and 1e by X/XO, NADPH/CYPOR and NADPH/DT-Diaphorase. .80

Figure 3.11. Fluorescence intensity of enzymatic assays in water. .81

Figure 3.12. Fluorescence quantum yield (QY) and emission maximum (Em. Max.) of 3d and $3 \mathbf{e}$ in water in the presence of various concentrations of bovine serum albumin (BSA)

Figure 3.13. Fluorescence intensity of enzymatic assays in ethyl acetate with $\mathrm{X} / \mathrm{XO}$ and human prostate cancer (PC-3) cell extract.

Figure 3.14. Fluorescence intensity of enzymatic assays in ethyl acetate with xanthine/xanthine oxidase. .84

Figure 3.15. Compound $\mathbf{1 d}$ as fluorescence probe for the detection of drug-related bioreductive enzymes .85

\section{Chapter 4}

Figure 4.1. UV absorption spectrum of $100 \mu \mathrm{M}$ 8a in DMSO. .99

Figure 4.2. HPLC chromatogram of $10 \mathrm{mM}$ of 8a in DMSO.....................................100

Figure 4.3. HPLC chromatogram of DMSO tolerance assay.....................................101

Figure 4.4. MS spectra of 8a with CI ionization in position ion mode..........................102

Figure 4.5. LC-MS spectra of $\mathbf{8 a}$ with ESI ionization in position ion mode. 103 


\section{LIST OF SCHEMES}

\section{Chapter 1}

Scheme 1.1. The two-electron reduction of mitomycin C yields a bifunctional alkylating

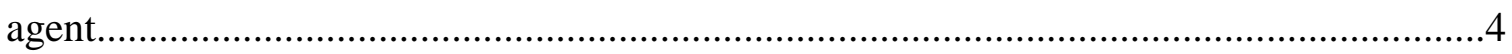

Scheme 1.2. The hypoxia-selective one-electron reduction of nitroaryl compounds .........5

Scheme 1.3. The hypoxia-selective activation of TH-302.............................................6

Scheme 1.4. The hypoxia-selective activation of PR-104................................................6

Scheme 1.5. The hypoxia-selective activation of TPZ ...................................................

Scheme 1.6. Chemical structure of SN30000/CEN-209.................................................

Scheme 1.7. Co(III) complex as hypoxia-selective prodrugs............................................8

Scheme 1.8. Examples of PET and SPECT probes used in preclinical and clinical studies

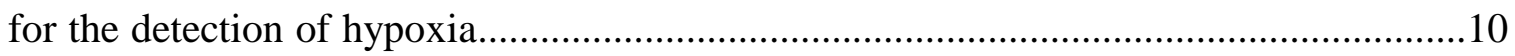

Scheme 1.9. Examples of nitroaryl probes based on the alteration of fluorescence

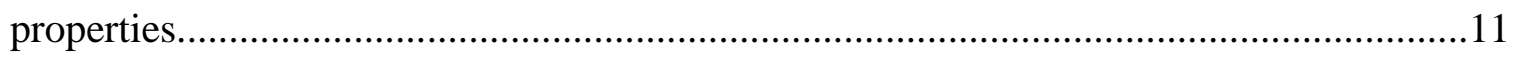

Scheme 1.10. Examples of nitroaryl probes based on the release of fluorescent

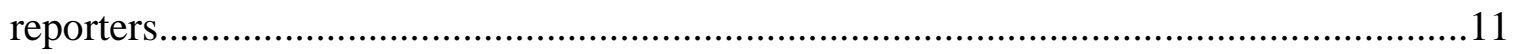

Scheme 1.11. The in vitro enzymatic metabolism of non-fluorescent 6-NQ yields

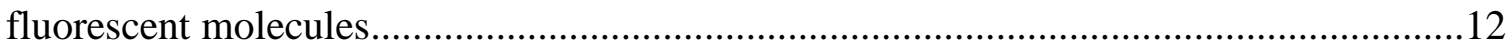

Scheme 1.12. Near infrared fluorescent probes based on selective retention in cells. 


\section{Chapter 2}

Scheme 2.1. The structure of tirapazamine and SN 30000/CEN-209.

Scheme 2.2. Bioreductively-activated, hypoxia-selective metabolism of tirapazamine and its analogs .30

Scheme 2.3. Isotopic labeling experiments to elucidate the mechanism of DNA strand cleavage by $\mathbf{1 b}$ .31

Scheme 2.4. Tentative fragmentation patterns of the hypoxic metabolism of $1 \mathbf{b}$ .40

\section{Chapter 3}

Scheme 3.1. Hypoxic metabolism of tirapazamine (1a) and the generation of fluorescent

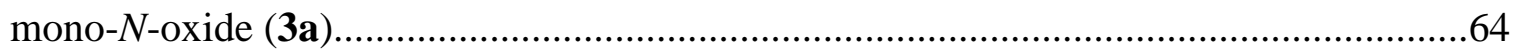

Scheme 3.2. The thirty-one compound library of 1,2-4-benzotriazine 1-oxides..............65

Scheme 3.3. The synthesis of 1,2,4-benzotriazine-1,4-di- $N$-oxides and 1-oxides............68

Scheme 3.4. Schematic procedure for the quantitative application of the probe $1 \mathbf{d}$.........84

\section{Chapter 4}

Scheme 4.1. Synthesis of ${ }^{18} \mathrm{O}-$ lebaled TPZ (1f) and desamino TPZ (1g).......................96

Scheme 4.2. In vitro enzymatic metabolism of ${ }^{18} \mathrm{O}-$ lebaled TPZ (1f)............................97

Scheme 4.3. Effective trapping of hydroxyl radical with DMSO that yields MSA.........98

Scheme 4.4. The formation of diazosulfone by MSA and diazonium salts....................98

Scheme 4.5. Diazosulfones (8a-b) and the corresponding diazonium salts (9a-b)..........99

Scheme 4.6. The potential solvent exchange reaction of hydroxyl radical and water.....100 


\section{LIST OF TABLES}

\section{Chapter 2}

Table 2.1. LC-MS/MS properties of the mixture generated by in vitro metabolism of $\mathbf{1 b}$

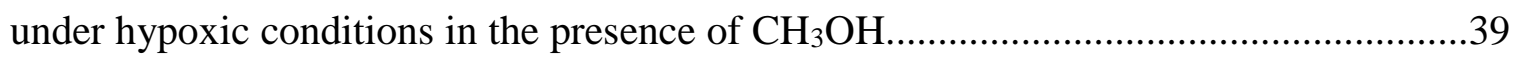

\section{Chapter 3}

Table 3.1. Preliminary photophysical properties for benzotriazine 1-oxides...............66-67

Table 3.2. Static photophysical properties of 1,2,4-benzotriazine oxides......................70

Table 3.3. Generation of mono-N-oxide via in vitro metabolism of $\mathbf{1 a}, \mathbf{1 d}$, and $\mathbf{1 e}$.........76 


\section{LIST OF ABBREVIATIONS}

\begin{tabular}{|c|c|}
\hline HIFs & hypoxia inducible factors \\
\hline MDR1 & multidrug resistance protein 1 \\
\hline TPZ & 3-amino-1,2,4-benzotriazine-1,4-di- $N$-oxide \\
\hline desamino TPZ & 1,2,4-benzotriazine-1,4-di- $N$-oxide \\
\hline CYPOR & NADPH: cytochrome $\mathrm{P} 450$ reductase \\
\hline $\mathrm{XO}$ & xanthine oxidase \\
\hline NADPH/CYPOR & NADPH/ NADPH: cytochrome P450 reductase enzyme system \\
\hline $\mathrm{X} / \mathrm{XO}$ & xanthine/ xanthine oxidase enzyme system \\
\hline CYB5R3 & NADH-dependent cytochrome b5 reductase 3 \\
\hline MTRR & methionine synthase reductase \\
\hline NOS & nitric oxide synthase \\
\hline DTD & DT-diaphorase \\
\hline MRI & magnetic resonance imaging \\
\hline PET & positron emission tomography \\
\hline SPECT & single photon emission computed tomography \\
\hline CT & computed tomography \\
\hline${ }^{18} \mathrm{~F}-\mathrm{FMISO}$ & ${ }^{18} \mathrm{~F}$-fluoromisonidazole \\
\hline \multirow[t]{2}{*}{${ }^{18} \mathrm{~F}-\mathrm{EF} 5$} & 2-(2-nitro- $1 H$-imidazol-1-yl)- $N$-(2,3,3,3-[ $\left.{ }^{18} \mathrm{~F}\right]$-pentafluoropropyl)- \\
\hline & Acetamide \\
\hline 6-NQ & 6-nitroquinoline \\
\hline $6-\mathrm{AQ}$ & 6-aminoquinoline \\
\hline
\end{tabular}




$\begin{array}{ll}\text { SOD } & \text { superoxide dismutase } \\ \text { NQ } & \text { 1,4-naphthoquinone } \\ \text { DMNQ } & \text { 2,3-dimethyl-1,4-naphthoquinone } \\ \text { hydroNQ } & \text { 1,4-hydroxyl-naphthoquinone } \\ \text { hydroDMNQ } & \text { 2,3-Dimethyl-1,4-hydroxyl-naphthoquinone } \\ \text { BSA } & \text { bovine serum albumin } \\ \text { DMSO } & \text { dimethyl sulfoxide } \\ \text { THF } & \text { tetrahydrofuran } \\ \text { MeCN/ACN } & \text { acetonitrile } \\ \text { EtOAc } & \text { ethyl acetate } \\ \text { MeOH } & \text { methanol } \\ \text { EtOH } & \text { ethanol } \\ \text { OctOH } & \text { octanol } \\ \text { DMF } & N, N \text {-dimethylformamide } \\ \text { TFA } & \text { trifluoroacetic acid } \\ \text { TFAA } & \text { trifluoroacetic anhydride } \\ \text { MSA } & \text { methanesulfinic acid }\end{array}$




\begin{abstract}
Hypoxia-selective antitumor prodrugs utilize the unique feature of most tumors hypoxia (low oxygen concentration), for therapeutic purpose and are widely studied in preclinical and clinical stages.

Tirapazamine (TPZ, 3-amino-1,2,4-benzotriazine-1,4-di- $N$-oxide) is a hypoxiaselective cytotoxin that has been examined in Phase II and III clinical trials. The mechanism of DNA strand cleavage by TPZ and its analogs is still unknown. We described two isotopic labeling studies followed by MS analysis to explain the DNA strand cleavage of TPZs. One is to use desamino TPZ (1,2,4-benzotriazine 1,4-di- $N$ oxide) to provided evidence against the generation of benzotriazinyl radical intermediates. The other one is to use ${ }^{18} \mathrm{O}$-labeled TPZ and DMSO-diazonium salt derivatization to provide direct evidence for the generation of hydroxyl radical.

At least two conditions are required for successful clinical application of hypoxiaselective prodrugs: i. target tumors must be hypoxic and ii. appropriate enzymes involved in bioactivation of the drug must be expressed in the tissue. In this regard, it will be necessary to develop diagnostic probes to assess the expression of these enzymes. Here we described tirapazamine analogs as pro-fluorescent substrates of enzymes that catalyze the bioreductive activation of hypoxia-selective prodrugs. That is, the reduced metabolites generated by one-electron enzymatic activation of these compounds under hypoxic condition are fluorescent, while the parent compounds are non-fluorescent. Our results could facilitate the development of useful fluorescent probes in detecting one electron reductases involved in bioactivation of hypoxia-selective antitumor prodrugs.
\end{abstract}




\section{Chapter 1. Introduction}

\subsection{The occurrence of tumor hypoxia}

The fact that tumor tissues are hypoxic (low oxygen concentration) was early suggested by Mottram in 1936 and Thomlinson and Gray in 1955, based upon the observation that many tumor cells are far away from capillaries. ${ }^{1,2}$ Tumors are hypoxic because they have poor vascularization, which means the development of new blood vessels cannot catch up with the rapid tumor growth.

In 1990s, tumor cell hypoxia can be directly measured. ${ }^{4}$ In normal oxygenated cells, the cellular $\mathrm{O}_{2}$ concentration is about $20-90 \mu \mathrm{M}\left(2-9 \%\right.$ saturated with $\left.\mathrm{O}_{2}\right)$. The $\mathrm{O}_{2}$ concentration is $1000 \mu \mathrm{M}$ when water was saturated with pure $\mathrm{O}_{2}(100 \%)$, and $210 \mu \mathrm{M}$ when water was saturated with air $(21 \%)$. In contrast, the cellular $\mathrm{O}_{2}$ concentration is $0.2-$ $20 \mu \mathrm{M}$ in hypoxic cells. ${ }^{5}$ There are two types of hypoxia. One is termed as "chronic" or "diffusion limited" hypoxia, which occurs when the tumor cells are away from the blood vessels and deficient in oxygen diffusion. ${ }^{6}$ Another type occurs when the blood vessels are temporarily or permanently shut down, thus is called "acute" or "perfusion limited" hypoxia. $^{7}$

Hypoxia can occur in vascular disease, pulmonary disease and cancer. In addition, some normal human tissues are also hypoxic: cartilage, germinal epithelium of the testis, retinal tissue, bone marrow, and liver. ${ }^{8,9}$

\subsection{The therapeutic importance of tumor hypoxia}

Hypoxia is of medical importance because it adds challenges to cancer therapy. Although hypoxia can induce apoptosis and is toxic for both tumors and normal tissues, 
tumor cells can survive and grow in hypoxic conditions via up-regulations including hypoxia inducible factors (HIFs) regulation pathways. ${ }^{8}$ It has been demonstrated that hypoxia in tumors correlates with the promotion to more malignant tumor phenotypes ${ }^{10}$, increase in mutation rates ${ }^{11}$, tumor invasion ${ }^{12}$, development to a more metastatic phenotype of human cancers ${ }^{13,14}$, and a poor clinical prognosis ${ }^{15}$. In addition, hypoxia is associated with the resistance to radiotherapy and chemotherapy. Radiotherapy often requires oxygen as radiosensitizer to combine with radicals generated in cells to destroy target cells ${ }^{16}$. Tumor cells in hypoxic areas were found to be 2 to 3 times more resistant to radiation treatment than tumors in normoxic regions ${ }^{17}$. Similarly, hypoxia is correlated with chemoresistance for various reasons, including the decreased drug diffusion and delivery to hypoxic cells via blood flow ${ }^{18}$, the altered $\mathrm{pH}$ gradient ${ }^{19}$, and the upregulation of genes involved in drug resistance, including genes encoding $p$ glycoprotein multidrug resistance protein 1 (MDR1) ${ }^{20,21}$, etc.

The characteristic occurrence of hypoxia in tumor tissues and its medical consequences highlights hypoxia as a high priority drug target, eliciting interest in the development of hypoxia-selective antitumor prodrugs to kill hypoxic tumor cells ${ }^{9,22-24}$, as well as developing diagnostic probes for the detection of hypoxia and drug-related bioreductive enzymes ${ }^{25-28}$.

\subsection{Hypoxia-selective antitumor prodrug}

Tumor hypoxia was often viewed as a therapeutic disadvantage. However, hypoxia-selective antitumor prodrugs (also called bioreductive prodrugs) was designed and developed to utilize hypoxia as a therapeutic gain. The most recent review literature was in 2011 by Wilson and Hay. ${ }^{23}$ Therefore, comprehensive review of hypoxia- 
selective antitumor prodrugs was not necessary. Instead, some important aspects and examples of hypoxia-selective cytotoxins related to the work in this thesis was addressed.

\subsubsection{Quinones}

The idea of hypoxia-selective antitumor prodrugs was inspired by mitomycin $\mathrm{C}$ in 1972. ${ }^{29}$ Mitomycin C was found in 1960 s as a bifunctional alkylating agent that can cause DNA crosslinks. ${ }^{30,31}$ It is proposed that mitomycin $\mathrm{C}$ can be selectively reduced in hypoxic conditions by two steps of one-electron reduction, which the first step can be oxygen sensitive. However, it is proven that mitomycin $\mathrm{C}$ actually undergoes oxygen insensitive two-electron reduction, which outcompetes the oxygen sensitive one-electron reduction process. Some quinones that are good substrates of a one-electron reductase but poor substrates of two-electron reductase can act as hypoxia selective prodrugs. ${ }^{32}$

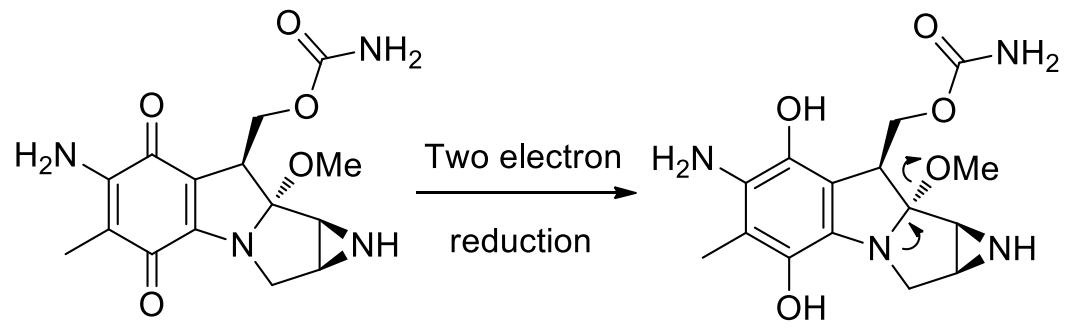

Mitomycin C

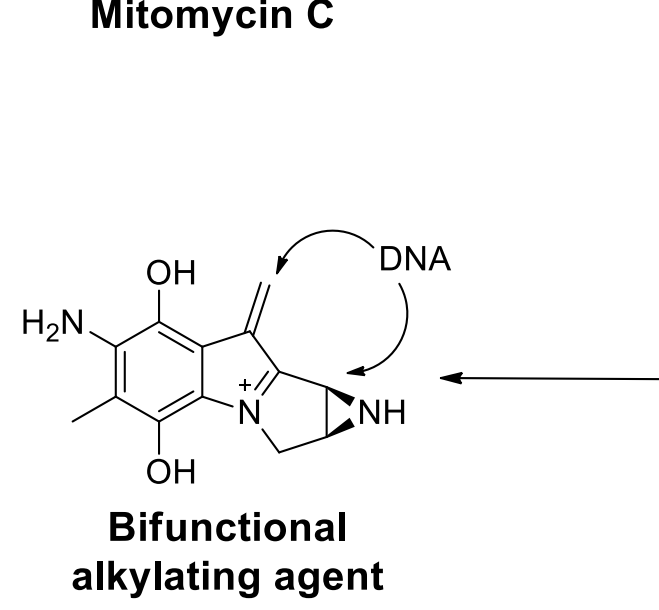

aromatization<smiles>Cc1c(N)c(O)c2c(CCOC(N)=O)c3n(c2c1O)CC1NC31</smiles>

Scheme 1.1. The two-electron reduction of mitomycin $\mathrm{C}$ yields a bifunctional alkylating agent. 


\subsubsection{Nitroaryl compounds}

Nitroaryl compounds also have the potential to design hypoxia-selective antitumor prodrugs because they can undergo a series of one-electron enzymatic reductions under hypoxic conditions utilizing ubiquitously expressed reductive enzymes in cells ${ }^{33}$. Nitroaryls can accept up to six electrons allowing this sequential reduction to produce the intermediate aromatic nitroso compounds, aromatic hydroxylamines, or the final reduced form, aromatic amines. (Scheme 1.2) This conversion increases the electron density of the molecule (Hammett $\sigma_{\mathrm{p}}$ value: $-\mathrm{NO}_{2}, 0.78$; -NO, 0.91 ; $-\mathrm{NHOH},-0.34 ;-\mathrm{NH}_{2},-0.66$ ), by which the electron deficient nitro group is reduced to the electron rich functional groups such as hydroxylamino or amino group. ${ }^{34}$ In addition, the oxygen sensitive step is the first reduction step, in which the nitro radical anion can be readily oxidized back to the parent nitro compound by $\mathrm{O}_{2}$ in aerobic condition. ${ }^{35}$

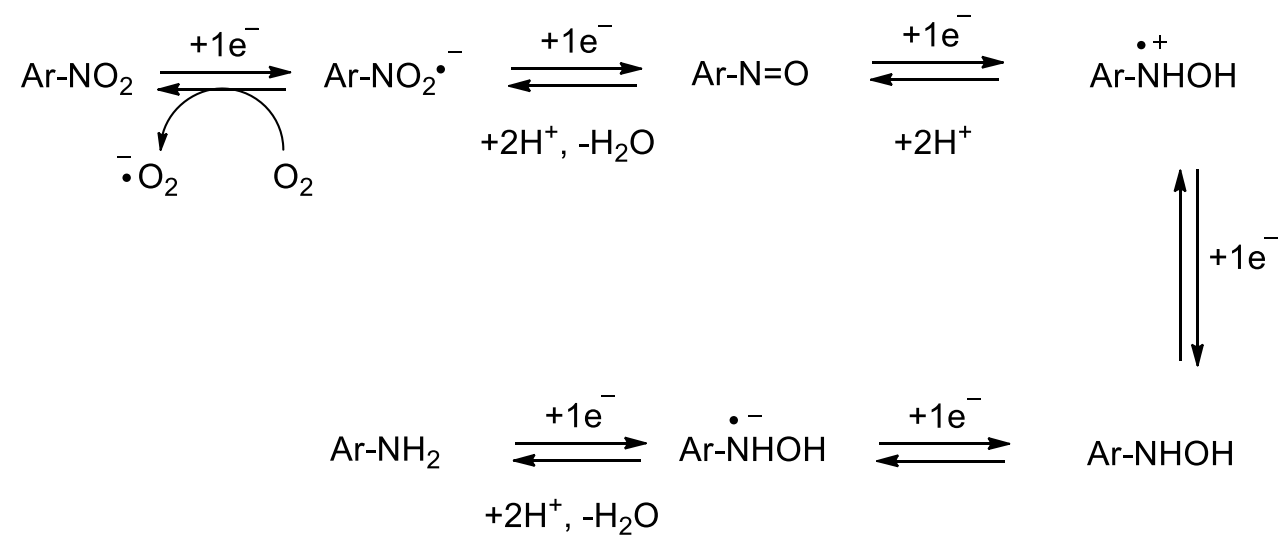

Scheme 1.2. The hypoxia-selective one-electron reduction of nitroaryl compounds.

Among many nitroaryl compounds that have been tested extensively in preclinical and clinical trials as hypoxia-selective antitumor prodrugs, most efforts were put on TH-302 and PR-104. TH-302 (also known as evofosfamide) is developed by 
Threshold Pharmaceuticals. It is a 2-nitroimidazole mustard prodrug which can be selectively activated by NADPH:cytochrome P450 reductase under hypoxic conditions to unmask the cytotoxin isophosphoramide mustard (Br-IPM) (Scheme 1.3) ${ }^{36-38}$. It has been tested both as alone and in combination with other chemotherapy drugs and the two Phase III trials failed in December 2015, due to the lack of efficacy ${ }^{39-42}$. PR-104 is designed by University of Auckland and has been evaluated phase I and II clinical trials by Proacta, Inc. It is a 3,5-dinitrobenzamide mustard pre-prodrug which can be dephosphorylated in cells to generate the prodrug PR-104A, and further activated to better DNA alkylating agents PR-104H and PR-104M due to the increase of the electron density at the mustard nitrogen atom (Scheme 1.4) ${ }^{43-47}$.<smiles>Cn1c(COP(=O)(NCCBr)NCCBr)cnc1[N+](=O)[O-]</smiles>

TH-302<smiles>O=P([O-])(NCCBr)NCCBr</smiles>

activated mustard
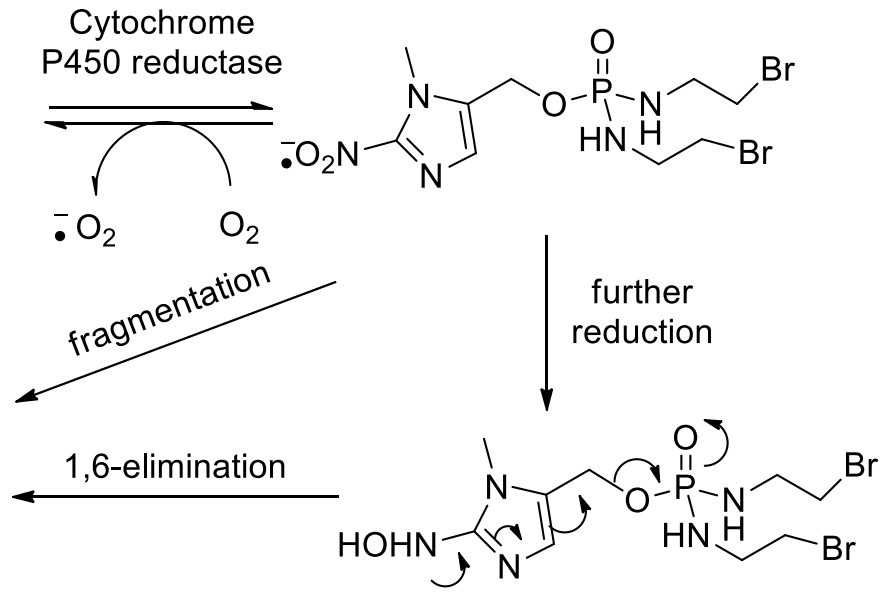

Scheme 1.3. The hypoxia-selective activation of TH-302. 

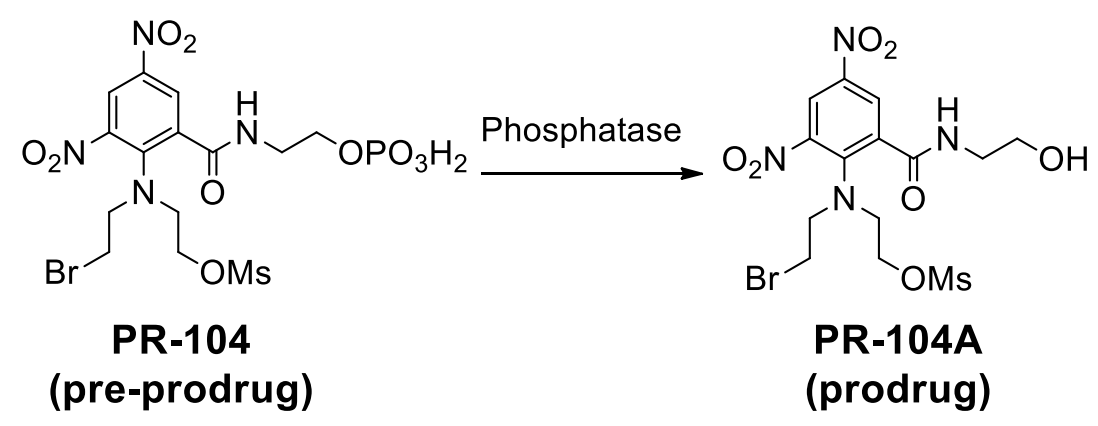

PR-104A

(prodrug)

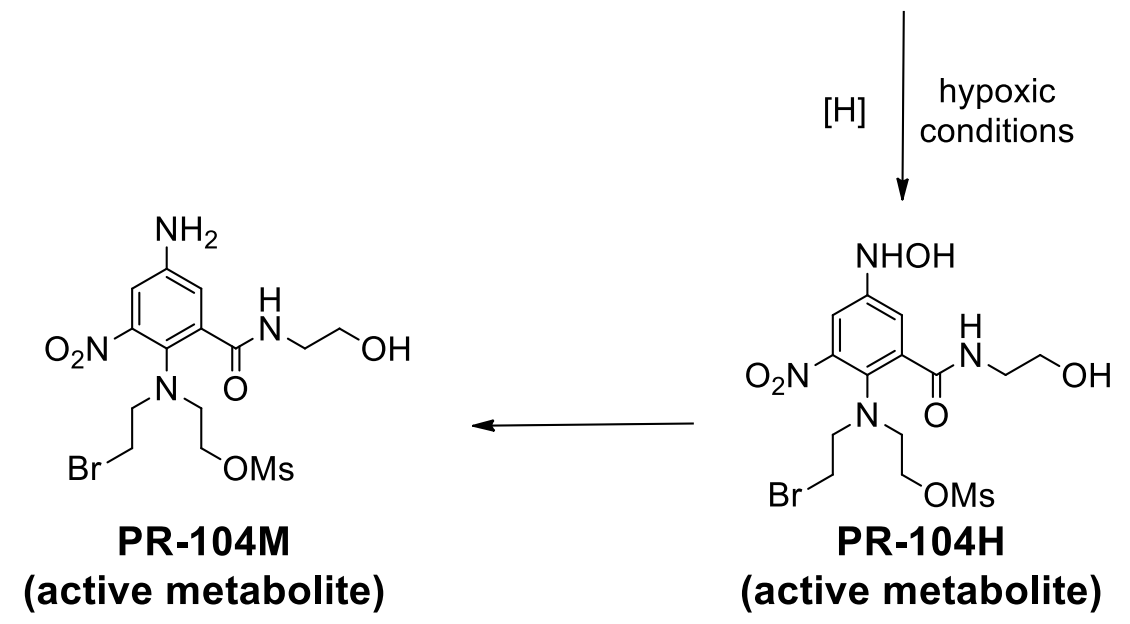

Scheme 1.4. The hypoxia-selective activation of PR-104.

\subsection{3. $N$-oxides}

Besides quinones and nitroaryls, aromatic and aliphatic $N$-oxides are also an important class of hypoxia-selective antitumor prodrugs. ${ }^{24}$ Among them, tirapazamine (TPZ) is probably one of the best studied prodrug. Tirpazamine showed its potential clinical use in $1986{ }^{48}$ and has been tested in Phase III trials. ${ }^{49-52}$ It selectively kills hypoxic tumor cells. In normal tissue, oxygen can oxidize the one-electron reduced radical anion back to its parent drug. And in hypoxic tissues, the radical anion has a longer lifetime to undergo further reduction so that radicals can be generated to damage cellular DNA (Scheme 1.5). ${ }^{53-57}$ Although tirapazamine failed Phase III trials due to the lack of efficacy, its analog SN30000/CEN-209 (Scheme 1.6) with better pharmacokinetic properties is advancing toward the clinical trials. ${ }^{58-60}$ 


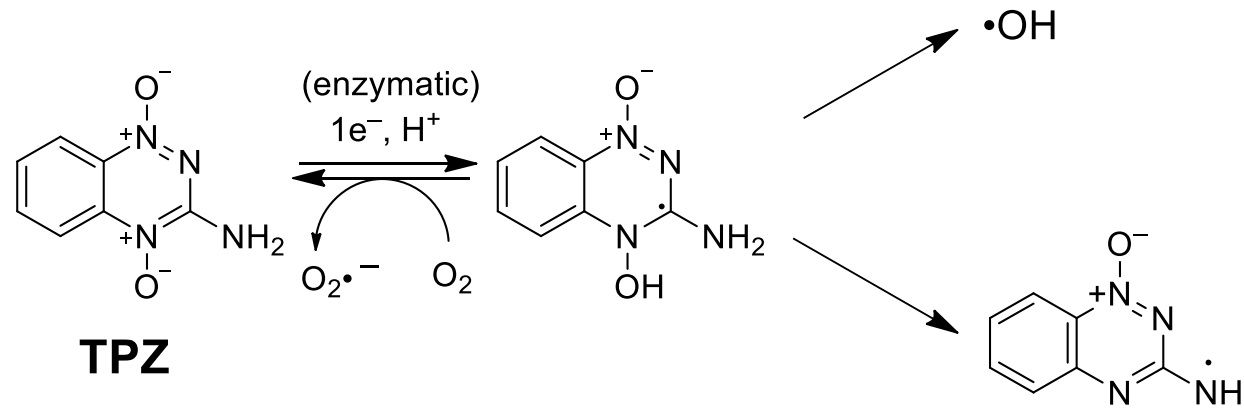

Scheme 1.5. The hypoxia-selective activation of TPZ.

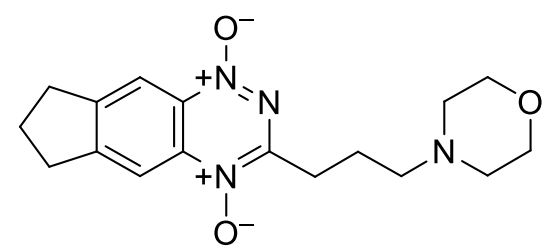

SN30000/CEN-209

Scheme 1.6. Chemical structure of SN30000/CEN-209.

\subsubsection{Metal complexes}

In addition, metal complexes have also been explored as hypoxia-selective prodrugs, which relies on the difference in stability in two different oxidation states of metal ions to release the active cytotoxins in hypoxia. As shown in Scheme 1.7, cobalt (III) can be selectively reduced to less ligand affinity state cobalt (II) and release the drug ligand. ${ }^{61}$ But till now, none of them has been tested in clinical trials. ${ }^{62-65}$

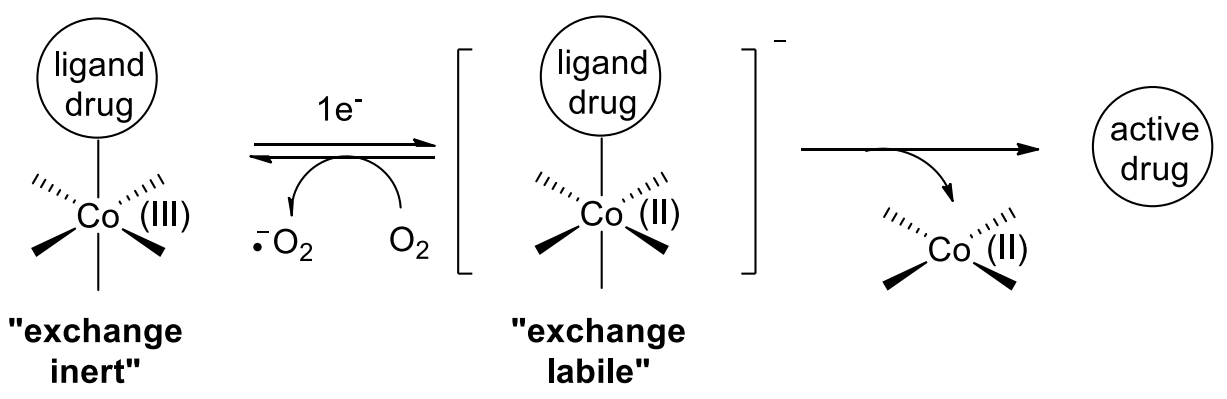

Scheme 1.7. Co(III) complex as hypoxia-selective prodrugs (Scheme reproduced from Chen, Y.; et al. ${ }^{24}$ ). 


\subsection{Probes for the detection of hypoxia and drug-related reductive enzymes}

Efforts have been devoted to the development of hypoxia selective antitumor prodrugs for more than 30 years, but there is no drug approved on market so far. At least two conditions are required for successful clinical application of hypoxia-selective prodrugs: i. target tumor must be hypoxic and ii. appropriate reductive enzymes involved in activation of the drug must be expressed in the target tissue. Therefore, along with drug development, diagnostic tools to detect the distribution of hypoxic regions in tumor tissue and/or to detect the bioreductive enzymes required for the activation of prodrugs were also developed, to match the drug to the patients. ${ }^{25,66,67}$

\subsubsection{Reductase involved in bioactivation of hypoxia-selective prodrugs}

The reductases required for the transformation of hypoxia-selective prodrugs are ubiquitously expressed in human cells, and they are mostly one-electron reductases, such as NADPH:cytochrome P450 reductase (CYPOR) ${ }^{68}$, xanthine oxidase (XO) ${ }^{69}$, aldehyde

oxidase ${ }^{70}$, NADH-dependent cytochrome b5 reductase 3 (CYB5R3) ${ }^{71}$, methionine synthase reductase (MTRR) ${ }^{46}$, nitric oxide synthase (NOS) ${ }^{72}$ and thioredoxin reductase ${ }^{73}$. Some of the drugs can be metabolized by two-electron reductases, (e.g. DT-diaphorase ${ }^{74}$ ), but they often can be metabolized in aerobic conditions, thus losing the hypoxia selectivity. 


\subsubsection{Approaches for the evaluation of tumor hypoxia}

Existing methods for the detection of tumor hypoxia includes invasive probebased methods, such as the Eppendorf oxygen electrode ${ }^{75}$ and optical needle probe OxyLite ${ }^{76}$, and image-based methods ${ }^{25,66}$, including MRI (magnetic resonance imaging), PET (positron emission tomography), SPECT (single photon emission computed tomography), and fluorescent imaging, etc.

Invasive probe-based methods were developed in the 1990s, but they suffer from some disadvantages because $\mathrm{CT}$ or ultrasound is often required to operate and the probes can invade and damage the tissues. ${ }^{77}$

Among imaging-based methods, PET imaging and SPECT imaging are widely used in preclinical and clinical applications with some well-known probes (Scheme 1.8), like the 2-nitroimidazole PET probes ${ }^{18}$ F-fluoromisonidazole $\left({ }^{18} \mathrm{~F}\right.$-FMISO) ${ }^{78,79}$ and 2-(2nitro- $1 H$-imidazol-1-yl)- $N$-(2,3,3,3-[ $\left.{ }^{18} \mathrm{~F}\right]$-pentafluoropropyl)-acetamide $\left({ }^{18} \mathrm{~F}\right.$-EF5) ${ }^{80}$, as well as the SPECT probe $\left[{ }^{99 \mathrm{~m}} \mathrm{Tc}\right]-\mathrm{HL} 91^{81,82}$.

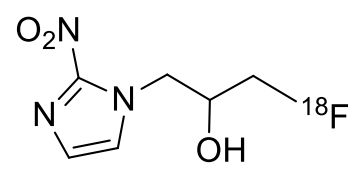

$\left[{ }^{18} \mathrm{~F}\right]$-FMISO<smiles>O=C(Cn1ccnc1[N+](=O)[O-])NCC(F)(F)C(F)(F)F</smiles>

$\left[{ }^{18} \mathrm{~F}\right]-\mathrm{EF} 5$

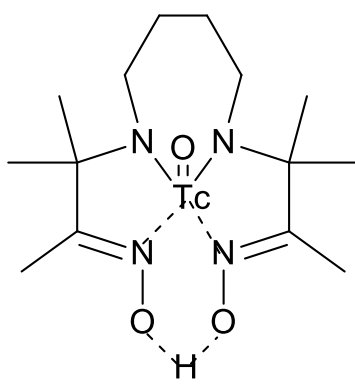

$\left[{ }^{99 \mathrm{~m}} \mathrm{Tc}\right]-\mathrm{HL}$ - 1

Scheme 1.8. Examples of PET and SPECT probes used in preclinical and clinical studies for the detection of hypoxia. 


\subsubsection{Fluorescent probes for the detection of hypoxia and drug-related bioreductive enzymes}

Compared to the techniques described above, fluorescent based probes have both advantages and disadvantages. The advantages include non-invasiveness, reduced cost, and no ionizing radiation exposure for the the patients. However, this technique is limited by the capability of visible light to penetrate tissues and the cell autofluorescence interference from biological molecules such as flavins and NADPH ${ }^{83}$. Although this technique has not been applied in clinical studies in human, it still plays an important role in evaluating tumor hypoxia and bioreductive enzymes in biopsies level ${ }^{27}$. The most recent review for bioreductive fluorescent probes to detect hypoxia and reductase was in 2016, so there is no need for a comprehensive review, only important aspects were discussed below. ${ }^{25}$

As described in section 1.2, nitroaryls can be selectively reduced via one-electron reductase under hypoxic conditions. Therefore, two approaches can be used to develop fluorescent probes based on these bioreduction reactions to detect the presence of hypoxia and reductive enzymes. One involves in the alteration of fluorescence properties or retention of fluorescence via reduction, and another one relies on the release of a fluorescent reporter upon reduction.

Numerous nitroaryl based fluorescent probes were developed for hypoxia and reductive enzymes both both in vitro and in vivo. Examples are shown in Scheme 1.9 and Scheme 1.10. ${ }^{84-88}$ 
<smiles>CC(=O)Cn1ccc(=O)c2cc([N+](=O)[O-])ccc21</smiles>

FSL-61<smiles>O=[N+]([O-])c1ccc2ncccc2c1</smiles>

6-NQ

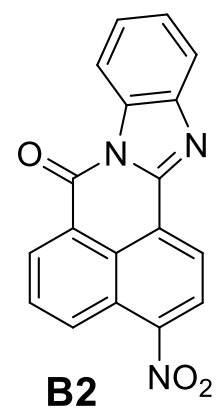

Scheme 1.9. Examples of nitroaryl probes based on the alteration of fluorescence properties.

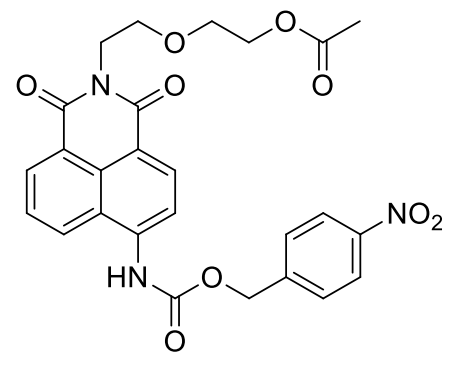

RHP

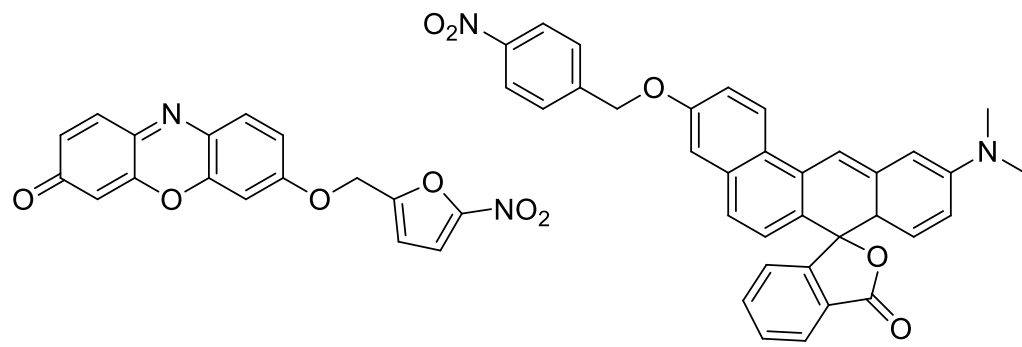

Probe 1
UTX-12

Scheme 1.10. Examples of nitroaryl probes based on the release of fluorescent reporters.

Our group developed that non-fluorescent 6-nitroquinoline (6-NQ) can be converted into fluorescence molecules with reductive enzymes under hypoxic conditions. In NADPH/CYPOR enzyme system, an unexpected fluorescent helicene (Helicene 4, Scheme 1.11) was formed with emission wavelength at $445 \mathrm{~nm}$, while fluorescent 6aminoquinoline (6-AQ, emission maximum at $530 \mathrm{~nm}$ ) was generated under xanthine/xanthine oxidase enzyme system. ${ }^{89,90}$ 


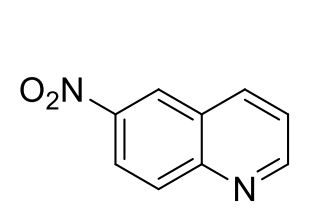

6-NQ

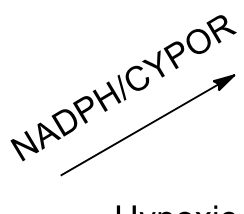

Hypoxic conversion

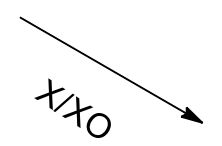

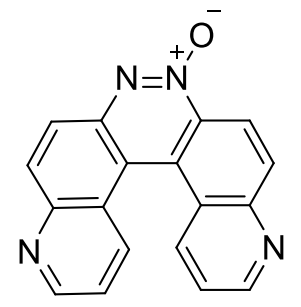

Helicene 4<smiles>Nc1ccc2cccnc2c1</smiles>

6-AQ

Scheme 1.11. The in vitro enzymatic metabolism of non-fluorescent 6-NQ yields fluorescent molecules.

Notably, some nitroaryls are designed as near-infrared (NIR) fluorescent probes to efficiently penetrate into target tissues and distinguish from cell autofluorescence with the excitation and emission wavelengths in near-infrared (NIR) range $(650-900 \mathrm{~nm})$ (Scheme 1.12) ${ }^{91,92}$. They are not "off-on" fluorescent probes, which means they are fluorescent in the nitro form, while conversion to amino form helps the retention of the probes in target cells due to the selective binding effect of 2-aminoimidazole. ${ }^{79}$

In addition to nitroaryl based fluorescent probes, there are also other structures involved in this field, e.g. the indolequinone based ${ }^{93,94}$, naththalimide $N$-oxide based ${ }^{95}$ and the azo based fluorescent probes ${ }^{96-101}$. Some other methods, such as transition metal phosphorescent probe PtCPK ${ }^{102}$ and fluorescein-labeled avidin-biotin system on $\mathrm{Fe}_{3} \mathrm{O}_{4}$ nanoparticles ${ }^{103}$, were also developed as the probes to detect hypoxia and drug-related bioreductive enzymes. 


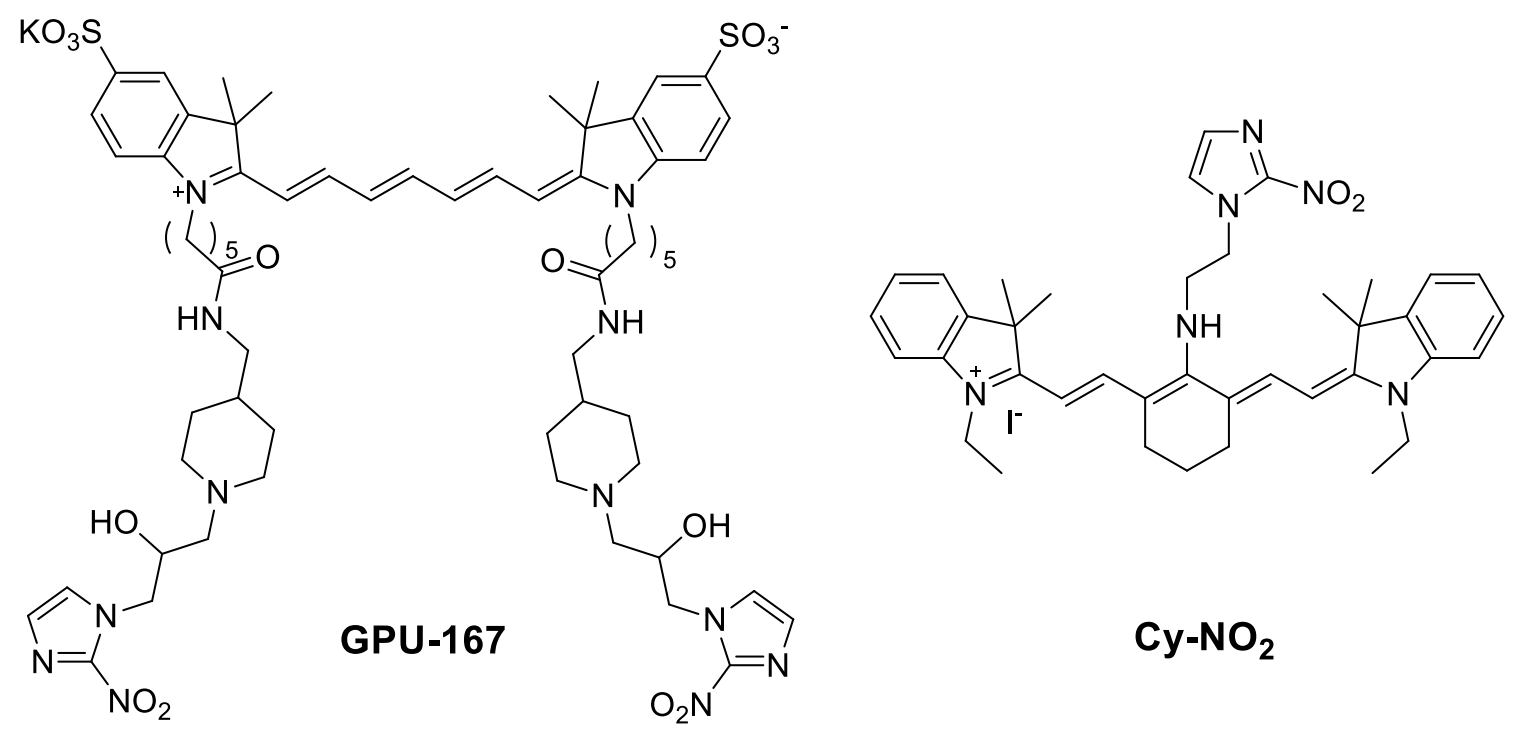

Scheme 1.12. Near infrared fluorescent probes based on selective retention in cells. 


\subsection{References}

(1) Mottram, J., A factor of importance in the radio sensitivity of tumours. The British Journal of Radiology 1936, 9 (105), 606-614.

(2) Thomlinson, R.; Gray, L., The histological structure of some human lung cancers and the possible implications for radiotherapy. British journal of cancer 1955, 9 (4), 539.

(3) Kizaka-Kondoh, S.; Inoue, M.; Harada, H.; Hiraoka, M., Tumor hypoxia: a target for selective cancer therapy. Cancer science 2003, 94 (12), 1021-1028.

(4) Raleigh, J. A.; Dewhirst, M. W.; Thrall, D. E. Seminars in radiation oncology; Elsevier: 1996; Vol. 6, p 37-45.

(5) Höckel, M.; Vaupel, P., Tumor hypoxia: definitions and current clinical, biologic, and molecular aspects. Journal of the National Cancer Institute 2001, 93 (4), 266-276.

(6) Vaupel, P. Seminars in radiation oncology; Elsevier: 2004; Vol. 14, p 198-206.

(7) Brown, J. M.; Giaccia, A. J., The unique physiology of solid tumors: opportunities (and problems) for cancer therapy. Cancer research 1998, 58 (7), 14081416.

(8) Harris, A. L., Hypoxia—a key regulatory factor in tumour growth. Nature Reviews Cancer 2002, 2 (1), 38-47.

(9) Brown, J. M.; Wilson, W. R., Exploiting tumour hypoxia in cancer treatment. Nature Reviews Cancer 2004, 4 (6), 437-447.

(10) Graeber, T. G.; Osmanian, C.; Jacks, T.; Housman, D. E.; Koch, C. J.; Lowe, S. W.; Giaccia, A. J., Hypoxia-mediated selection of cells with diminished apoptotic potential in solid tumours. Nature 1996, 379 (6560), 88-91. 
(11) Yuan, J.; Glazer, P. M., Mutagenesis induced by the tumor microenvironment. Mutation Research/Fundamental and Molecular Mechanisms of Mutagenesis 1998, 400 (1), 439-446.

(12) Pennacchietti, S.; Michieli, P.; Galluzzo, M.; Mazzone, M.; Giordano, S.; Comoglio, P. M., Hypoxia promotes invasive growth by transcriptional activation of the met protooncogene. Cancer cell 2003, 3 (4), 347-361.

(13) Rofstad, E., Microenvironment-induced cancer metastasis. International journal of radiation biology 2000, 76 (5), 589-605.

(14) Subarsky, P.; Hill, R. P., The hypoxic tumour microenvironment and metastatic progression. Clinical \& experimental metastasis 2003, 20 (3), 237-250.

(15) Fang, J. S.; Gillies, R. D.; Gatenby, R. A. Seminars in cancer biology; Elsevier: 2008; Vol. 18, p 330-337.

(16) Moeller, B. J.; Richardson, R. A.; Dewhirst, M. W., Hypoxia and radiotherapy: opportunities for improved outcomes in cancer treatment. Cancer and Metastasis Reviews 2007, 26 (2), 241-248.

(17) Wouters, B. G.; Brown, J. M., Cells at intermediate oxygen levels can be more important than the "hypoxic fraction" in determining tumor response to fractionated radiotherapy. Radiation research 1997, 147 (5), 541-550.

(18) Tannock, I. F., Conventional cancer therapy: promise broken or promise delayed? The Lancet 1998, 351, SII9-SII16.

(19) Loncaster, J. A.; Harris, A. L.; Davidson, S. E.; Logue, J. P.; Hunter, R. D.; Wycoff, C. C.; Pastorek, J.; Ratcliffe, P. J.; Stratford, I. J.; West, C. M., Carbonic anhydrase (CA IX) expression, a potential new intrinsic marker of hypoxia: correlations 
with tumor oxygen measurements and prognosis in locally advanced carcinoma of the cervix. Cancer Research 2001, 61 (17), 6394-6399.

(20) Kamura, T.; Sato, S.; Iwai, K.; Czyzyk-Krzeska, M.; Conaway, R. C.; Conaway, J. W., Activation of HIF $1 \alpha$ ubiquitination by a reconstituted von Hippel-Lindau (VHL) tumor suppressor complex. Proceedings of the National Academy of Sciences 2000, 97 (19), 10430-10435.

(21) Tanimoto, K.; Makino, Y.; Pereira, T.; Poellinger, L., Mechanism of regulation of the hypoxia-inducible factor-1 $\alpha$ by the von Hippel-Lindau tumor suppressor protein. The EMBO journal 2000, 19 (16), 4298-4309.

(22) Guise, C. P.; Mowday, A. M.; Ashoorzadeh, A.; Yuan, R.; Lin, W.-H.; Wu, D.H.; Smaill, J. B.; Patterson, A. V.; Ding, K., Bioreductive prodrugs as cancer therapeutics: targeting tumor hypoxia. Chinese Journal of Cancer 2014, 33 (2), 80-86.

(23) Wilson, W. R.; Hay, M. P., Targeting hypoxia in cancer therapy. Nature Reviews Cancer 2011, 11 (6), 393-410.

(24) Chen, Y.; Hu, L., Design of anticancer prodrugs for reductive activation. Medicinal research reviews 2009, 29 (1), 29-64.

(25) Elmes, R. B., Bioreductive Fluorescent Imaging Agents: Applications to Tumour Hypoxia. Chemical Communications 2016.

(26) Chitneni, S. K.; Palmer, G. M.; Zalutsky, M. R.; Dewhirst, M. W., Molecular imaging of hypoxia. Journal of Nuclear Medicine 2011, 52 (2), 165-168.

(27) Krohn, K. A.; Link, J. M.; Mason, R. P., Molecular imaging of hypoxia. Journal of Nuclear Medicine 2008, 49 (Suppl 2), 129S-148S. 
(28) Tatum, J. L., Hypoxia: importance in tumor biology, noninvasive measurement by imaging, and value of its measurement in the management of cancer therapy. International journal of radiation biology 2006, 82 (10), 699-757.

(29) Lin, A. J.; Cosby, L. A.; Shansky, C. W.; Sartorelli, A. C., Potential bioreductive alkylating agents. 1. Benzoquinone derivatives. Journal of medicinal chemistry 1972, 15 (12), 1247-1252.

(30) Schwartz, H. S.; Sodergren, J.; Philips, F., Mitomycin C: chemical and biological studies on alkylation. Science 1963, 142 (3596), 1181-1183.

(31) Iyer, V.; Szybalski, W., Mitomycins and porfiromycin: chemical mechanism of activation and cross-linking of DNA. Science 1964, 145 (3627), 55-58.

(32) Asche, C., Antitumour quinones. Mini reviews in medicinal chemistry 2005, 5 (5), 449-467.

(33) Wardman, P.; Clarke, E.; Hodgkiss, R.; Middleton, R.; Parrick, J.; Stratford, M., Nitroaryl compounds as potential fluorescent probes for hypoxia. I. Chemical criteria and constraints. International Journal of Radiation Oncology* Biology* Physics 1984, 10 (8), $1347-1351$.

(34) Denny, W. A.; Wilson, W. R., Considerations for the design of nitrophenyl mustards as agents with selective toxicity for hypoxic tumor cells. Journal of medicinal chemistry 1986, 29 (6), 879-887.

(35) Wilson, W. R.; Anderson, R. F.; Denny, W. A., Hypoxia-selective antitumor agents. 1. Relationships between structure, redox properties and hypoxia-selective cytotoxicity for 4-substituted derivatives of nitracrine. Journal of medicinal chemistry 1989, $32(1), 23-30$. 

G.; Banica, M.; Jung, D.; Wang, J., Potent and highly selective hypoxia-activated achiral phosphoramidate mustards as anticancer drugs. Journal of medicinal chemistry 2008, 51 (8), 2412-2420.

Meng, F.; Evans, J. W.; Bhupathi, D.; Banica, M.; Lan, L.; Lorente, G.; Duan, J.X.; Cai, X.; Mowday, A. M.; Guise, C. P., Molecular and cellular pharmacology of the hypoxia-activated prodrug TH-302. Molecular cancer therapeutics 2012, 11 (3), 740751.

(38) Sun, J. D.; Liu, Q.; Wang, J.; Ahluwalia, D.; Ferraro, D.; Wang, Y.; Duan, J.-X.; Ammons, W. S.; Curd, J. G.; Matteucci, M. D., Selective tumor hypoxia targeting by hypoxia-activated prodrug TH-302 inhibits tumor growth in preclinical models of cancer. Clinical cancer research 2012, 18 (3), 758-770.

(39) Weiss, G. J.; Infante, J. R.; Chiorean, E. G.; Borad, M. J.; Bendell, J. C.; Molina, J. R.; Tibes, R.; Ramanathan, R. K.; Lewandowski, K.; Jones, S. F., Phase 1 study of the safety, tolerability, and pharmacokinetics of TH-302, a hypoxia-activated prodrug, in patients with advanced solid malignancies. Clinical cancer research 2011, 17 (9), 29973004.

(40) Chawla, S. P.; Cranmer, L. D.; Van Tine, B. A.; Reed, D. R.; Okuno, S. H.; Butrynski, J. E.; Adkins, D. R.; Hendifar, A. E.; Kroll, S.; Ganjoo, K. N., Phase II study of the safety and antitumor activity of the hypoxia-activated prodrug TH-302 in combination with doxorubicin in patients with advanced soft tissue sarcoma. Journal of Clinical Oncology 2014, JCO. 2013.2054. 3660. 
(41) Borad, M. J.; Reddy, S. G.; Bahary, N.; Uronis, H. E.; Sigal, D.; Cohn, A. L.; Schelman, W. R.; Stephenson, J.; Chiorean, E. G.; Rosen, P. J., Randomized phase II trial of gemcitabine plus TH-302 versus gemcitabine in patients with advanced pancreatic cancer. Journal of Clinical Oncology 2015, 33 (13), 1475-1481.

(42) Threshold pharmaceuticals announces its two phase 3 studies evaluating evofosfamide did not meet primary endpoints. Threshold Pharmaceuticals, 2015. http://investor.thresholdpharm.com/releasedetail.cfm?ReleaseID=945765.

(43) Patterson, A. V.; Ferry, D. M.; Edmunds, S. J.; Gu, Y.; Singleton, R. S.; Patel, K.; Pullen, S. M.; Hicks, K. O.; Syddall, S. P.; Atwell, G. J., Mechanism of action and preclinical antitumor activity of the novel hypoxia-activated DNA cross-linking agent PR-104. Clinical Cancer Research 2007, 13 (13), 3922-3932.

(44) Jameson, M. B.; Rischin, D.; Pegram, M.; Gutheil, J.; Patterson, A. V.; Denny, W. A.; Wilson, W. R., A phase I trial of PR-104, a nitrogen mustard prodrug activated by both hypoxia and aldo-keto reductase $1 \mathrm{C} 3$, in patients with solid tumors. Cancer chemotherapy and pharmacology 2010, 65 (4), 791-801.

(45) McKeage, M. J.; Gu, Y.; Wilson, W. R.; Hill, A.; Amies, K.; Melink, T. J.; Jameson, M. B., A phase I trial of PR-104, a pre-prodrug of the bioreductive prodrug PR104A, given weekly to solid tumour patients. BMC cancer 2011, 11 (1), 1.

(46) Guise, C. P.; Abbattista, M. R.; Tipparaju, S. R.; Lambie, N. K.; Su, J.; Li, D.; Wilson, W. R.; Dachs, G. U.; Patterson, A. V., Diflavin oxidoreductases activate the bioreductive prodrug PR-104A under hypoxia. Molecular pharmacology 2012, 81 (1), $31-40$. 
Konopleva, M.; Thall, P. F.; Yi, C. A.; Borthakur, G.; Coveler, A.; Bueso-Ramos,

C.; Benito, J.; Konoplev, S.; Gu, Y.; Ravandi, F., Phase I/II study of the hypoxiaactivated prodrug PR104 in refractory/relapsed acute myeloid leukemia and acute lymphoblastic leukemia. Haematologica 2015, haematol. 2014.118455.

Zeman, E. M.; Brown, J. M.; Lemmon, M. J.; Hirst, V. K.; Lee, W. W., SR-4233:

a new bioreductive agent with high selective toxicity for hypoxic mammalian cells. International Journal of Radiation Oncology* Biology* Physics 1986, 12 (7), 1239-1242.

(49) Denny, W. A., Prospects for hypoxia-activated anticancer drugs. Current Medicinal Chemistry-Anti-Cancer Agents 2004, 4 (5), 395-399.

(50) Gandara, D. R.; Lara, P. N.; Goldberg, Z.; Le, Q. T.; Mack, P. C.; Lau, D. H.; Gumerlock, P. H. Seminars in oncology; Elsevier: 2002; Vol. 29, p 102-109.

(51) Hay, M. P.; Hicks, K. O.; Pruijn, F. B.; Pchalek, K.; Siim, B. G.; Wilson, W. R.; Denny, W. A., Pharmacokinetic/pharmacodynamic model-guided identification of hypoxia-selective 1,2,4-benzotriazine 1,4-dioxides with antitumor activity: the role of extravascular transport. Journal of medicinal chemistry 2007, 50 (25), 6392-6404.

(52) Rischin, D.; Peters, L. J.; O'Sullivan, B.; Giralt, J.; Fisher, R.; Yuen, K.; Trotti, A.; Bernier, J.; Bourhis, J.; Ringash, J., Tirapazamine, cisplatin, and radiation versus cisplatin and radiation for advanced squamous cell carcinoma of the head and neck (TROG 02.02, HeadSTART): a phase III trial of the Trans-Tasman Radiation Oncology Group. Journal of Clinical Oncology 2010, 28 (18), 2989-2995.

Daniels, J. S.; Gates, K. S., DNA cleavage by the antitumor agent 3-amino-1,2,4benzotriazine 1,4-dioxide (SR4233): Evidence for involvement of hydroxyl radical. Journal of the American Chemical Society 1996, 118 (14), 3380-3385. 
(54) Junnotula, V.; Sarkar, U.; Sinha, S.; Gates, K. S., Initiation of DNA strand cleavage by 1,2,4-benzotriazine 1,4-dioxide antitumor agents: mechanistic insight from studies of 3-methyl-1,2,4-benzotriazine 1,4-dioxide. Journal of the American Chemical Society 2008, 131 (3), 1015-1024.

(55) Shinde, S. S.; Anderson, R. F.; Hay, M. P.; Gamage, S. A.; Denny, W. A., Oxidation of 2-deoxyribose by benzotriazinyl radicals of antitumor 3-amino-1,2,4benzotriazine 1,4-dioxides. Journal of the American Chemical Society 2004, 126 (25), 7865-7874.

(56) Shinde, S. S.; Hay, M. P.; Patterson, A. V.; Denny, W. A.; Anderson, R. F., Spin trapping of radicals other than the $\bullet \mathrm{OH}$ radical upon reduction of the anticancer agent tirapazamine by cytochrome P450 reductase. Journal of the American Chemical Society 2009, 131 (40), 14220-14221.

(57) Shinde, S. S.; Maroz, A.; Hay, M. P.; Patterson, A. V.; Denny, W. A.; Anderson, R. F., Characterization of radicals formed following enzymatic reduction of 3-substituted analogues of the hypoxia-selective cytotoxin 3-amino-1,2,4-benzotriazine 1,4-dioxide (tirapazamine). Journal of the American Chemical Society 2010, 132 (8), 2591-2599.

(58) Hicks, K. O.; Siim, B. G.; Jaiswal, J. K.; Pruijn, F. B.; Fraser, A. M.; Patel, R.; Hogg, A.; Liyanage, $\quad$ H. $\quad$ S.; Dorie, M. J.; Brown, J. M., Pharmacokinetic/pharmacodynamic modeling identifies SN30000 and SN29751 as tirapazamine analogues with improved tissue penetration and hypoxic cell killing in tumors. Clinical Cancer Research 2010, 16 (20), 4946-4957.

(59) Anderson, R. F.; Yadav, P.; Patel, D.; Reynisson, J.; Tipparaju, S. R.; Guise, C. P.; Patterson, A. V.; Denny, W. A.; Maroz, A.; Shinde, S. S., Characterisation of radicals 
formed by the triazine 1,4-dioxide hypoxia-activated prodrug, SN30000. Organic \& biomolecular chemistry 2014, 12 (21), 3386-3392.

(60) Wang, J.; Guise, C. P.; Dachs, G. U.; Phung, Y.; Lambie, N. K.; Patterson, A. V.; Wilson, W. R., Identification of one-electron reductases that activate both the hypoxia prodrug SN30000 and diagnostic probe EF5. Biochemical pharmacology 2014, 91 (4), $436-446$.

(61) Hall, M. D.; Failes, T. W.; Yamamoto, N.; Hambley, T. W., Bioreductive activation and drug chaperoning in cobalt pharmaceuticals. Dalton Transactions 2007, (36), 3983-3990.

(62) Ware, D. C.; Palmer, B. D.; Wilson, W. R.; Denny, W. A., Hypoxia-selective antitumor agents. 7. Metal complexes of aliphatic mustards as a new class of hypoxiaselective cytotoxins. Synthesis and evaluation of cobalt (III) complexes of bidentate mustards. Journal of medicinal chemistry 1993, 36 (13), 1839-1846.

(63) Parker, L. L.; Lacy, S. M.; Farrugia, L. J.; Evans, C.; Robins, D. J.; O'Hare, C. C.; Hartley, J. A.; Jaffar, M.; Stratford, I. J., A novel design strategy for stable metal complexes of nitrogen mustards as bioreductive prodrugs. Journal of medicinal chemistry 2004, 47 (23), 5683-5689.

(64) Bustamante, F. L.; Metello, J. M.; de Castro, F. A.; Pinheiro, C. B.; Pereira, M. D.; Lanznaster, M., Lawsone dimerization in cobalt (III) complexes toward the design of new prototypes of bioreductive prodrugs. Inorganic chemistry 2013, 52 (3), 1167-1169.

(65) Bustamante, F. L.; Miranda, F. S.; Castro, F. A.; Resende, J. A.; Pereira, M. D.; Lanznaster, M., A study on the properties and reactivity of naphthoquinone-cobalt (III) 
prototypes for bioreductive prodrugs. Journal of inorganic biochemistry 2014, 132, 3744.

(66) Apte, S.; T Chin, F.; E Graves, E., Molecular imaging of hypoxia: strategies for probe design and application. Current organic synthesis 2011, 8 (4), 593-603.

(67) Horsman, M. R.; Mortensen, L. S.; Petersen, J. B.; Busk, M.; Overgaard, J., Imaging hypoxia to improve radiotherapy outcome. Nature Reviews Clinical Oncology 2012, 9 (12), 674-687.

(68) Wang, J.; Foehrenbacher, A.; Su, J.; Patel, R.; Hay, M. P.; Hicks, K. O.; Wilson, W. R., The 2-nitroimidazole EF5 is a biomarker for oxidoreductases that activate the bioreductive prodrug CEN-209 under hypoxia. Clinical Cancer Research 2012, 18 (6), 1684-1695.

(69) Ueda, O.; Kitamura, S.; Ohashi, K.; Sugihara, K.; Ohta, S., Xanthine oxidasecatalyzed metabolism of 2-nitrofluorene, a carcinogenic air pollutant, in rat skin. Drug metabolism and disposition 2003, 31 (4), 367-372.

(70) Wolpert, M.; Althaus, J.; Johns, D., Nitroreductase activity of mammalian liver aldehyde oxidase. Journal of Pharmacology and Experimental Therapeutics 1973, 185 (2), 202-213.

(71) Papadopoulou, M. V.; Ji, M.; Rao, M. K.; Bloomer, W. D., Reductive metabolism of the nitroimidazole-based hypoxia-selective cytotoxin NLCQ-1 (NSC 709257). Oncology Research Featuring Preclinical and Clinical Cancer Therapeutics 2003, 14 (1), 21-29.

(72) Ask, K.; Dijols, S.; Giroud, C.; Casse, L.; Frapart, Y.-M.; Sari, M.-A.; Kim, K.-S.; Stuehr, D.; Mansuy, D.; Camus, P., Reduction of nilutamide by NO synthases: 
implications for the adverse effects of this nitroaromatic antiandrogen drug. Chemical research in toxicology 2003, 16 (12), 1547-1554.

(73) Cenas, N.; Prast, S.; Nivinskas, H.; Sarlauskas, J.; Arnér, E. S., Interactions of nitroaromatic compounds with the mammalian selenoprotein thioredoxin reductase and the relation to induction of apoptosis in human cancer cells. Journal of biological chemistry 2006, 281 (9), 5593-5603.

(74) Knox, R. J.; Friedlos, F.; Sherwood, R. F.; Melton, R. G.; Anlezark, G. M., The bioactivation of 5-(aziridin-1-yl)-2, 4-dinitrobenzamide (CB1954)-II: A comparison of an Escherichia coli nitroreductase and Walker DT diaphorase. Biochemical pharmacology 1992, 44 (12), 2297-2301.

(75) Kallinowski, F.; Zander, R.; Hoeckel, M.; Vaupel, P., Tumor tissue oxygenation as evaluated by computerized- $\mathrm{pO}_{2}$-histography. International Journal of Radiation Oncology* Biology* Physics 1990, 19 (4), 953-961.

(76) Griffiths, J.; Robinson, S., The OxyLite: A fibre-optic oxygen sensor. The British journal of radiology 1999, 72 (859), 627-630.

(77) Vaupel, P.; Schlenger, K.; Knoop, C.; Höckel, M., Oxygenation of human tumors: evaluation of tissue oxygen distribution in breast cancers by computerized $\mathrm{O}_{2}$ tension measurements. Cancer research 1991, 51 (12), 3316-3322.

(78) Varghese, A. J.; Gulyas, S.; Mohindra, J. K., Hypoxia-dependent reduction of 1(2-nitro-1-imidazolyl)-3-methoxy-2-propanol by Chinese hamster ovary cells and KHT tumor cells in vitro and in vivo. Cancer research 1976, 36 (10), 3761-3765.

(79) Jerabek, P. A.; Patrick, T. B.; Kilbourn, M. R.; Dischino, D. D.; Welch, M. J., Synthesis and biodistribution of ${ }^{18} \mathrm{~F}$-labeled fluoronitroimidazoles: potential in vivo 
markers of hypoxic tissue. International Journal of Radiation Applications and Instrumentation. Part A. Applied Radiation and Isotopes 1986, 37 (7), 599-605.

(80) Chin, F.; Subbarayan, M.; Sorger, J.; Gambhir, S.; Graves, E. Journal of Labelled Compounds \& radiopharmaceuticals; JOHN WILEY \& SONS LTD THE ATRIUM, SOUTHERN GATE, CHICHESTER PO19 8SQ, W SUSSEX, ENGLAND: 2009; Vol. 52, p S274-S274.

(81) Cook, G. J.; Houston, S.; Barrington, S. F.; Fogelman, I., Technetium $-{ }^{99} \mathrm{~m}$-labeled HL91 to identify tumor hypoxia: correlation with fluorine-18-FDG. The Journal of Nuclear Medicine 1998, 39 (1), 99.

(82) Zhang, X.; Melo, T.; Ballinger, J.; Rauth, A., Studies of ${ }^{99} \mathrm{~m}$ Tc-BnAO (HL-91): a non-nitroaromatic compound for hypoxic cell detection. International Journal of Radiation Oncology* Biology* Physics 1998, 42 (4), 737-740.

(83) Lavis, L. D.; Raines, R. T., Bright ideas for chemical biology. ACS chemical biology 2008, 3 (3), 142-155.

(84) Su, J.; Guise, C. P.; Wilson, W. R., FSL-61 is a 6-nitroquinolone fluorogenic probe for one-electron reductases in hypoxic cells. Biochemical Journal 2013, 452 (1), $79-86$.

(85) Dai, M.; Zhu, W.; Xu, Y.; Qian, X.; Liu, Y.; Xiao, Y.; You, Y., Versatile nitrofluorophore as highly effective sensor for hypoxic tumor cells: design, imaging and evaluation. Journal of fluorescence 2008, 18 (2), 591-597.

(86) Cui, L.; Zhong, Y.; Zhu, W.; Xu, Y.; Du, Q.; Wang, X.; Qian, X.; Xiao, Y., A new prodrug-derived ratiometric fluorescent probe for hypoxia: high selectivity of nitroreductase and imaging in tumor cell. Organic letters 2011, 13 (5), 928-931. 
Li, Z.; Li, X.; Gao, X.; Zhang, Y.; Shi, W.; Ma, H., Nitroreductase detection and hypoxic tumor cell imaging by a designed sensitive and selective fluorescent probe, 7[(5-Nitrofuran-2-yl) methoxy]-3H-phenoxazin-3-one. Analytical chemistry 2013, 85 (8), 3926-3932.

(88) Nakata, E.; Yukimachi, Y.; Kariyazono, H.; Im, S.; Abe, C.; Uto, Y.; Maezawa, H.; Hashimoto, T.; Okamoto, Y.; Hori, H., Design of a bioreductively-activated fluorescent $\mathrm{pH}$ probe for tumor hypoxia imaging. Bioorganic \& medicinal chemistry 2009, 17 (19), 6952-6958.

(89) Rajapakse, A.; Gates, K. S., Hypoxia-selective, enzymatic conversion of 6nitroquinoline into a fluorescent helicene: pyrido[3,2-f]quinolino[6,5-c]cinnoline 3-oxide. The Journal of organic chemistry 2012, 77 (7), 3531-3537.

(90) Rajapakse, A.; Linder, C.; Morrison, R. D.; Sarkar, U.; Leigh, N. D.; Barnes, C. L.; Daniels, J. S.; Gates, K. S., Enzymatic conversion of 6-nitroquinoline to the fluorophore 6-aminoquinoline selectively under hypoxic conditions. Chemical research in toxicology 2013, 26 (4), 555-563.

(91) Okuda, K.; Okabe, Y.; Kadonosono, T.; Ueno, T.; Youssif, B. G.; KizakaKondoh, S.; Nagasawa, H., 2-Nitroimidazole-tricarbocyanine conjugate as a near-infrared fluorescent probe for in vivo imaging of tumor hypoxia. Bioconjugate chemistry 2012, 23 (3), 324-329.

(92) Xu, K.; Wang, F.; Pan, X.; Liu, R.; Ma, J.; Kong, F.; Tang, B., High selectivity imaging of nitroreductase using a near-infrared fluorescence probe in hypoxic tumor. Chemical Communications 2013, 49 (25), 2554-2556. 
(93) Tanabe, K.; Hirata, N.; Harada, H.; Hiraoka, M.; Nishimoto, S. i., Emission under hypoxia: one-electron reduction and fluorescence characteristics of an indolequinonecoumarin conjugate. ChemBioChem 2008, 9 (3), 426-432.

(94) Komatsu, H.; Harada, H.; Tanabe, K.; Hiraoka, M.; Nishimoto, S.-i., Indolequinone-rhodol conjugate as a fluorescent probe for hypoxic cells: enzymatic activation and fluorescence properties. Medicinal Chemical Communications 2010, 1 (1), $50-53$.

(95) Yin, H.; Zhu, W.; Xu, Y.; Dai, M.; Qian, X.; Li, Y.; Liu, J., Novel aliphatic Noxide of naphthalimides as fluorescent markers for hypoxic cells in solid tumor. European journal of medicinal chemistry 2011, 46 (7), 3030-3037.

(96) Kiyose, K.; Hanaoka, K.; Oushiki, D.; Nakamura, T.; Kajimura, M.; Suematsu, M.; Nishimatsu, H.; Yamane, T.; Terai, T.; Hirata, Y., Hypoxia-sensitive fluorescent probes for in vivo real-time fluorescence imaging of acute ischemia. Journal of the American Chemical Society 2010, 132 (45), 15846-15848.

(97) Takahashi, S.; Piao, W.; Matsumura, Y.; Komatsu, T.; Ueno, T.; Terai, T.; Kamachi, T.; Kohno, M.; Nagano, T.; Hanaoka, K., Reversible off-on fluorescence probe for hypoxia and imaging of hypoxia-normoxia cycles in live cells. Journal of the American Chemical Society 2012, 134 (48), 19588-19591.

(98) Kushida, Y.; Hanaoka, K.; Komatsu, T.; Terai, T.; Ueno, T.; Yoshida, K.; Uchiyama, M.; Nagano, T., Red fluorescent scaffold for highly sensitive protease activity probes. Bioorganic \& medicinal chemistry letters 2012, 22 (12), 3908-3911.

(99) Piao, W.; Tsuda, S.; Tanaka, Y.; Maeda, S.; Liu, F.; Takahashi, S.; Kushida, Y.; Komatsu, T.; Ueno, T.; Terai, T., Development of azo-based fluorescent probes to detect 
different levels of hypoxia. Angewandte Chemie International Edition 2013, 52 (49), 13028-13032.

(100) Chevalier, A.; Mercier, C.; Saurel, L.; Orenga, S.; Renard, P.-Y.; Romieu, A., The first latent green fluorophores for the detection of azoreductase activity in bacterial cultures. Chemical Communications 2013, 49 (78), 8815-8817.

(101) Cai, Q.; Yu, T.; Zhu, W.; Xu, Y.; Qian, X., A turn-on fluorescent probe for tumor hypoxia imaging in living cells. Chemical Communications 2015, 51 (79), 14739-14741. (102) O'Riordan, T. C.; Fitzgerald, K.; Ponomarev, G. V.; Mackrill, J.; Hynes, J.; Taylor, C.; Papkovsky, D. B., Sensing intracellular oxygen using near-infrared phosphorescent probes and live-cell fluorescence imaging. American Journal of Physiology-Regulatory, Integrative and Comparative Physiology 2007, 292 (4), R1613R1620.

(103) Hirata, N.; Tanabe, K.; Narita, A.; Tanaka, K.; Naka, K.; Chujo, Y.; Nishimoto, S.-i., Preparation and fluorescence properties of fluorophore-labeled avidin-biotin system immobilized on $\mathrm{Fe}_{3} \mathrm{O}_{4}$ nanoparticles through functional indolequinone linker. Bioorganic \& medicinal chemistry 2009, 17 (11), 3775-3781. 


\section{Chapter 2: Mechanistic study of DNA strand cleavage by 1,2,4- benzotriazine-1,4-di- $N$-oxide}

\subsection{Introduction}

1,2,4-benzotriazine-1,4-di- $N$-oxides are an important class of hypoxia-selective antitumor agents, which exploit the unique feature of most tumor cells. ${ }^{1}$ Tirapazamine (1a, 3-amino-1,2,4-benzotriazine-1,4-di- $N$-oxide, TPZ) is the lead compounds of this type that has been examined in Phase II and III clinical trials, ${ }^{2-6}$ and the new analog SN 30000/CEN-209 (4, Scheme 2.1) is advancing toward clinical development. ${ }^{7,8}$

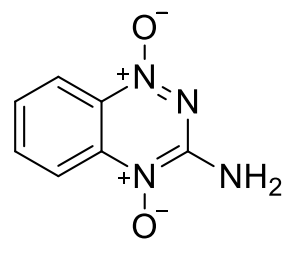

$1 \mathrm{a}$

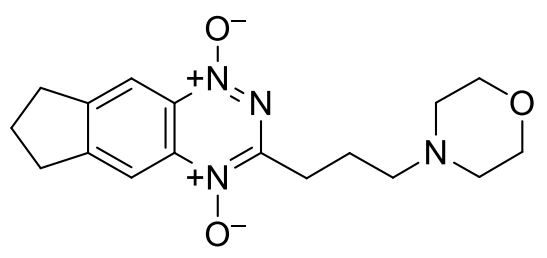

4

Scheme 2.1. The structure of tirapazamine and SN 30000/CEN-209.

The mechanism of DNA strand cleavage by TPZ has been studied extensively. Tirapazamine and its analogs can be reduced by ubiquitously expressed one-electron reductases to generate an oxygen-sensitive drug radical intermediate (2). ${ }^{9-12}$ In normoxic condition, $\mathbf{2}$ is readily oxidized back to its parent drug $\mathbf{1}$; while in hypoxic conditions, the life time of radical 2 is extended and it can be further reduced to generate a stable inactive mono- $N$-oxide $\mathbf{3}$, as well as a highly reactive radical that damage cellular DNA by abstraction of hydrogen atoms from the 2'-deoxyribose phosphate backbone. ${ }^{13-16}$

However, the exact nature of DNA-damaging species in this bioreductivelyactivated, hypoxia-selective metabolism is still unknown. There are two mechanisms 
proposed in current literature to explain the DNA strand cleavage by tirapazamine and its analogs. First, evidence has been shown that the generation of hydroxyl radical $(\bullet \mathrm{OH})$ by $\mathrm{N}-\mathrm{OH}$ homolysis of the radical intermediate 2 is account for the DNA damaging properties. ${ }^{15,17-21}$ Second, another mechanistic proposal involves the generation of a benzotriazinyl radical 5a by a dehydration step of the radical intermediate 2 (Scheme $1)^{22-26}$

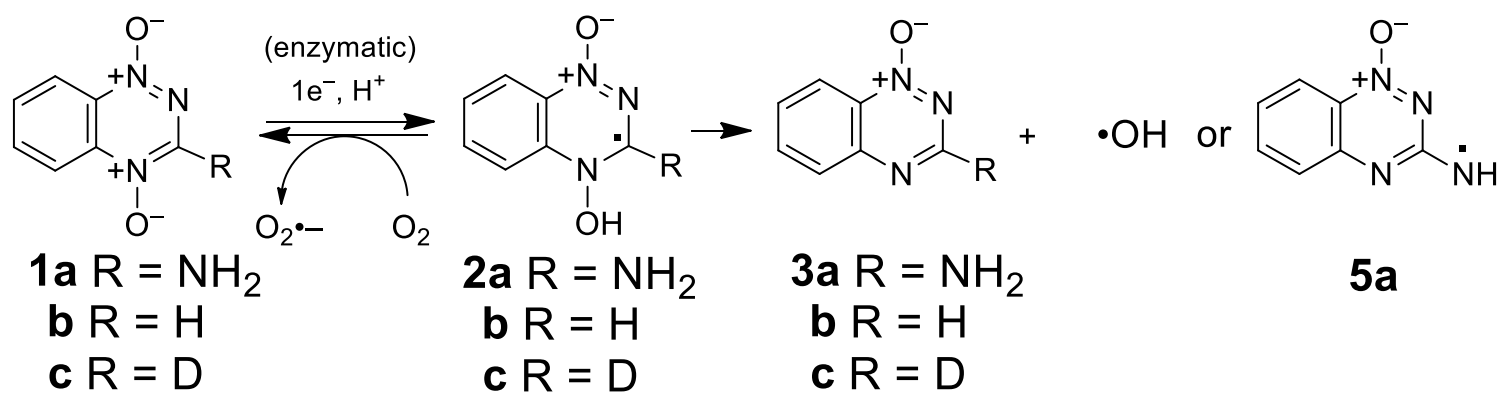

Scheme 2.2. Bioreductively-activated, hypoxia-selective metabolism of tirapazamine and its analogs.

Isotopic labeling experiments have the potential to distinguish between the above two proposed mechanisms. For tirapazamine analog 1,2,4-benzotriazine-1,4-di- $\mathrm{N}$-oxide (1b), the dehydration mechanism would generate an aryl radical intermediate $\mathbf{5 b}$ while the $\mathrm{N}-\mathrm{OH}$ homolysis mechanism produces $\cdot \mathrm{OH}^{27,28}$ If the hypoxic metabolism is provided with only a deuterium-atom donor source, it is expected to abstract $\mathrm{D} \bullet$ and yield a deuterated drug metabolite $\mathbf{3 c}$ by the dehydration mechanism, whereas the $\mathrm{N}-\mathrm{OH}$ homolysis mechanism will generate non-deuterated metabolite $\mathbf{3 b}$. We considered $\mathbf{1 b}$ was a good model for mechanistic study because this compound displayed comparable hypoxia-selective cytotoxicity to that of tirapazamine. ${ }^{15,29}$

In this chapter, we performed DNA damaging assays of $\mathbf{1 b}$ and conducted the isotopic labeling studies utilizing biochemical assays and LC-MS/MS. We found that $\mathbf{1 b}$ 
displays hypoxia-selective DNA-strand-cleaving properties analogous to the lead compound tirapazamine. The results of two complementary isotopic labeling studies provided evidence against the generation of drug radicals such as $\mathbf{5 b}$ following the hypoxic reduction of $\mathbf{1 b}$ with one-electron reductase, leaving $\bullet \mathrm{OH}$ as the only viable alternative.

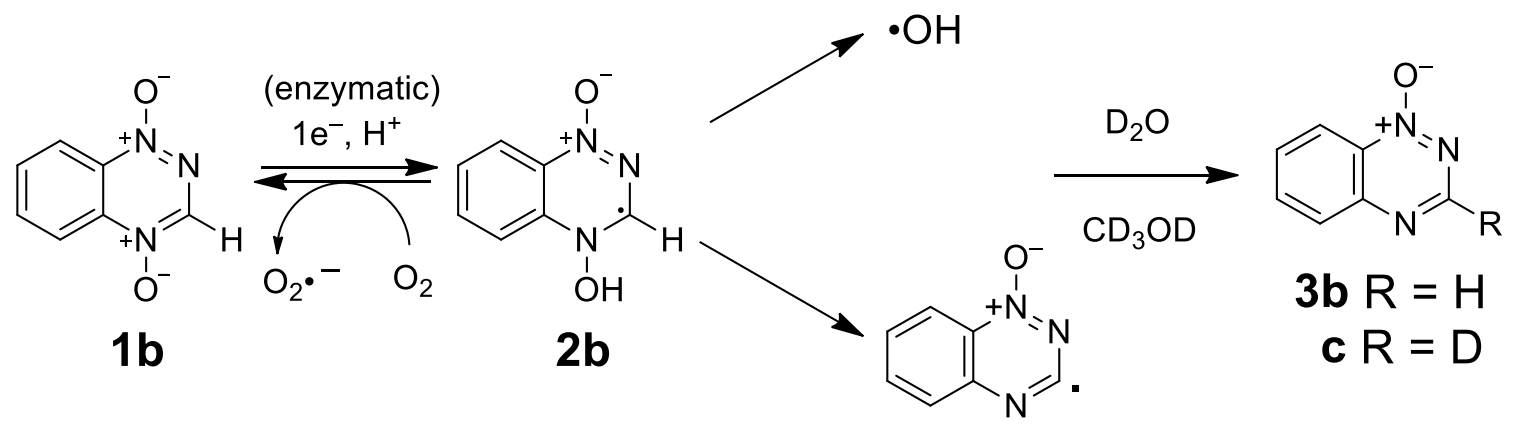

$5 b$

Scheme 2.3. Isotopic labeling experiments to elucidate the mechanism of DNA strand cleavage by $\mathbf{1 b}$.

\subsection{Bioreductively-activated, hypoxia-selective DNA strand cleavage by compound 1b}

We synthesized $\mathbf{1 b}$ by the treatment of $\mathbf{1 a}$ with $t$-butyl nitrite in DMF as well as the deuterated analog $\mathbf{1 c}$ in DMF- $d 7{ }^{30}$ We prepared the mono- $N$-oxide metabolite $\mathbf{3 b}$ via the reaction on 3a. ${ }^{15}$ In addition, the second expected no-oxide metabolite $\mathbf{6}$ was prepared by treatment of $\mathbf{3 b}$ with sodium dithionite in ethanol-water. ${ }^{31}$

A plasmid-based agarose gel electrophoresis assay was employed to measure the DNA strand cleavage by $\mathbf{1 b}$. In this assay, an intact supercoiled plasmid substrate (form I) can be damaged to the nicked circular form II by oxidative DNA strand cleavage, which can be separated and visualized by staining with ethidium bromide. ${ }^{32-35}$ Recombinant human NADPH:cytochrome P450 reductase was used to catalyze the one- 
electron reduction of $\mathbf{1 b}$ because this or a related enzyme is considers to be responsible for the intracellular activation of 1,2,4-benzotriazine 1,4 -di- $N$-oxides. ${ }^{36-38}$ For reactions carried out under hypoxic conditions, molecular oxygen was removed from stock solutions by freeze-pump-thaw degassing with argon and each component of the assay was mixed and incubated in an inert atmosphere glove bag. Catalase, superoxide dismutase, and desferal were added to prevent potential background strand cleavage resulting from the conversion of adventitious molecular oxygen to reactive oxygen species. ${ }^{15}$

We found that $\mathbf{1 b}$ caused substantial DNA strand cleavage with NADPH/ NADPH:cytochrome P450 reductase under hypoxic conditions. The DNA strand cleavage is comparable to that of 1a (Figure 2.1 and Figure 2.2). Control experiments showed that $\mathbf{1 b}$ alone, NADPH/Cytochrome P450 reductase system, $\mathbf{1 b}$ incubated with NADPH alone or the enzyme alone did not cause significant amount of DNA damage. In addition, we found that the DNA strand cleavage by the hypoxic metabolism of 1a and 1b is higher in the presence of $\mathrm{D}_{2} \mathrm{O} / \mathrm{CD}_{3} \mathrm{OD}$ than that in $\mathrm{H}_{2} \mathrm{O} / \mathrm{CH}_{3} \mathrm{OH}$ (Figure 2.1 \& 2.3 and Figure $2.2 \& 2.4)$. Of vital importance, the addition of $500 \mathrm{mM} \mathrm{CH}_{3} \mathrm{OH}$ or $\mathrm{CD}_{3} \mathrm{OD}$ significantly inhibit the DNA strand cleavage, which is consistent with the generation of radicals by bioreductively-activated, hypoxia-selective metabolism of $\mathbf{1 a}$ and $\mathbf{1 b}$ (Figure 2.2 and Figure 2.4). ${ }^{39}$ Further controls showed that $\mathbf{1 b}$ incubated with NADPH/cytochrome P450 reductase in aerobic conditions did not cause DNA strand cleavage. The two major metabolites $\mathbf{3 b}$ and $\mathbf{7}$, were not responsible for the DNA strand cleavage in hypoxic metabolism of $\mathbf{1 b}$, either alone or with NADPH/cytochrome P450 reductase enzyme system in hypoxic condition. (Figure 2.5) 


\section{$\begin{array}{lllllllll}1 & 2 & 3 & 4 & 5 & 6 & 7 & 8 & 9\end{array}$}
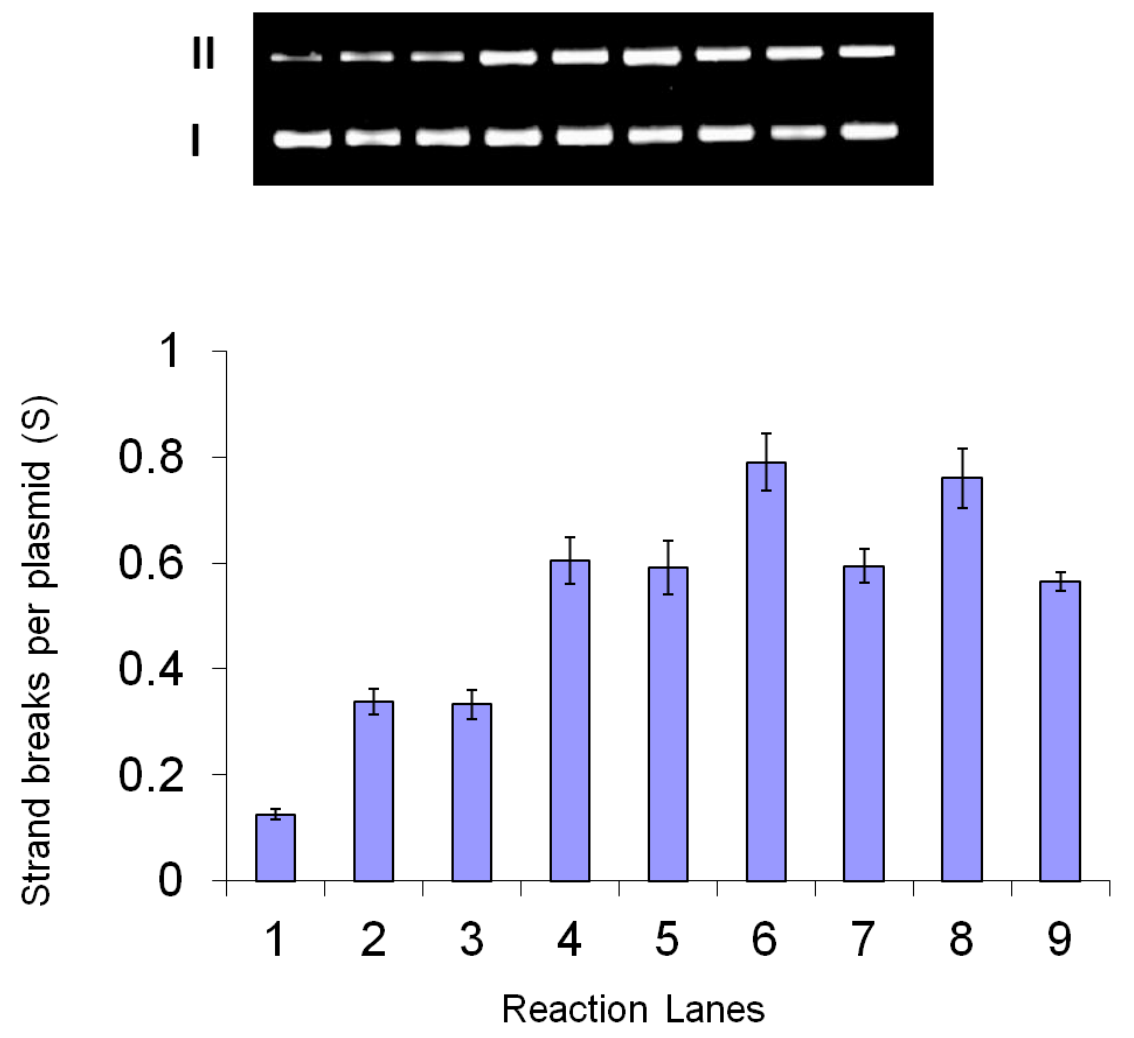

Figure 2.1. Cleavage of supercoiled plasmid DNA by TPZ (1a, 50-100 $\mu \mathrm{M})$ in the presence of NADPH:cytochrome $\mathrm{P} 450$ reductase in phosphate-buffered $\mathrm{H}_{2} \mathrm{O} / \mathrm{CH}_{3} \mathrm{OH}$. On the agarose gel, supercoiled (form I), nicked (form II) and/or linear (form III) DNA are shown. All reactions contained DNA (33 ng/mL, pGL-2 Basic), sodium phosphate buffer $(50 \mathrm{mM}, \mathrm{pH} 7.0)$, acetonitrile $(3.3 \% \mathrm{v} / \mathrm{v})$, catalase $(100 \mu \mathrm{g} / \mathrm{mL})$, superoxide dismutase $(10 \mu \mathrm{g} / \mathrm{mL})$, and desferal $(1 \mathrm{mM})$ and were incubated under anaerobic conditions at $25^{\circ} \mathrm{C}$ for $4 \mathrm{~h}$, followed by agarose gel electrophoretic analysis. lane 1, DNA only ( $\mathrm{S}=0.13 \pm$ $0.01)$; lane 2, DNA + catalase + desferol + SOD $(\mathrm{S}=0.34 \pm 0.02)$; lane 3, DNA + catalase + desferol + SOD + methanol $(\mathrm{S}=0.33 \pm 0.03)$; lane 4 , DNA + catalase + desferal + SOD + cytochrome P450 reductase + NADPH (but no 1a) $(\mathrm{S}=0.61 \pm 0.04)$; lane 5, DNA + catalase + desferal + SOD + NADPH and $50 \mu \mathrm{M}$ 1a (no enzyme) $(\mathrm{S}=$ $0.59 \pm 0.05)$; lane 6 , DNA + catalase + desferal + SOD + cytochrome P450 reductase + NADPH and $50 \mu \mathrm{M} 1 \mathrm{a}(\mathrm{S}=0.79 \pm 0.05)$; lane 7 , same as lane 6 , except containing methanol $(500 \mathrm{mM})(\mathrm{S}=0.59 \pm 0.03)$; lane 8 , DNA + catalase + desferal + SOD + cytochrome P450 reductase + NADPH and $100 \mu \mathrm{M} 1 \mathrm{1a}(\mathrm{S}=0.76 \pm 0.06)$; lane 9 , same as lane 8 , except containing methanol $(500 \mathrm{mM})(\mathrm{S}=0.57 \pm 0.02)$. The results are averaged by three gels. The value $S$ represents the mean number of strand breaks per plasmid molecule and is calculated using the equation $S=-\ln f_{I}$, where $f_{I}$ is the fraction of plasmid present as form I. 

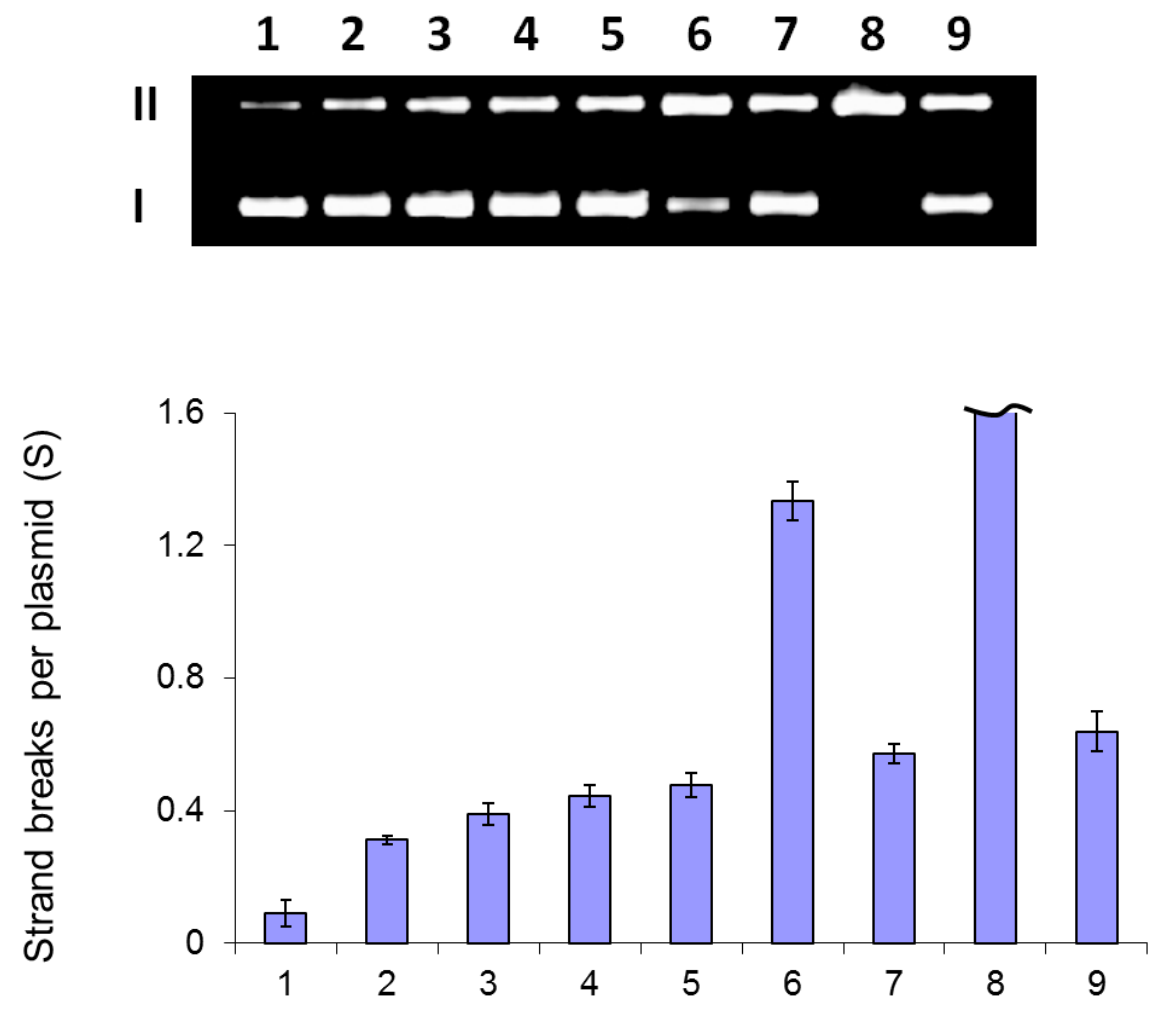

Reaction Lanes

Figure 2.2. Cleavage of supercoiled plasmid DNA by desamino TPZ (1b, 50-100 $\mu \mathrm{M})$ in the presence of NADPH:cytochrome $\mathrm{P} 450$ reductase as an activating system in phosphate-buffered $\mathrm{H}_{2} \mathrm{O} / \mathrm{CH}_{3} \mathrm{OH}$. On the agarose gel, supercoiled (form I), nicked (form II) and/or linear (form III) DNA are shown. All reactions contained DNA (33 ng/mL, pGL-2 Basic), sodium phosphate buffer $(50 \mathrm{mM}, \mathrm{pH} 7.0)$, acetonitrile $(3.3 \% \mathrm{v} / \mathrm{v})$, catalase $(100 \mu \mathrm{g} / \mathrm{mL})$, superoxide dismutase $(10 \mu \mathrm{g} / \mathrm{mL})$, and desferal $(1 \mathrm{mM})$ and were incubated under anaerobic conditions at $25{ }^{\circ} \mathrm{C}$ for $4 \mathrm{~h}$, followed by agarose gel electrophoretic analysis. lane 1 , DNA only $(S=0.09 \pm 0.04)$; lane 2 , DNA + catalase + desferol + SOD $(\mathrm{S}=0.31 \pm 0.01)$; lane 3, DNA + catalase + desferol + SOD + methanol $(\mathrm{S}=0.38 \pm 0.03)$; lane 4 , DNA + catalase + desferal + SOD + cytochrome P450 reductase + NADPH (but no 1b) $(\mathrm{S}=0.44 \pm 0.03)$; lane 5, DNA + catalase + desferal + $\mathrm{SOD}+\mathrm{NADPH}$ and $50 \mu \mathrm{M} 1 \mathrm{~b}$ (no enzyme) $(\mathrm{S}=0.48 \pm 0.04)$; lane 6 , DNA + catalase + desferal + SOD + cytochrome P450 reductase + NADPH and $50 \mu \mathrm{M} \mathbf{1 b}(\mathrm{S}=1.33 \pm$ 0.06); lane 7, same as lane 6, except containing methanol (500 mM) $(\mathrm{S}=0.57 \pm 0.03)$; lane 8, DNA + catalase + desferal + SOD + cytochrome P450 reductase + NADPH and $100 \mu \mathrm{M} 1 \mathrm{~b}(>99 \%$ strand cleavage, $\mathrm{S}>4.61)$; lane 9, same as lane 8, except containing methanol $(500 \mathrm{mM})(\mathrm{S}=0.64 \pm 0.06)$. The results are averaged by three gels. The value $S$ represents the mean number of strand breaks per plasmid molecule and is calculated using the equation $S=-\ln f_{I}$, where $f_{I}$ is the fraction of plasmid present as form $I$. 

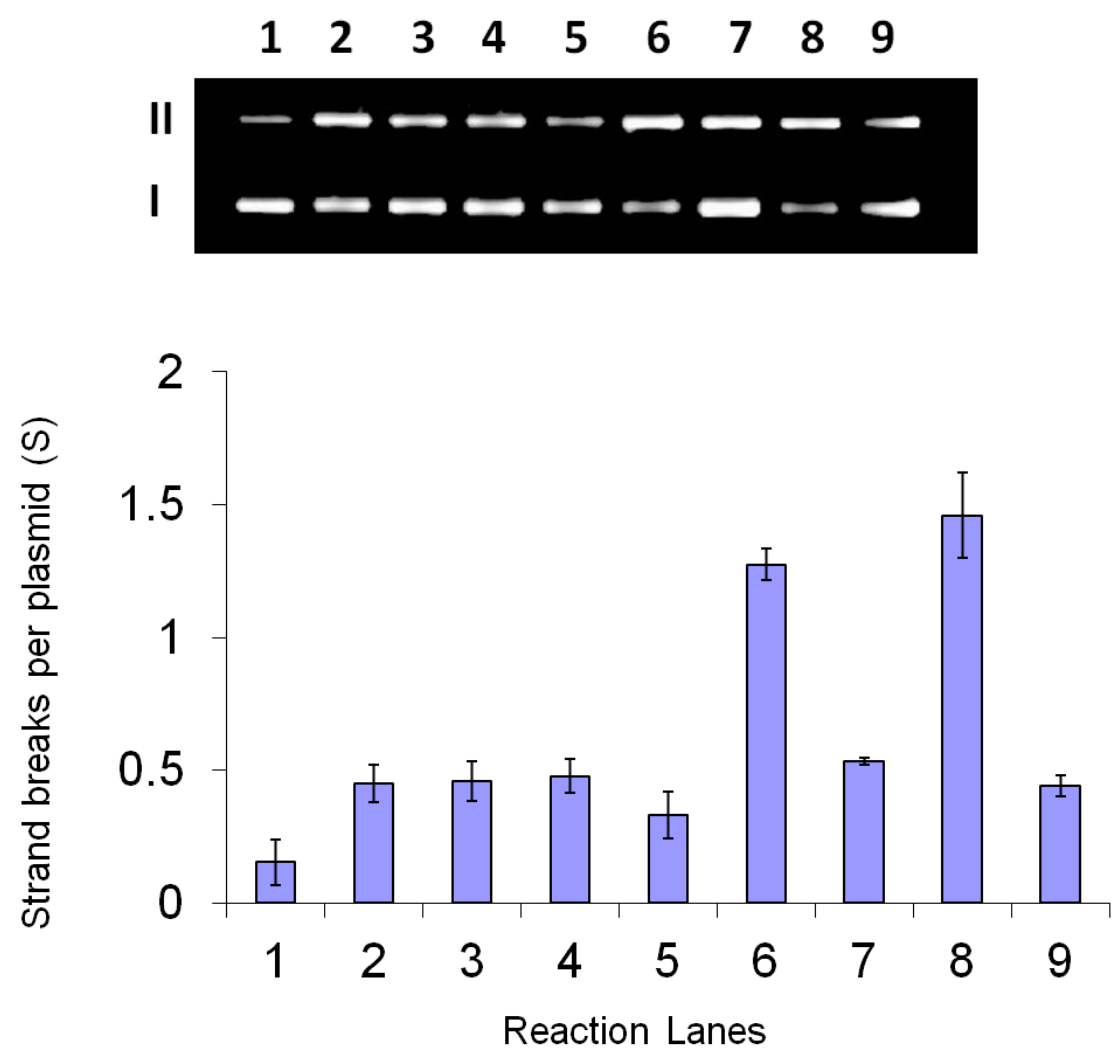

Figure 2.3. Cleavage of supercoiled plasmid DNA by TPZ (1a, 50-100 $\mu \mathrm{M})$ in the presence of NADPH:cytochrome $\mathrm{P} 450$ reductase as an activating system phosphatebuffered $\mathrm{D}_{2} \mathrm{O} / \mathrm{CD}_{3} \mathrm{OD}$. On the agarose gel, supercoiled (form I), nicked (form II) and/or linear (form III) DNA are shown. All reactions contained DNA (33 ng/mL, pGL-2 Basic), sodium phosphate buffer (in $\mathrm{D}_{2} \mathrm{O}, 50 \mathrm{mM}, \mathrm{pD} 7.4$ ), acetonitrile $(3.3 \% \mathrm{v} / \mathrm{v}$ ), catalase $(100 \mu \mathrm{g} / \mathrm{mL})$, superoxide dismutase $(10 \mu \mathrm{g} / \mathrm{mL})$, and desferal $(1 \mathrm{mM})$ and were incubated under anaerobic conditions at $25{ }^{\circ} \mathrm{C}$ for $4 \mathrm{~h}$, followed by agarose gel electrophoretic analysis. lane 1 , DNA only $(\mathrm{S}=0.15 \pm 0.03)$; lane 2 , DNA + catalase + desferol + SOD $(\mathrm{S}=0.45 \pm 0.07)$; lane 3, DNA + catalase + desferol + SOD + methanol$d_{4}(\mathrm{~S}=0.46 \pm 0.08)$; lane 4 , DNA + catalase + desferal + SOD + cytochrome P450 reductase + NADPH (but no 1a) $(\mathrm{S}=0.48 \pm 0.06)$; lane 5 , DNA + catalase + desferal + $\mathrm{SOD}+\mathrm{NADPH}$ and $50 \mu \mathrm{M} 1 \mathrm{la}$ (no enzyme) $(\mathrm{S}=0.33 \pm 0.09)$; lane 6 , DNA + catalase + desferal $+\mathrm{SOD}+$ cytochrome $\mathrm{P} 450$ reductase $+\mathrm{NADPH}$ and $50 \mu \mathrm{M} 1 \mathrm{a}(\mathrm{S}=1.27 \pm$ 0.06); lane 7, same as lane 6, except containing methanol- $d_{4}(500 \mathrm{mM})(\mathrm{S}=0.53 \pm 0.01)$; lane 8, DNA + catalase + desferal + SOD + cytochrome P450 reductase + NADPH and $100 \mu \mathrm{M} 1 \mathrm{a}(\mathrm{S}=1.46 \pm 0.16)$; lane 9 , same as lane 8 , except containing methanol- $d_{4}$ (500 $\mathrm{mM})(\mathrm{S}=0.44 \pm 0.04)$. The results reflect the average of three experiments. The value $\mathrm{S}$ represents the mean number of strand breaks per plasmid molecule and is calculated using the equation $S=-\ln f_{I}$, where $f_{I}$ is the fraction of plasmid present as form $I$. 


\section{$\begin{array}{lllllllll}1 & 2 & 3 & 4 & 5 & 6 & 7 & 8 & 9\end{array}$}
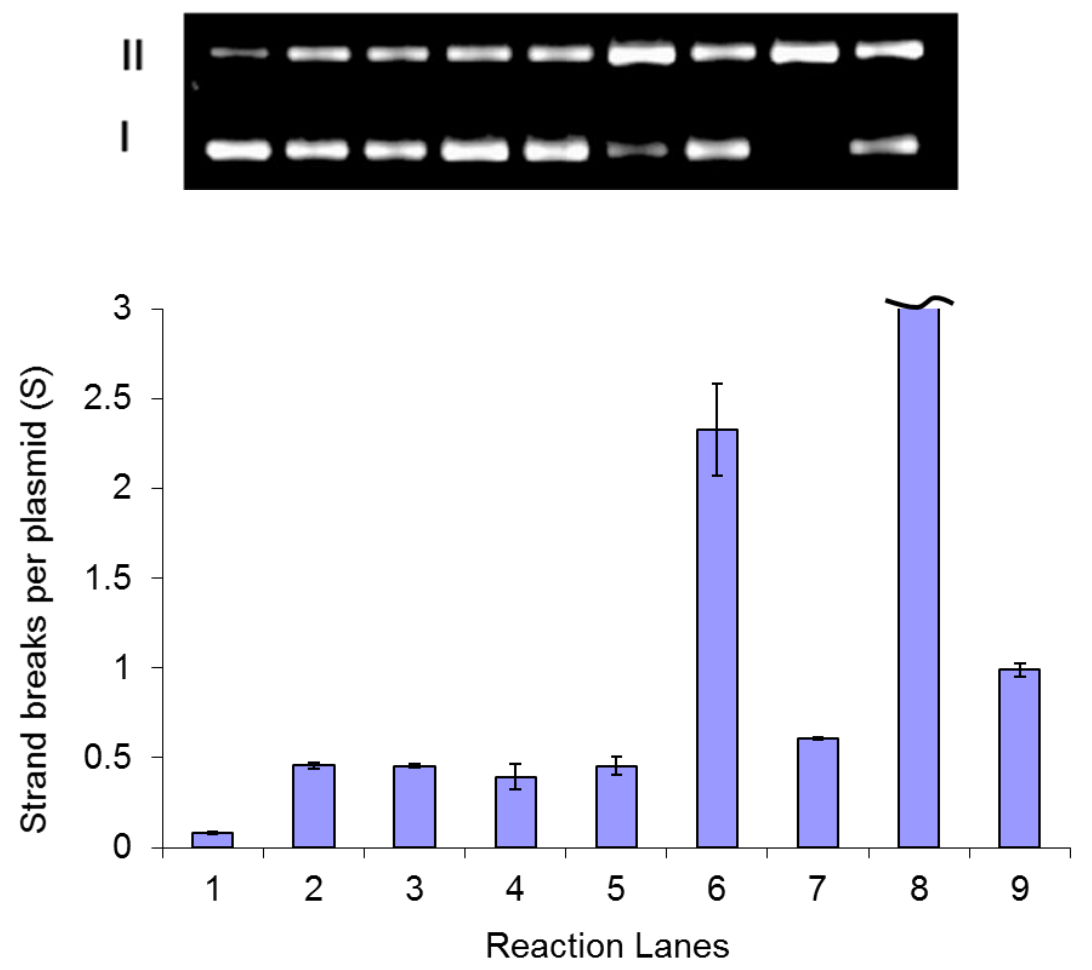

Figure 2.4. Gel and bar graph showing cleavage of supercoiled plasmid DNA by desamino TPZ $(\mathbf{1 b}, 50-100 \mu \mathrm{M})$ in the presence of the NADPH:cytochrome P450 reductase enzyme system in phosphate-buffered $\mathrm{D}_{2} \mathrm{O} / \mathrm{CD}_{3} \mathrm{OD}$. Uncut, supercoiled (form I) and nicked (form II) and/or linear (form III) DNA are labeled on the gel image. Unless otherwise mentioned, all reactions contained DNA ( $33 \mu \mathrm{g} / \mathrm{mL}$, pGL-2 Basic), sodium phosphate buffered- $\mathrm{D}_{2} \mathrm{O}(50 \mathrm{mM}$, employing the same buffer ratio as that used for preparation of a $\mathrm{pH} 7.0$ buffer in $\left.\mathrm{H}_{2} \mathrm{O}\right)$, acetonitrile $(3.3 \% \mathrm{v} / \mathrm{v})$, catalase $(100 \mu \mathrm{g} / \mathrm{mL})$, superoxide dismutase $(10 \mu \mathrm{g} / \mathrm{mL})$, and desferal $(1 \mathrm{mM})$ and were incubated under anaerobic conditions at $25^{\circ} \mathrm{C}$ for $4 \mathrm{~h}$, followed by agarose gel electrophoretic analysis. In reactions containing enzyme the concentration was $(33 \mathrm{mU} / \mathrm{mL})$ and in the reactions containing NADPH the concentration was $500 \mu \mathrm{M}$. Lane 1, DNA alone $(\mathrm{S}=0.08 \pm$ $0.01)$; lane 2, DNA + catalase + desferal + SOD $(\mathrm{S}=0.46 \pm 0.02)$; lane 3, same as lane 2 except with $500 \mathrm{mM}$ methanol- $d_{4}(\mathrm{~S}=0.45 \pm 0.01)$; lane 4 , DNA + catalase + desferal + $\mathrm{SOD}+$ cytochrome $\mathrm{P} 450$ reductase + NADPH (but no $\mathbf{1 b})(\mathrm{S}=0.39 \pm 0.07)$; lane 5 , $\mathrm{DNA}+$ catalase + desferal + SOD + NADPH and $50 \mu \mathrm{M} \mathbf{1 b}$ (no enzyme) $(\mathrm{S}=0.45 \pm$ 0.05 ); lane $6, \mathrm{DNA}+$ catalase + desferal $+\mathrm{SOD}+$ cytochrome P450 reductase + NADPH and $50 \mu \mathrm{M} 1 \mathrm{~b}(\mathrm{~S}=2.33 \pm 0.26)$; lane 7 , same as lane 6 , except containing methanol- $d_{4}$ $(500 \mathrm{mM})(\mathrm{S}=0.61 \pm 0.01)$; lane 8 , DNA + catalase + desferal + SOD + cytochrome P450 reductase + NADPH and $100 \mu \mathrm{M} 1 \mathbf{b}(>99 \%$ strand cleavage, $\mathrm{S}>4.61)$; lane 9 , same as lane 8 , except containing methanol- $d_{4}(500 \mathrm{mM})(\mathrm{S}=0.99 \pm 0.04)$. The results reflect the average of three experiments. The value $\mathrm{S}$ represents the mean number of strand breaks per plasmid molecule and is calculated using the equation $\mathrm{S}=-\ln \mathrm{f}_{\mathrm{I}}$, where $\mathrm{f}_{\mathrm{I}}$ is the fraction of plasmid present as form I. 


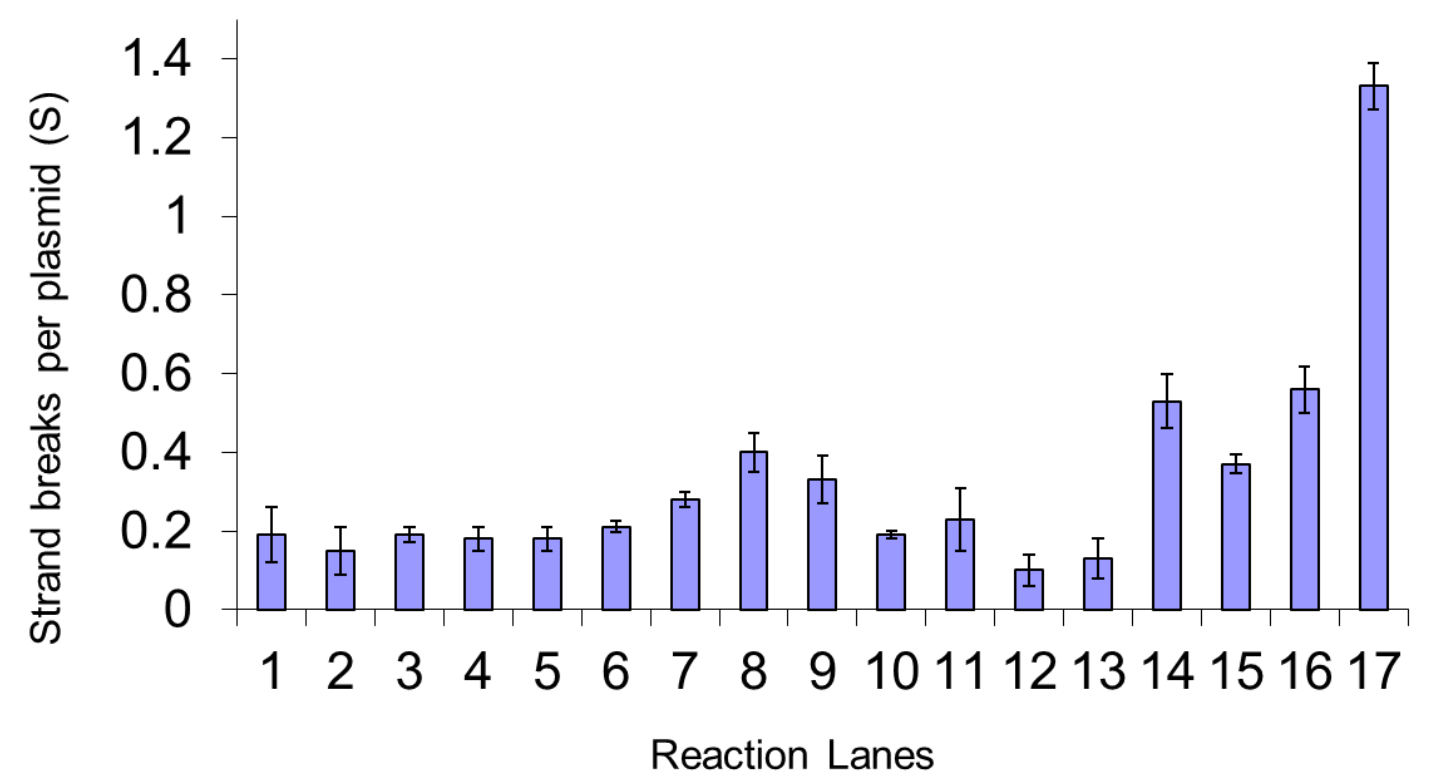

Figure 2.5. Control reactions relevant to DNA strand cleavage by $\mathbf{1 b}$. Unless otherwise noted, all reactions contained DNA (33 $\mu \mathrm{g} / \mathrm{mL}$, pGL-2 Basic), 1b $(50 \mu \mathrm{M})$, sodium phosphate buffer (in $\left.\mathrm{H}_{2} \mathrm{O}, 50 \mathrm{mM}, \mathrm{pH} 7.0\right)$, acetonitrile $(3.3 \% \mathrm{v} / \mathrm{v})$, catalase $(100 \mu \mathrm{g} /$ $\mathrm{mL})$, superoxide dismutase $(10 \mu \mathrm{g} / \mathrm{mL})$, and desferal $(1 \mathrm{mM})$ and were incubated under anaerobic conditions at $25{ }^{\circ} \mathrm{C}$ for $4 \mathrm{~h}$, followed by analysis using agarose gel electrophoresis. In reactions containing enzyme, the concentration was $(33 \mathrm{mU} / \mathrm{mL})$ and in the reactions containing NADPH the concentration was $500 \mu \mathrm{M}$. Lane 1, DNA only (S $=0.19 \pm 0.07)$; lane $2, \mathrm{DNA}+$ cytochrome $\mathrm{P} 450$ reductase $+\mathrm{NADPH}$ aerobic $(\mathrm{S}=0.15 \pm$ $0.06)$; lane 3 , DNA + cytochrome P450 reductase $(\mathrm{S}=0.19 \pm 0.02)$; lane 4 , DNA + 1b alone $(\mathrm{S}=0.18 \pm 0.03)$; lane 5 , DNA $+\mathbf{1 b}+$ cytochrome P450 reductase + NADPH aerobic $(\mathrm{S}=0.18 \pm 0.03)$; lane 6 , DNA $+\mathbf{1 b}+$ cytochrome $\mathrm{P} 450$ reductase $(\mathrm{S}=0.21 \pm$ $0.01)$; lane 7, DNA + 1b + NADPH aerobic $(\mathrm{S}=0.28 \pm 0.02)$; lane $8, \mathrm{DNA}+\mathbf{1 c}$ alone $(\mathrm{S}$ $=0.40 \pm 0.05)$; lane 9 , DNA $+\mathbf{1 c}+$ cytochrome $\mathrm{P} 450$ reductase $+\mathrm{NADPH}$ aerobic $(\mathrm{S}=$ $0.33 \pm 0.06)$; lane 10 , DNA + 1a alone $(\mathrm{S}=0.19 \pm 0.01)$; lane 11, DNA + 1a + cytochrome P450 reductase + NADPH aerobic $(S=0.23 \pm 0.08)$; lane 12 , DNA $+\mathbf{3 b}$ alone $(\mathrm{S}=0.10 \pm 0.04)$; lane 13 , DNA +7 alone $(\mathrm{S}=0.13 \pm 0.05)$; lane 14 , DNA $+\mathbf{3 b}+$ cytochrome P450 reductase $+\mathrm{NADPH}(\mathrm{S}=0.53 \pm 0.07)$; lane 15 , DNA $+\mathbf{6}+$ cytochrome P450 reductase + NADPH $(S=0.37 \pm 0.02)$; lane 16 , DNA $+3 \mathbf{3 b}+\mathbf{6}+$ cytochrome P450 reductase + NADPH $(\mathrm{S}=0.56 \pm 0.06)$; lane $17, \mathrm{DNA}+\mathbf{1 b}+\mathbf{6}+$ cytochrome P450 reductase + NADPH $(S=1.33 \pm 0.06)$. The results are the average of three or more experiments. The value $\mathrm{S}$ represents the mean number of strand breaks per plasmid molecule and is calculated using the equation $S=-\ln f_{I}$, where $f_{I}$ is the fraction of plasmid present as form I. 


\subsection{In vitro bioreductive metabolism of $1 \mathrm{~b}$}

We characterized the metabolites by LC-MS/MS generated from in vitro bioreductive metabolism of $\mathbf{1 b}$ under hypoxic conditions with NADPH/Cytochrome P450 reductase in the presence of methanol/methanol- $d_{4}$. As expected from the hypoxic metabolism of $\mathbf{1 a}, \mathbf{1 b}$ was reduced into several metabolites. Combine with $\mathrm{m} / \mathrm{z}$ by MS/MS analysis (Table 2.1), the 1,4-di- $N$-oxide $\mathbf{1 b}$ eluted at $6.5 \mathrm{~min}$ with the $\mathrm{m} / \mathrm{z}$ of molecular ion 164. The major metabolite $\mathbf{3 b}$ was eluted at 18.8 min with $[\mathrm{M}+\mathrm{H}]^{+} \mathrm{m} / \mathrm{z}=$ 148 , and the minor product 6 was eluted at 17.7 min with $[M+H]^{+} \mathrm{m} / \mathrm{z}=132$. (Figure 2.6) The minor peaks eluted at $14.6 \mathrm{~min}$ in methanol and $14.4 \mathrm{~min}$ in methanol- $d_{4}$ were tentatively assigned to the structures $\mathbf{7 a}$ and $\mathbf{7 b}$, based on their $\mathrm{m} / \mathrm{z}$ of 178 and 180 by several possible pathways including addition of methanol-derived radical ${ }^{-} \mathrm{CH}_{2} \mathrm{OH}$ or - $\mathrm{CD}_{2} \mathrm{OD}$ followed by solvent exchange. (Figure $\left.2.6 \& 2.7\right)^{40}$

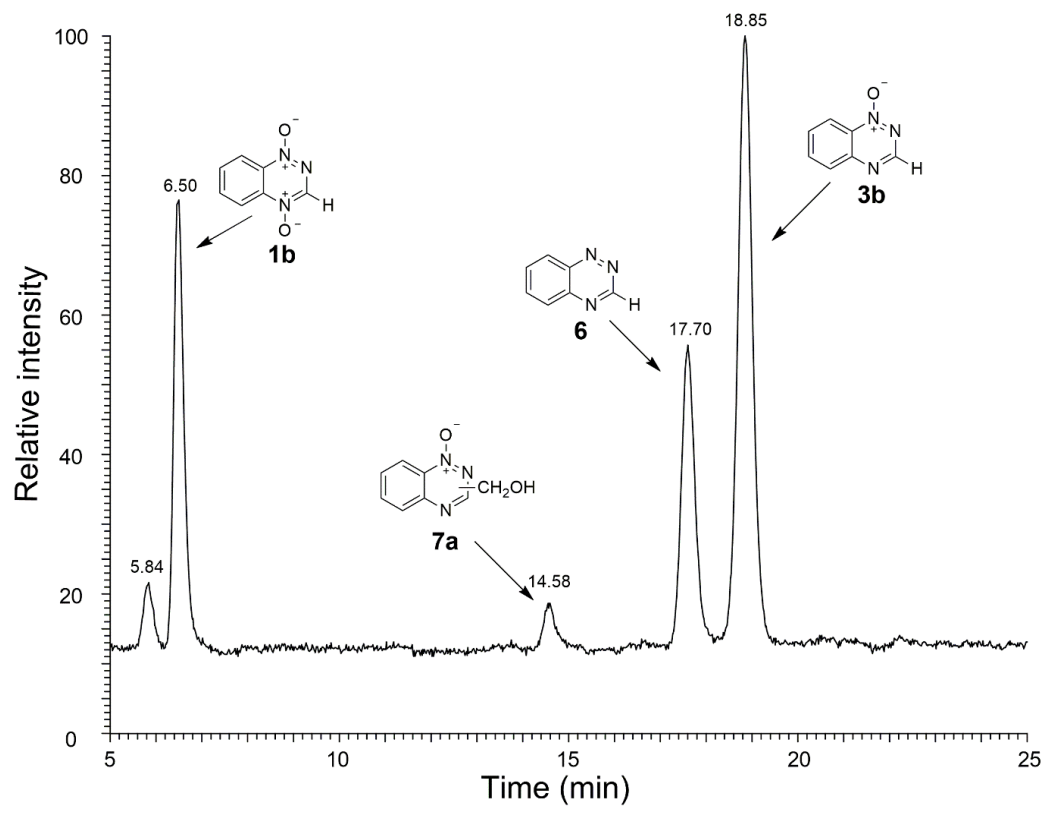

Figure 2.6. Reverse-phase HPLC chromatogram (UV $240 \mathrm{~nm}$ ) of the products generated by in vitro hypoxic metabolism of $\mathbf{1 b}$ in buffered $\mathrm{H}_{2} \mathrm{O} / \mathrm{CH}_{3} \mathrm{OH}$. 


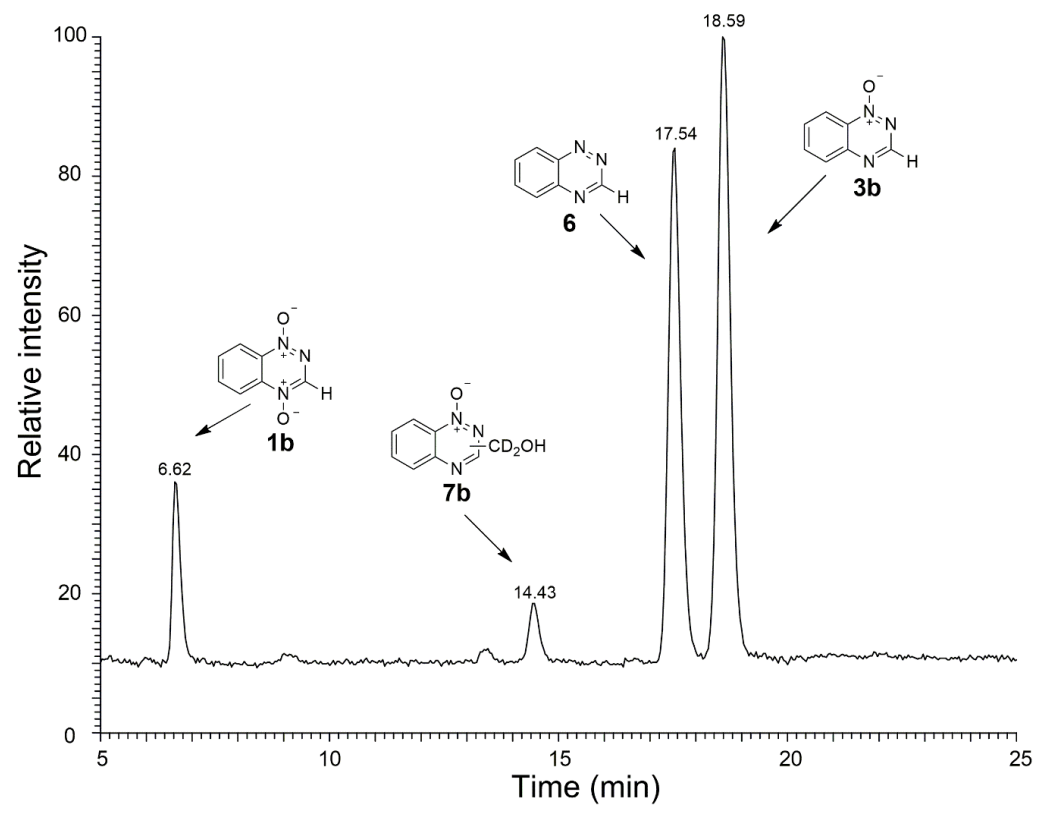

Figure 2.7. Reverse-phase HPLC chromatogram (UV $240 \mathrm{~nm}$ ) of the products generated by in vitro hypoxic metabolism of $\mathbf{1 b}$ in buffered $\mathrm{D}_{2} \mathrm{O} / \mathrm{CD}_{3} \mathrm{OD}$.

Table 2.1. LC-MS/MS properties of the mixture generated by in vitro metabolism of $\mathbf{1 b}$ under hypoxic conditions in the presence of $\mathrm{CH}_{3} \mathrm{OH}$.

\begin{tabular}{llll}
\hline Metabolites & Retention time & {$[\mathrm{M}+\mathrm{H}]^{+}$} & MS/MS fragments \\
\hline $\mathbf{1 b}$ & 6.5 & 164 & $147,137,119,93,92,65$ \\
$\mathbf{6}$ & 17.7 & 132 & 105,77 \\
$\mathbf{3 b}$ & 18.8 & 148 & $120,93,92,65$ \\
$\mathbf{7 a}$ & 14.6 & 178 & $160,132,120,104,93,92,77,65$ \\
\hline
\end{tabular}

The fragmentation patterns were tentatively assigned in Scheme 2.4 according to MS/MS analysis. For example, 7a can undergo a dehydration step to generate $\mathrm{m} / \mathrm{z}=160$. The structure of $\mathrm{m} / \mathrm{z}=132$ could be the mass of $[6+H]^{+}$. The structure of $\mathrm{m} / \mathrm{z}=120$ can be produced by a $\mathrm{C}-\mathrm{N}$ bond dissociation followed by the loss of $\mathrm{NO}$ and protonation from $\mathbf{3 b}$, which was suggested by Yin, et al. ${ }^{21}$ The structure of $\mathrm{m} / \mathrm{z}=104$ could be the loss of $\mathrm{NH}_{3}$ and protonation by $\mathrm{m} / \mathrm{z}=120$. The structure of $\mathrm{m} / \mathrm{z}=93$ and 92 could be the loss of $\cdot \mathrm{CH}_{2}$ followed by protonation. And $\mathrm{m} / \mathrm{z}=77$ and 65 was the mass fragmentation of a benzyl radical cation. In addition, the structures of $\mathrm{m} / \mathrm{z}=119$ and 137 were also assigned. 

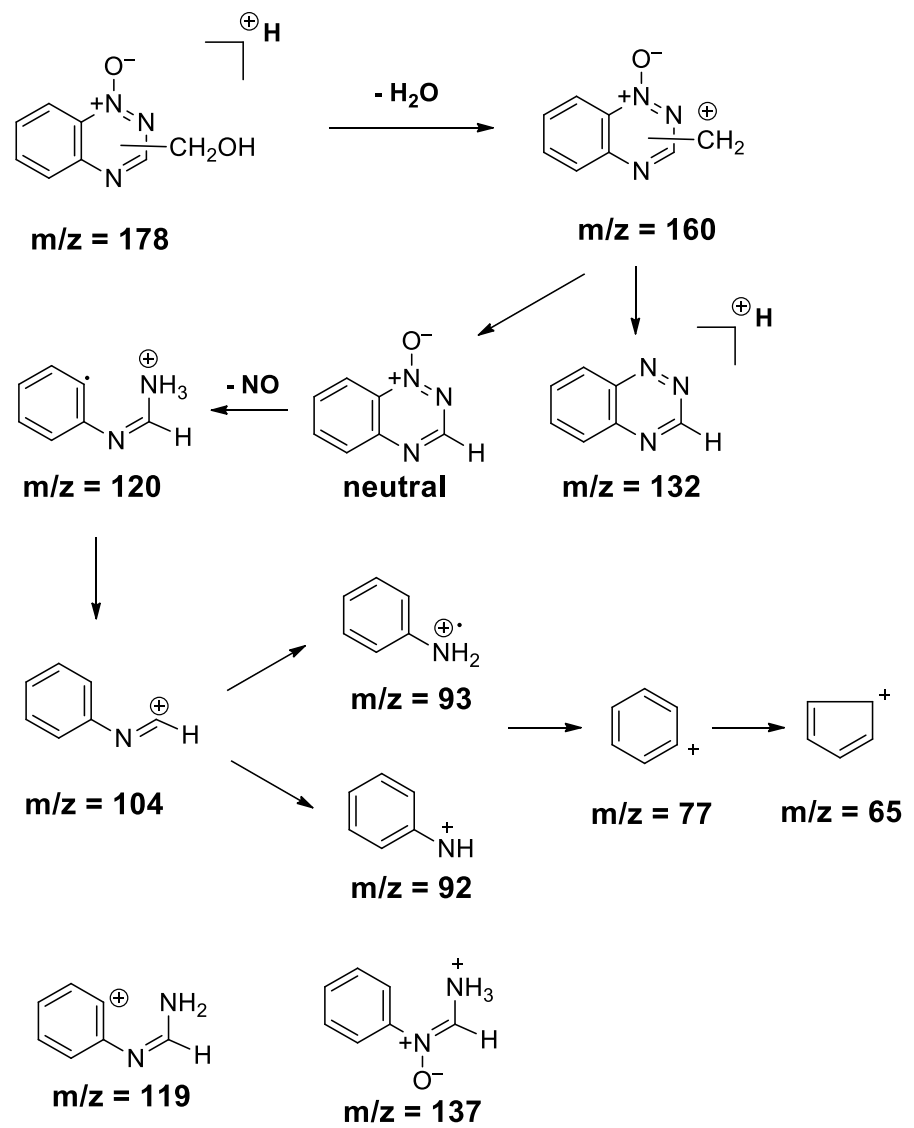

Scheme 2.4. Tentative fragmentation patterns of the hypoxic metabolism of $\mathbf{1 b}$.
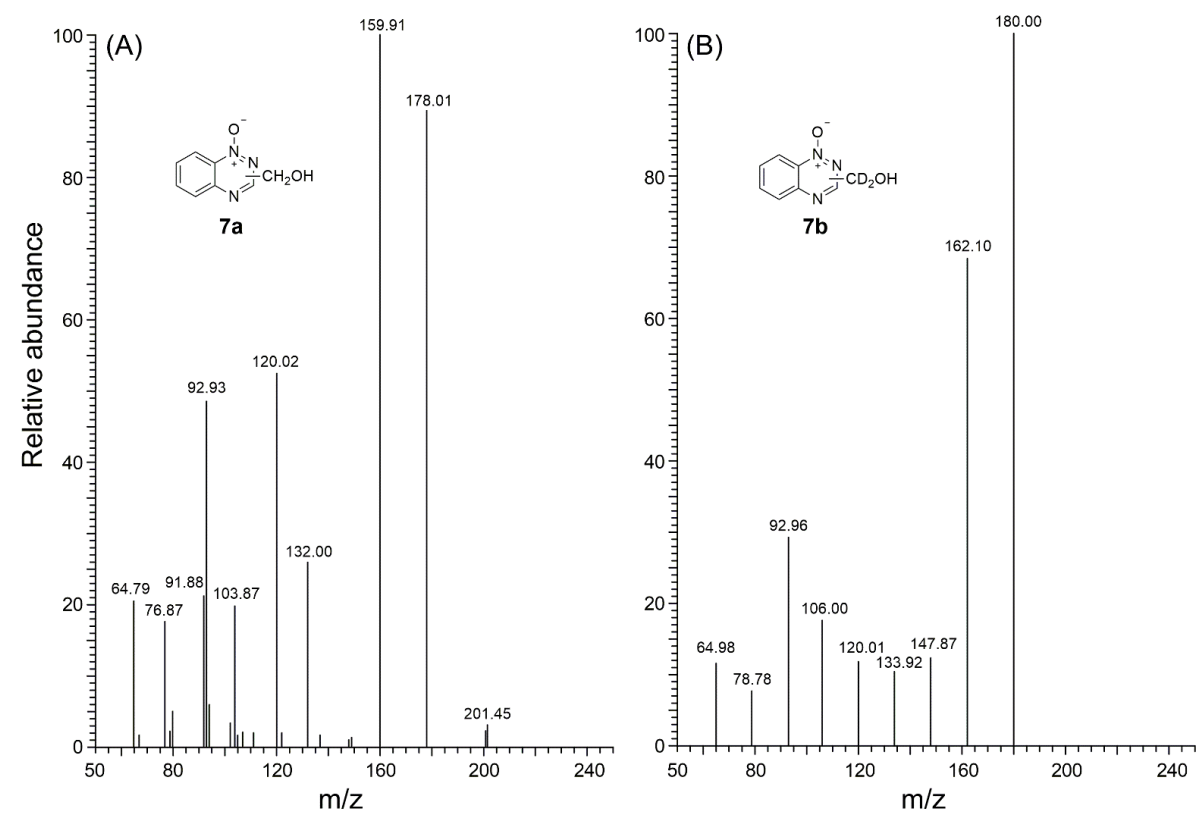

Figure 2.8. MS/MS spectra of the metabolite 7 generated (A) in the presence of methanol (7a) and (B) in the presence of methanol- $d_{4}(\mathbf{7 b})$. 


\subsection{In vitro bioreductive metabolism of $1 \mathrm{~b}$ in phosphate-buffered $\mathrm{D}_{2} \mathrm{O}$ - methanol- $d_{4}$}

The experiments above set the foundation for the potential of isotopic labeling experiments to determine whether the benzotrizinyl radical $\mathbf{5 b}$ was generated during the hypoxic metabolism of $\mathbf{1 b}$. On one hand, the DNA strand cleavage and hypoxic metabolism of $\mathbf{1 b}$ resembled that of $\mathbf{1 a}$, which reasoned the expansion of the dehydration mechanism. On the other hand, DNA strand cleavage of $\mathbf{1 b}$ was inhibited with methanol and methanol- $d_{4}$, which indicated that the DNA-damaging radical intermediate indeed react with methanol- $d_{4}$. In the presence of methanol- $d_{4}$, the metabolite would incorporate the deuterium from the solvent to generate the deuterated metabolite $\mathbf{3 c}$ if the mechanism is the release of the benzotrizinyl radical, while the non-deuterated metabolite $\mathbf{3 b}$ was expected if the mechanism involves the generation of $\bullet \mathrm{OH}$.

Therefore, 1b was incubated in hypoxic conditions with NADPH/cytochrome P450 reductase enzyme systems in phosphate-buffered $\mathrm{D}_{2} \mathrm{O}$ with addition of $500 \mathrm{mM}$ methanol- $d_{4}$ and the proteins were removed by filtration through Amicon Microcon (YM3) filters, followed by LC-MS analysis of the mono- $N$-oxide metabolite (3). LC-MS analysis showed the isotopic cluster ratio for the molecular ion $(\mathrm{m} / \mathrm{z}=148: 149: 150)$ is 100:8.2:0.6 in deuterium donor solvent $\mathrm{D}_{2} \mathrm{O} / \mathrm{CD}_{3} \mathrm{OD}$, which is corresponding to the natural abundance of ${ }^{2} \mathrm{H}$ and ${ }^{13} \mathrm{C}$ of the mono- $\mathrm{N}$-oxide formula $\mathrm{C}_{7} \mathrm{H}_{5} \mathrm{~N}_{3} \mathrm{O}$ (isotopic cluster ratio is $100: 7.9: 0.5$ at $\mathrm{m} / \mathrm{z}=148: 149: 150$ ) (Figure 2.9). This data strongly supported that no significant amount of deuterium was incorporated into the mono- $N$-oxide metabolite (3) during the hypoxic metabolism in $\mathrm{D}_{2} \mathrm{O} / \mathrm{CD}_{3} \mathrm{OD}$, which provided evidence against the generation of the benzotriazinyl radical $\mathbf{5 b}$. 


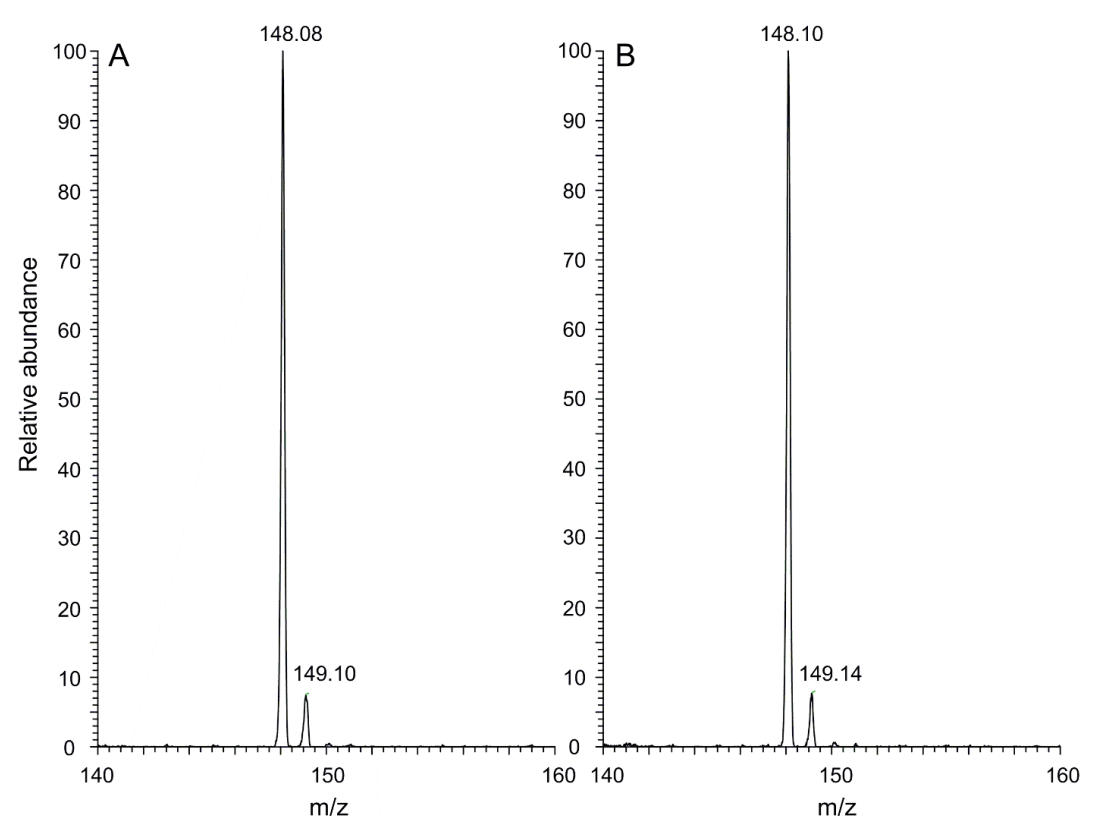

Figure 2.9. Hypoxic metabolism of $\mathbf{1 b}$ in phosphate-buffered $\mathrm{D}_{2} \mathrm{O} / \mathrm{CD}_{3} \mathrm{OD}$ does not lead to incorporation of deuterium into the metabolite 3. LC-MS of the mono- $N$-oxide metabolite $\mathbf{3}$ generated by hypoxic metabolism of $\mathbf{1 b}$. Panel A, isotope cluster for the $[\mathrm{M}+\mathrm{H}]^{+}$ion of 3 generated in phosphate-buffered $\mathrm{H}_{2} \mathrm{O} / \mathrm{CH}_{3} \mathrm{OH}$ (relative peak intensities for $\mathrm{m} / \mathrm{z}$ 148:149:150 = 100:7.9:0.5). Panel $\mathrm{B}$, isotope cluster for the $[\mathrm{M}+\mathrm{H}]^{+}$ion of 3 generated in phosphate-buffered $\mathrm{D}_{2} \mathrm{O} / \mathrm{CD}_{3} \mathrm{OD}$ (relative peak intensities for $\mathrm{m} / \mathrm{z}$ 148:149:150 = 100:8.2:0.6).

\subsection{In vitro bioreductive metabolism of the deuterium-labeled analog 1c}

In addition, we synthesized the deuterium-labeled analog 1c by treatment of 1a with $t$-butyl nitrite in DMF- $d_{7}^{30,41}$ and carried out the isotopic labeling experiments that are complementary to the experiments described above. Therefore, if the mechanism is involved in the generation of benzotriazinyl radical 5a, it would be expected to lose the deuterium and produce mono- $N$-oxide $\mathbf{3 b}$ during the hypoxic metabolism with protium donor source.

Therefore, hypoxic metabolism of 1c with NADPH/cytochrome P450 reductase was performed and analyzed by LC-MS analysis. As illustrated in Figure 2.10, there is no significant loss of deuterium with the stable metabolite $\mathbf{3 c}$ as well as the parent compound 
$\mathbf{1 c}$ in the hypoxic metabolism. The fact that the deuterium of compound 1c and $\mathbf{3 c}$ does not "wash off" under our conditions can further validate the results that are against the generation of benzotriazinyl radical, ruling out the possibility that in the isotopic labeling experiments, deuterium was incorporated into the metabolite $\mathbf{3 b}$ but was totally washed off with the solvent prior to mass spectrometric analysis.

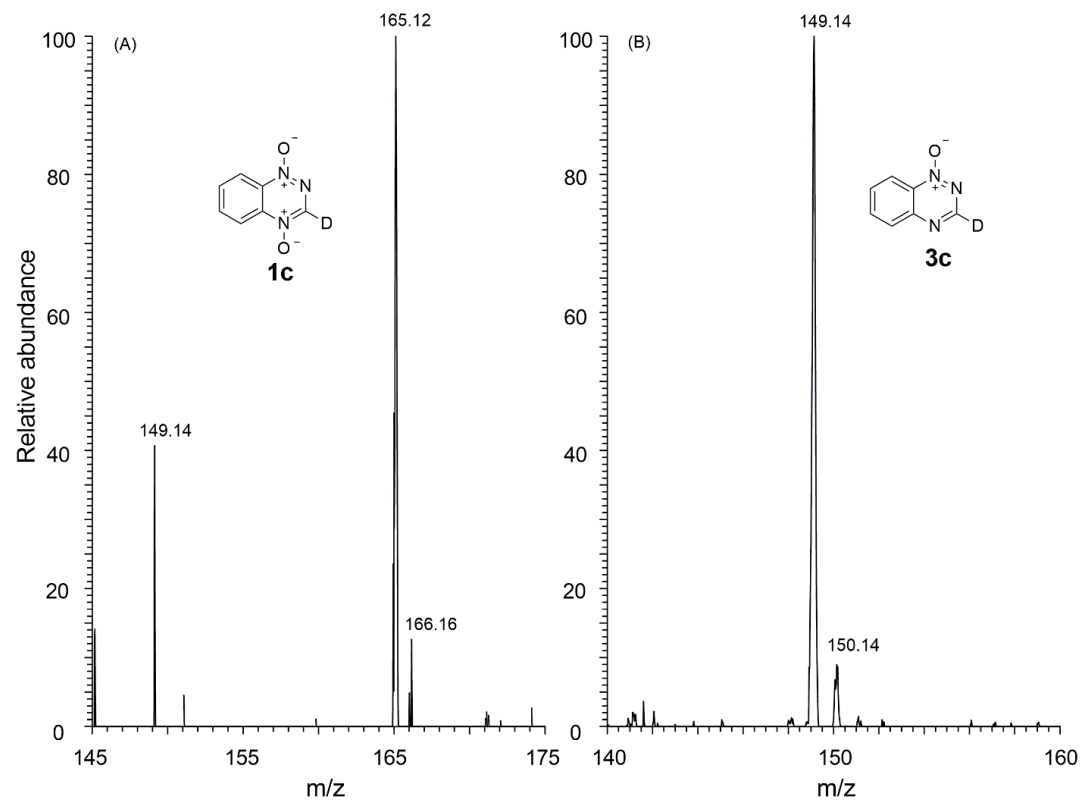

Figure 2.10. MS of $1 \mathrm{c}$ and $3 \mathbf{c}$ present in the mixture generated by hypoxic metabolism of 1c by NADPH:cytochrome $\mathrm{P} 450$ reductase in buffered $\mathrm{H}_{2} \mathrm{O} / \mathrm{CH}_{3} \mathrm{OH}$. (A) MS spectra of 1c (relative peak intensities of $\mathrm{m} / \mathrm{z} 165: 166: 167=100: 8.0: 1.5)$ and $(\mathrm{B}) \mathrm{MS}$ spectra of the metabolite 3c (relative peak intensities of $\mathrm{m} / \mathrm{z} 149: 150: 151=100: 8.5: 1.6$ ).

\subsection{In vitro bioreductive metabolism of $1 \mathrm{~b}$ in phosphate-buffered $\mathrm{D}_{2} \mathrm{O}$ - methanol- $d_{4}$ with removal all exchangeable protium sources.}

In the hypoxic metabolism assay of $\mathbf{1 b}$, there is still trace amount of protium donor in phosphate-buffered $\mathrm{D}_{2} \mathrm{O}-\mathrm{CD}_{3} \mathrm{OD}$. For example, the enzyme cytochrome $\mathrm{P} 450$ reductase was introduced in the assay in buffered $\mathrm{H}_{2} \mathrm{O}(0.5 \mu \mathrm{L}$ of enzyme in $300 \mu \mathrm{L}$ final volume), and the phosphate buffer as well as NADPH contains trace amount of protium 
source. Therefore, due to the rapid solvent exchange between the hydroxyl proton and the solvent, it is expected that around $0.5 \%$ of $\mathrm{CD}_{3} \mathrm{OH}$ was presented in the solvent along with around $99.5 \% \mathrm{CD}_{3} \mathrm{OD}$.
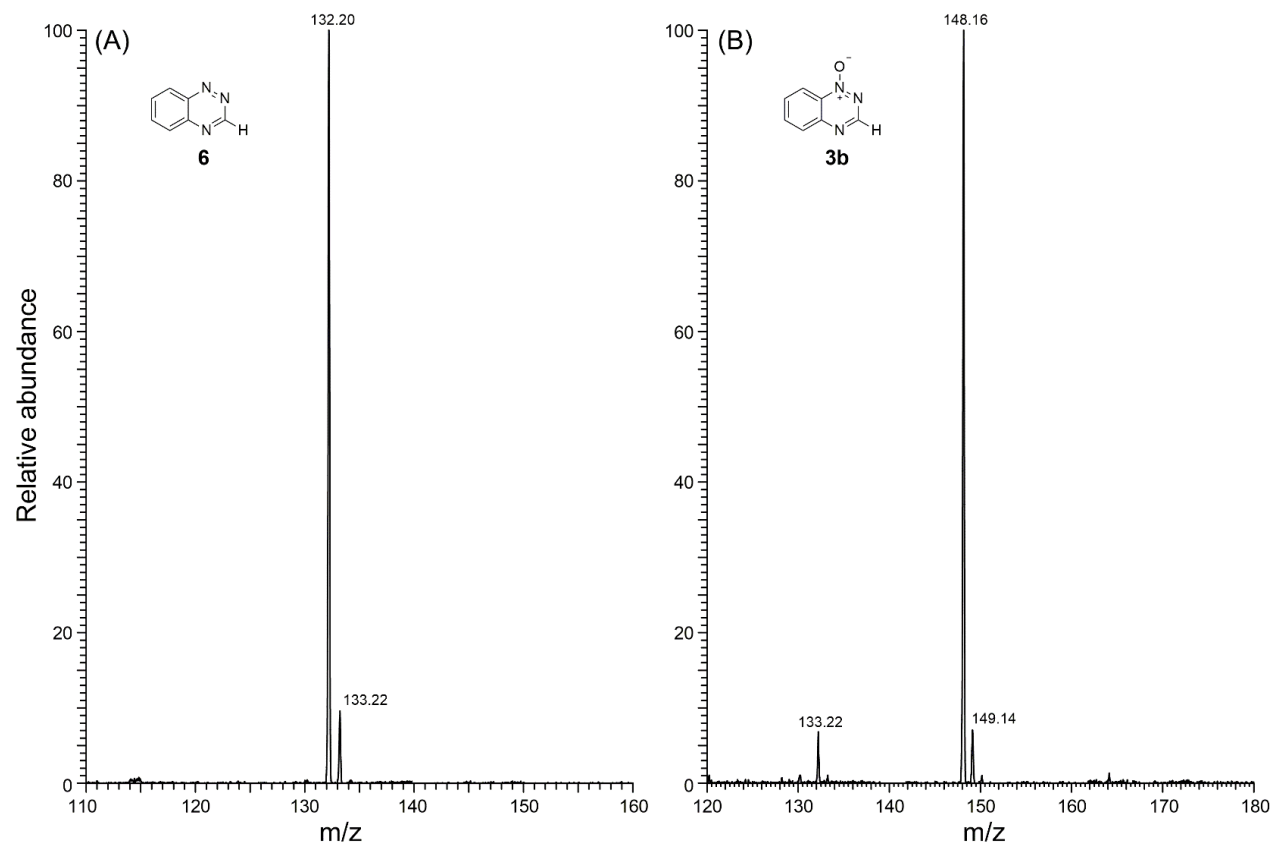

Figure 2.11. LC-MS of metabolites $\mathbf{6}$ and $\mathbf{3}$ generated by hypoxic metabolism of $\mathbf{1 b}$ by NADPH:cytochrome $\mathrm{P} 450$ reductase in "completely deuterated" $\mathrm{D}_{2} \mathrm{O} / \mathrm{CD}_{3} \mathrm{OD}$ buffer described below. (A) MS spectra of 6 (relative peak intensities of $\mathrm{m} / \mathrm{z}$ 132:133:134 = 100:9.2:0.8) and (B) MS spectra of the metabolite 3b (relative peak intensities of $\mathrm{m} / \mathrm{z}$ $148: 149: 150=100: 8.8: 1.0$ ). The ratio of $\mathrm{M}+\mathrm{H}, \mathrm{M}+\mathrm{H}+1$, and $\mathrm{M}+\mathrm{H}+2$ are very near to those expected to arise from natural isotope abundances in the molecular formulas $\mathrm{C}_{7} \mathrm{H}_{6} \mathrm{~N}_{3}(100: 8.8: 0.3)$ and $\mathrm{C}_{7} \mathrm{H}_{6} \mathrm{~N}_{3} \mathrm{O}(100: 8.8: 0.5)$.

Now the question is whether that $0.5 \%$ of $\mathrm{CD}_{3} \mathrm{OH}$ would affect the interpretation of the isotopic labeling experiments above. We think this is unlikely due to several reasons. First, previous studies showed that hydrogen atom abstraction by reactive radicals (such as hydroxyl radical) from methyl group is significantly favorable than from the hydroxyl group due to bond enthalpy issues. ${ }^{42}$ Second, the kinetic isotope effect of the hydrogen abstraction by reactive radicals is modest, in the range of $2-5 .^{43,44}$ Therefore, the trace amount of $\mathrm{CD}_{3} \mathrm{OH}$ would not affect the interpretation of the data. Finally, we 
also performed a hypoxic metabolism of $\mathbf{1 b}$ with all exchangeable protium sources removed. In the assay, cytochrome $\mathrm{P} 450$ reductase enzyme in $\mathrm{D}_{2} \mathrm{O}$ was prepared by passing the enzyme buffer water solution through a Sephadex G-25 (Sigma-Aldrich) spin column that had been equilibrated in deuterated water. The phosphate buffer salts and $\mathrm{NADPH}$ were dissolved in $\mathrm{D}_{2} \mathrm{O}$, lyophilized to remove residual exchangeable protium, and redissolved in $\mathrm{D}_{2} \mathrm{O}$. Desferal was not included the assay mixture because it might bring exchangeable protium to the assay. The same metabolites were observed as in Figure 2.9, and LC-MS analysis showed no significant incorporation of deuterium in the mono- $N$-oxide 3 and the no-oxide 6 (Figure 2.11).

\subsection{Conclusions}

The results in this chapter showed that 1,2,4-benzotriazine-1,4-di- $N$-oxide (1b) is able to conduct bioreductively-activated, hypoxic-selective metabolism and cause DNA strand cleavage comparable to TPZ (1a). The two complementary isotopic labeling experiments provided evidence against the generation of benzotriazinyl radical in the hypoxic metabolism of $\mathbf{1 b}$, leaving $\cdot \mathrm{OH}$ the only viable alternative. We hope that improved mechanistic understandings of heterocyclic $\mathrm{N}$-oxide drugs can aid in the design of second and third generation analogs toward cancer therapy.

\subsection{Experimental section}

Materials. Materials were of the highest purity available and were obtained from the following sources: Cytochrome P450 reductase, NADPH, sodium phosphate, mannitol, DMSO, desferal, catalase, superoxide dismutase (SOD), tert-butyl nitrite, silica 
gel (0.04-0.063 mm pore size) for column chromatography, and silica gel plates for thin layer chromatography from Sigma Chemical Co. (St. Louis, MO); agarose from Seakem; HPLC grade solvents (acetonitrile, methanol, ethanol, tert-butyl alcohol, ethyl acetate, hexane, and acetic acid) from Fischer (Pittsburgh, PA); ethidium bromide from Roche Molecular Biochemicals (Indianapolis, IN); deuterated NMR solvents (deuterium oxide, D $99.96 \%$, methanol- $d_{4}$, D $99.8 \%, N, N$-dimethylformamide- $d_{7}$, D $99.5 \%$; acetone- $d_{6}, \mathrm{D}$ 99.8\%) were from Cambridge Isotope Laboratories (Andover, MA). Compounds 1a and $\mathbf{1 b}$ were prepared by routes described previously in the literature. ${ }^{2,30,31}$ Compound $\mathbf{3 b}$ was prepared via the same general procedure used for $\mathbf{1} \mathbf{b}$ and the spectral data of this product matched that published previously. ${ }^{2}$

DNA cleavage assays. DNA strand cleavage reactions were carried out as described previously. ${ }^{45,46}$ Briefly, in normal hypoxic DNA cleaving assay, agents such as 1a, 1b $(25-150 \mu \mathrm{M})$ were incubated with supercoiled plasmid DNA (33 $\mu \mathrm{g} / \mathrm{mL}$, pGL-2 Basic), NADPH $(500 \mu \mathrm{M})$, cytochrome $\mathrm{P} 450$ reductase $(33 \mathrm{mU} / \mathrm{mL}$, where one unit is defined as the amount of enzyme required to cause the reduction of $1.0 \mu$ mole of cytochrome c by NADPH per minute at $\mathrm{pH} 7.4$ at $\left.37{ }^{\circ} \mathrm{C}\right)$, catalase $(100 \mu \mathrm{g} / \mathrm{mL})$, superoxide dismutase $(10 \mu \mathrm{g} / \mathrm{mL})$, sodium phosphate buffer $(50 \mathrm{mM}, \mathrm{pH}$ 7.0), acetonitrile $(0.5-3.3 \% \mathrm{v} / \mathrm{v})$, and desferal (deferoxamine mesylate salt, $10 \mathrm{mM})$ under anaerobic conditions at $25{ }^{\circ} \mathrm{C}$ for $4 \mathrm{~h}$. All components of the reactions except enzymes, NADPH, and DNA were degassed by three freeze-pump-thaw cycles. Enzymes, NADPH, and DNA were diluted with degassed water in an argon-filled glove bag to prepare stock solutions. Reactions were initiated by addition of cytochrome P450 
reductase, wrapped in aluminum foil to prevent exposure to light, and incubated in an argon filled glove bag. Following incubation, the reactions were quenched by addition of $4 \mu \mathrm{L}$ of loading buffer containing bromophenol blue dye and were loaded onto a $0.9 \%$ agarose gel. The gel was electrophoresed for approximately $2 \mathrm{~h}$ at $83 \mathrm{~V}$ in $1 \times \mathrm{TAE}$ buffer. The gel was then stained in a solution of aqueous ethidium bromide $(0.5 \mu \mathrm{g} / \mathrm{mL})$ for 15 min, destained in fresh distilled water for $15 \mathrm{~min}$, and the DNA in the gel visualized by UV-transillumination. The amount of DNA in each band was quantified using an Alpha Innotech IS-1000 digital imaging system. Buffers for the reactions performed in $\mathrm{D}_{2} \mathrm{O}$ were prepared using the same mixture of phosphate buffer salts used in the $\mathrm{H}_{2} \mathrm{O}$ experiments, as described by others..$^{47,48}$

Synthesis of 4-deutero-1,2,4-benzotriazine 1,4-dioxide (1c). In a $25 \mathrm{~mL}$ round bottom flask, tert-butyl nitrite $(0.25 \mathrm{~mL}, 2.10 \mathrm{mmol})$ was added to DMF- $d_{7}(2 \mathrm{~mL})$ and heated to $65{ }^{\circ} \mathrm{C}$. To this mixture, a solution of $1 \mathbf{a}(100 \mathrm{mg})$ in DMF- $d 7(2 \mathrm{~mL})$ and was added dropwise over the course of $15 \mathrm{~min}$. The reaction was monitored by thin layer chromatography every 10 min until all starting material was consumed. The reaction mixture was then cooled to room temperature and the DMF- $d 7$ was removed by high vacuum. Column chromatography on silica gel eluted with 1:1 ethyl acetate-hexane gave 1c as a yellow solid (23 mg, 25\%), $\mathrm{R}_{\mathrm{f}} 0.60$ (100\% ethyl acetate): ${ }^{1} \mathrm{H}$ NMR (DMSO, 500 MHz,): $\delta 8.39(\mathrm{~d}, \mathrm{~J}=8.5 \mathrm{~Hz}, 1 \mathrm{H}), 8.36(\mathrm{~d}, \mathrm{~J}=8.5 \mathrm{~Hz}, 1 \mathrm{H}), 8.14(\mathrm{ddd}, \mathrm{J}=8.5,7.5,1.0$ $\mathrm{Hz}, 1 \mathrm{H}), 8.10$ (ddd, J = 8.5, 7.5, $1.0 \mathrm{~Hz}, 1 \mathrm{H}) .{ }^{13} \mathrm{C}-\mathrm{NMR}$ (DMSO, $\left.125.8 \mathrm{MHz}\right): \delta 142.2(\mathrm{t}$, $\mathrm{J}=33.3 \mathrm{~Hz}), 141.0,136.0,135.6,133.3,121.5,119.4 . \mathrm{HRMS}\left(\mathrm{ES}^{+},[\mathrm{M}+\mathrm{H}]\right) \mathrm{m} / \mathrm{z}$ calcd $\mathrm{C}_{7} \mathrm{H}_{5} \mathrm{DN}_{3} \mathrm{O}_{2}$ calcd mass 165.0523; actual mass 165.0515. 
Synthesis of 1,2,4-benzotriazine (6). The benzotriazine 6 was prepared via a modification of the procedures described by Fuchs et al. and Mason and Tennant. ${ }^{31,49}$ To a solution of $\mathbf{3 b}$ (300 mg, $2.04 \mathrm{mmol})$ in $70 \%$ ethanol-water $(40 \mathrm{~mL})$ was added sodium dithionite (710 mg, $4.08 \mathrm{mmol})$. The resulting suspension was refluxed for $2 \mathrm{~h}$, an additional aliquot of sodium dithionite $(305 \mathrm{mg}, 2.04 \mathrm{mmol}$ ) added, and the suspension refluxed for another $30 \mathrm{~min}$, at which time all starting material was consumed (as judged by TLC). The solvent was removed by rotary evaporation and the resulting pale yellow residue purified by column chromatography on silica gel eluted with $30 \%$ ethyl acetatehexane to yield $\mathbf{6}$ as pale yellow solid (154 mg, 58\%), $\mathrm{R}_{\mathrm{f}}=0.57$ (30\% ethyl acetate/hexane): ${ }^{1} \mathrm{H}-\mathrm{NMR}(\mathrm{DMSO}, 500 \mathrm{MHz}$ ): $\delta 10.13(\mathrm{~s}, 1 \mathrm{H}), 8.61(\mathrm{~d}, \mathrm{~J}=8.5 \mathrm{~Hz}, 1 \mathrm{H})$, 8.18-8.24 (m, 2H), $8.10(\mathrm{ddd}, \mathrm{J}=8.5,6.5,1.5 \mathrm{~Hz}, 1 \mathrm{H}) .{ }^{13} \mathrm{C}-\mathrm{NMR}$ (DMSO, $\left.125.8 \mathrm{MHz}\right)$ :

$\delta 154.1,148.1,140.1,136.8,132.2,129.5,129.0$. Spectral data matched that reported by Boyd et al. ${ }^{50}$

\section{LC-MS/MS analysis of mixtures generated by in vitro hypoxic metabolism of}

1b and 1c. In the isotope incorporation assay, all stock solutions were made in $\mathrm{D}_{2} \mathrm{O}$ except for 1b. Stock solution preparation used in the assay were prepared as follows: a stock solution of $\mathbf{1 b}(15 \mathrm{mM})$ was prepared by dissolving $10 \mathrm{mg}$ of $\mathbf{1 b}$ in $4 \mathrm{~mL}$ acetonitrile, a stock solution of sodium phosphate buffer $(500 \mathrm{mM})$ was prepared by dissolving $409 \mathrm{mg} \mathrm{Na} 2 \mathrm{HPO}_{4}$ and $254 \mathrm{mg} \mathrm{NaH} \mathrm{PO}_{4}$ in $10 \mathrm{~mL} \mathrm{D}_{2} \mathrm{O}$ ), a stock solution of $10 \mathrm{mM}$ desferal was prepared by dissolving $3 \mathrm{mg}$ desferal in $455 \mu \mathrm{L} \mathrm{D}_{2} \mathrm{O}$, a stock solution of NADPH (30 $\mathrm{mM}$ ) was prepared by dissolving $1 \mathrm{mg}$ fresh $\mathrm{NADPH}$ in $40 \mu \mathrm{L} \mathrm{D}_{2} \mathrm{O}$, the stock solution of cytochrome P450 reductase $(120 \mathrm{U} / \mathrm{mL})$ was prepared by dissolving $3 \mu \mathrm{L} 260.4 \mathrm{U} / \mathrm{mL}$ 
stock solution of enzyme in $3.5 \mu \mathrm{L} \mathrm{D}_{2} \mathrm{O}$, and a stock solution of $\mathrm{CD}_{3} \mathrm{OD}(15 \mathrm{M})$ was prepared by dissolving $610 \mu \mathrm{L} \mathrm{CD}_{3} \mathrm{OD}$ in $390 \mu \mathrm{L} \mathrm{D}_{2} \mathrm{O}$.

All solutions except cytochrome P450 reductase were degassed by three cycles of freeze-pump-thaw cycles. For preparation of the assay, $1 \mathbf{b}(10 \mu \mathrm{L})$ was mixed with desferal $(30 \mu \mathrm{L})$, sodium phosphate buffer in $\mathrm{D}_{2} \mathrm{O}(30 \mu \mathrm{L}), \mathrm{NADPH}(30 \mu \mathrm{L}), 15 \mathrm{M}$ $\mathrm{CD}_{3} \mathrm{OD}\left(10 \mathrm{~mL}\right.$ of the $15 \mathrm{M} \mathrm{CD} \mathrm{CD}_{3} \mathrm{OD}$ in $\left.\mathrm{D}_{2} \mathrm{O}\right)$ and $209 \mu \mathrm{L}$ of $\mathrm{D}_{2} \mathrm{O}$. Finally, the enzymatic reactions were initialed by the addition of $1 \mu \mathrm{L} 120 \mathrm{U} / \mathrm{mL}$ cytochrome $\mathrm{P} 450$ reductase. The final volume of the assay mixture was $300 \mu \mathrm{L}$.

After $4 \mathrm{~h}$ of incubation under argon at $25^{\circ} \mathrm{C}$, the proteins in the assay were removed by centrifugation through Amicon Microcon (YM3) filters. The filtrate was analyzed by Beckman Coulter HPLC employing a C18 reverse phase Betabasic column (5 $\mu \mathrm{m}$ particle size, $150 \AA$ pore size, $25 \mathrm{~cm}$ length, $4.6 \mathrm{~mm}$ i.d.) eluted with gradient starting from 5\% B $(0.1 \%$ trifluoacetic acid in acetonitrile) and $95 \% \mathrm{~A}(0.1 \%$ trifluoacetic acid in water) for 5 min followed by linear increase to $11 \% \mathrm{~B}$ in another $24 \mathrm{~min}$, then the gradient was increased linearly to $80 \%$ of B within in 6 min, and finally $80 \%$ of B was used to wash the column for $10 \mathrm{~min}$. A flow rate of $1.0 \mathrm{~mL} / \mathrm{min}$ was used and the products were monitored by their UV-absorbance at $240 \mathrm{~nm}$. LC/ESI-MS experiments were carried out using an ion trap mass analyzer, on a LCQ FLEET instrument (Thermo Fisher Scientific). Positive ion electrospray was used as the means of ionization. The heated inlet capillary temperature was $375^{\circ} \mathrm{C}$ and electrospray needle voltage was $5 \mathrm{kV}$. Nitrogen sheath gas was supplied at $45 \mathrm{psi}$ and the LC/ESI-MS analysis was done in the positive ion mode. Relative collision energies of $35 \%$ were used when the ion trap mass spectrometry was operated in the MS/MS mode. Parent ions were selected manually (164, 165, 148, 149, 
132, 133, 178, 180) and subsequent tandem mass spectrometry was performed automatically by XCalibur software (Thermo Fisher Scientific). 


\section{${ }^{1} \mathrm{H}$ NMR of 1c (DMSO, $\left.500 \mathrm{MHz}\right)$}

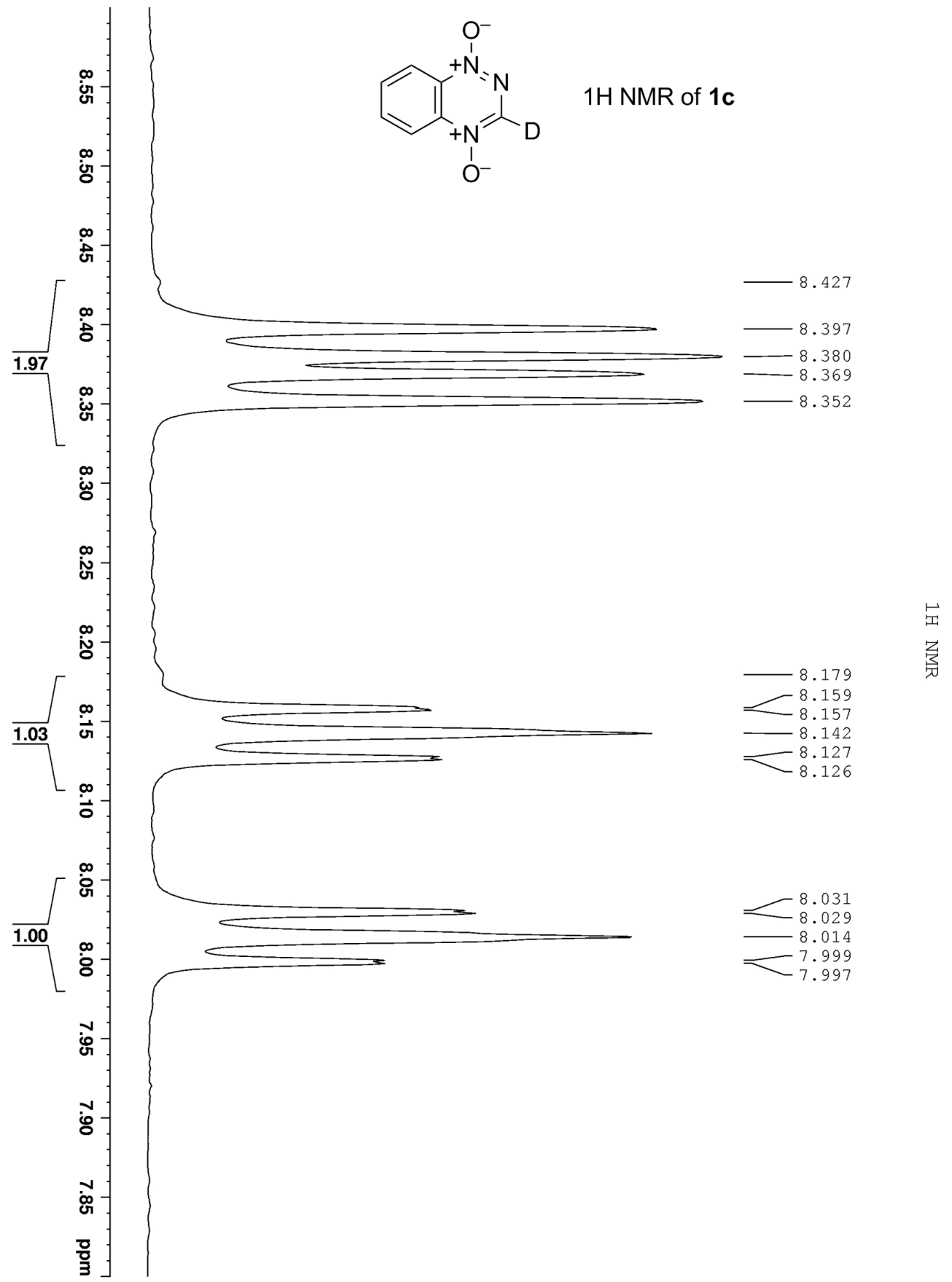




\section{${ }^{13} \mathrm{C}$ NMR of 1c (DMSO, $\left.125.8 \mathrm{MHz}\right)$}

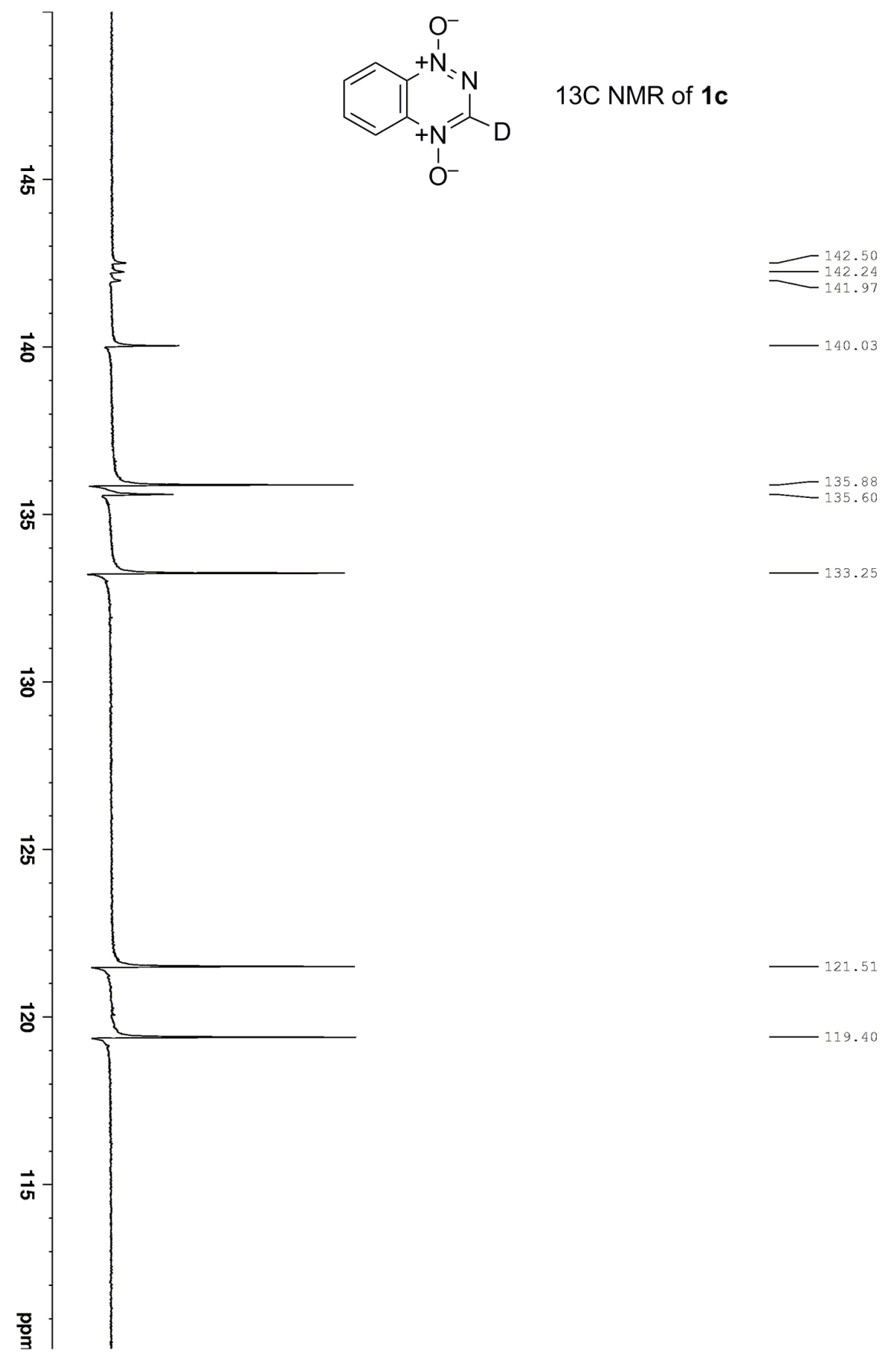




\section{${ }^{1} \mathrm{H}$ NMR of 6 (DMSO, $\left.500 \mathrm{MHz}\right)$}

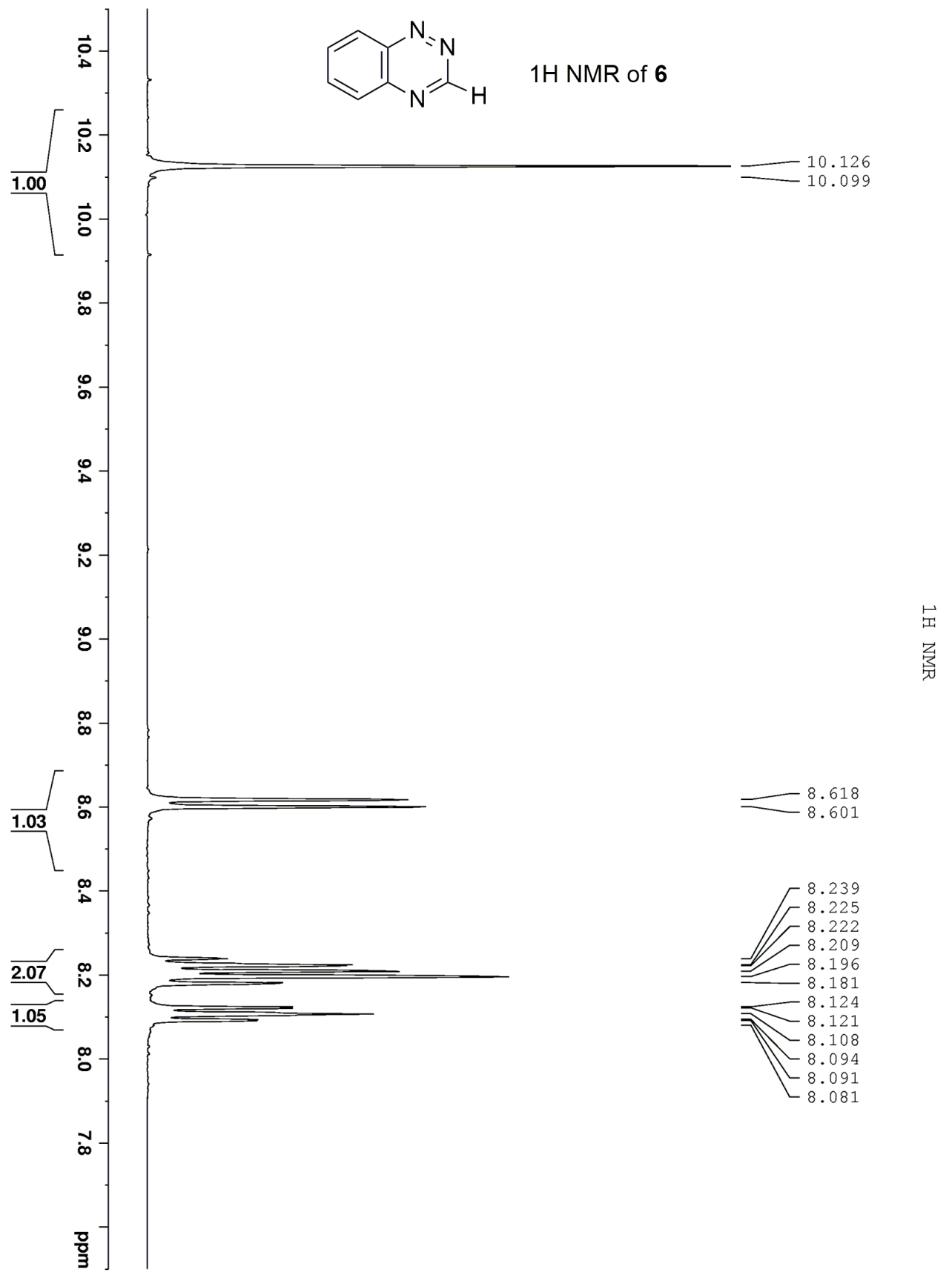




\section{${ }^{13} \mathrm{C}$ NMR of 6 (DMSO, $\left.125.8 \mathrm{MHz}\right)$}

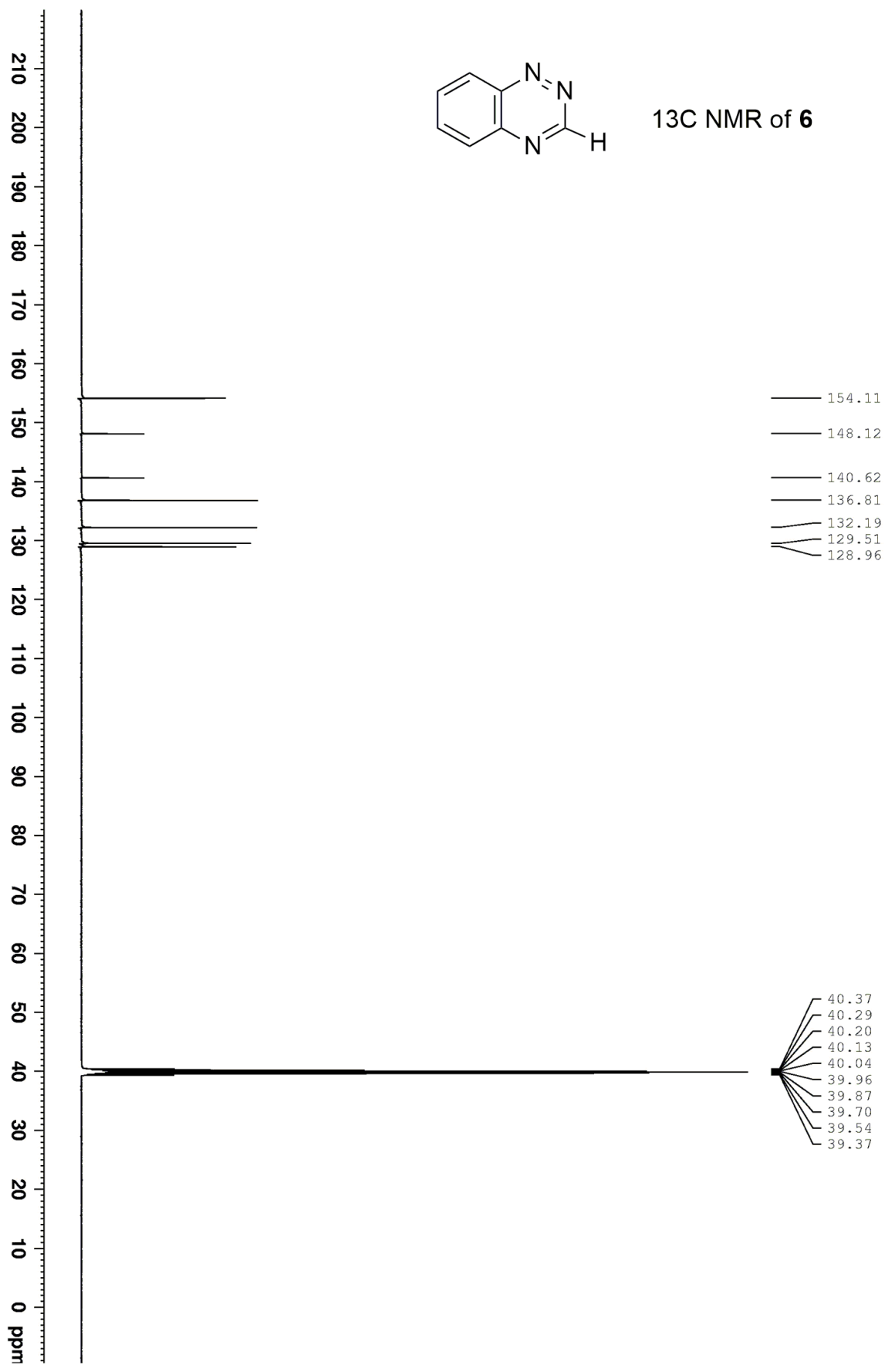




\subsection{Reference}

(1) Wilson, W. R.; Hay, M. P., Targeting hypoxia in cancer therapy. Nature Review Cancer 2011, 11, 393-409.

(2) Kelson, A. B.; McNamara, J. P.; Pandey, A.; Ryan, K. J.; Dorie, M. J.; McAfee, P. A.; Menke, D. R.; Brown, J. M.; Tracy, M., 1,2,4-Benzotriazine 1,4-dioxides. An important class of hypoxic cytotoxins with antitumor activity. Anti-Cancer Drug Design 1998, $13,575-592$.

(3) Hay, M. P.; Gamage, S. A.; Kovacs, M. S.; Pruijn, F. B.; Anderson, R. F.; Patterson, A. V.; Wilson, W. R.; Brown, J. M.; Denny, W. A., Structure-Activity Relationships of 1,2,4-Benzotriazine 1,4-Dioxides as Hypoxia-Selective Analogues of Tirapazamine. Journal of Medicinal Chemistry 2003, 46, 169-182.

(4) Hay, M. P.; Hicks, K. O.; Pchalek, K.; Lee, H. H.; Blaser, A.; Pruijn, F. B.; Anderson, R. F.; Shinde, S. S.; Wilson, W. R.; Denny, W. A., Tricyclic $[1,2,4]$ triazine 1,4-dioxides as hypoxia selective cytotoxins. Journal of Medicinal Chemistry 2008, 51, 6853-6865.

(5) Hay, M. P.; Hicks, K. O.; Pruijn, F. B.; Pchalek, K.; Siim, B. G.; Wilson, W. R.; Denny, W. A., Pharmaokinetic/pharmacodynamic model-guided identification of hypoxia-selective 1,2,4-benzotriazine 1,4-dioxides with antitumor activity: the role of extravascular transport. Journal of Medicinal Chemistry 2007, 50, 6392-6404.

(6) Xia, Q.; Zhang, L.; Zhang, J.; Sheng, R.; Yang, B.; He, Q.; Hu, Y., Synthesis, hypoxia-selective cytotoxicity of new 3-amino-1,2,4-benzotriazine 1,4-dioxide derivatives. European Journal of Medicinal Chemistry 2011, 46, 919-926. 
(7) Hicks, K. O.; Siim, B. G.; Jaiswal, J. K.; Pruijin, F. B.; Fraser, A. M.; Patel, R.; Hogg, A.; Liyanage, H. D. S.; Dorie, M. J.; Brown, J. M.; Denny, W. A.; Hay, M. P.; Wilson, W. R., Pharmacokinetic/phamacodynamic modeling identifies SN30000 and SN29751 as tirapazamine analogues with improved tissue penetration and hypoxic cell killing in tumors. Clinical Cancer Research 2010, 16 (20), 4946-4957.

(8) Chitneni, S. K.; Bida, G. T.; Yuan, H.; Palmer, G. M.; Hay, M. P.; Melcher, T.; Wilson, W. R.; Zalutsky, M. R.; Dewhirst, M. W., ${ }^{18}$ F-EF5 PET Imaging as an Early Response Biomarker for the Hypoxia-Activated Prodrug SN30000 Combined with Radiation Treatment in a Non-Small Cell Lung Cancer Xenograft Model. Journal of Nuclear Medicine 2013, 54, 1-8.

(9) Priyadarsini, K. I.; Tracy, M.; Wardman, P., The one-electron reduction potential of 3-amino-1,2,4-benzotriazine 1,4-dioxide (tirapazamine): A hypoxia-selective bioreductive drug. Free Radical Research 1996, 25 (5), 393-399.

(10) Lloyd, R. V.; Duling, D. R.; Rumyantseva, G. V.; Mason, R. P.; Bridson, P. K., Microsomal reduction of 3-amino-1,2,4,-benzotriazine 1,4-dioxide to a free radical. Molecular Pharmacology 1991, 40, 440-445.

(11) Wardman, P.; Priyadarsini, K. I.; Dennis, M. F.; Everett, S. A.; Naylor, M. A.; Patel, K. B.; Stratford, I. J.; Stratford, M. R. L.; Tracy, M., Chemical properties which control selectivity and efficacy of aromatic N-oxide bioreductive drugs. British Journal of Cancer 1996, 74, S70-S74.

(12) Laderoute, K. L.; Wardman, P.; Rauth, M., Molecular mechanisms for the hypoxia-dependent activation of 3-amino-1,2,4-benzotriazine 1,4-dioxide (SR4233). Biochemical Pharmacology 1988, 37 (8), 1487-1495. 
(13) Silva, J. M.; O'Brien, P. J., Molecular mechanisms of SR 4233-induced hepatocyte toxicity under aerobic versus hypoxic conditions. British Journal of Cancer 1993, 68, 484-491.

(14) Evans, J. W.; Chernikova, S. B.; Kachnic, L. A.; Banath, J. P.; Sordet, O.; Delahoussaye, Y. M.; Treszezamsky, A.; Chon, B. H.; Feng, Z.; Gu, Y.; Wilson, W. R.; Pommier, Y.; Olive, P. L.; Powell, S. N.; Brown, J. M., Homologous Recombination Is the Principal Pathway for the Repair of DNA Damage Induced by Tirapazamine in Mammalian Cells. Cancer Research 2008, 68 (1), 257-265.

(15) Daniels, J. S.; Gates, K. S., DNA Cleavage by the Antitumor Agent 3-Amino1,2,4-benzotriazine 1,4-Dioxide (SR4233): Evidence for Involvement of Hydroxyl Radical. Journal of the American Chemical Society 1996, 118 (14), 3380-3385.

(16) Kotandeniya, D.; Ganley, B.; Gates, K. S., Oxidative base damage by the antitumor agent 3-amino-1,2,4-benzotriazine 1,4-dioxide (tirapazamine). Bioorganic \& Medicinal Chemistry Letters 2002, 12, 2325-2329.

(17) Birincioglu, M.; Jaruga, P.; Chowdhury, G.; Rodriguez, H.; Dizdaroglu, M.; Gates, K. S., DNA Base Damage by the Antitumor Agent 3-Amino-1,2,4-benzotriazine 1,4-Dioxide (Tirapazamine). Journal of the American Chemical Society 2003, 125 (38), 11607-11615.

(18) Junnotula, V.; Sarkar, U.; Sinha, S.; Gates, K. S., Initiation of DNA strand cleavage by 1,2,4-benzotriazine 1,4-dioxides: mechanistic insight from studies of 3 methyl-1,2,4-benzotriazine 1,4-dioxide. Journal of the American Chemical Society 2009, $131,1015-1024$. 
Chowdhury, G.; Junnutula, V.; Daniels, J. S.; Greenberg, M. M.; Gates, K. S., DNA strand damage analysis provides evidence that the tumor cell-specific cytotoxin tirapazamine produces hydroxyl radical and acts as a surrogate for $\mathrm{O}_{2}$. Journal of the American Chemical Society 2007, 129, 12870-12877.

(20) Yin, J.; Glaser, R.; Gates, K. S., Electron and Spin-Density Analysis of Tirapazamine Reduction Chemistry. Chemical Research in Toxicology 2012, 25, 620633.

(21) Yin, J.; Glaser, R.; Gates, K. S., On the Reaction Mechanism of Tirapazamine Reduction Chemistry: Unimolecular N-OH Homolysis, Stepwise Dehydration, or Triazene Ring-Opening. Chemical Research in Toxicology 2012, 25, 634-645.

(22) Shinde, S. S.; Anderson, R. F.; Hay, M. P.; Gamage, S. A.; Denny, W. A., Oxidation of 2-Deoxyribose by Benzotriazinyl Radicals of Antitumor 3-Amino-1,2,4benzotriazine 1,4-Dioxides. Journal of the American Chemical Society 2004, 126 (25), 7865-7874.

(23) Shinde, S. S.; Hay, M. P.; Patterson, A. V.; Denny, W. A.; Anderson, R. F., Spin trapping of radicals other than the hydroxyl radical upon reduction of the anticancer agent tirapazamine by cytochrome P450 reductase. Journal of the American Chemical Society 2009, 131 (40), 14220-14221.

(24) Shinde, S. S.; Maroz, A.; Hay, M. P.; Patterson, A. V.; Denny, W. A.; Anderson, R. F., Characterization of Radicals Formed Following Enzymatic Reduction of 3Substituted Analogues of the Hypoxia-Selective Cytotoxin 3-Amino-1,2,4-Benzotriazine 1,4-Dioxide (Tirapazamine). Journal of the American Chemical Society 2010, 132 (8), 2591-2599. 
(25) Anderson, R. F.; Shinde, S. S.; Hay, M. P.; Gamage, S. A.; Denny, W. A., Activation of 3-Amino-1,2,4-benzotriazine 1,4-Dioxide Antitumor Agents to Oxidizing Species Following Their One-Electron Reduction. J. Am. Chem. Soc. 2003, 125, 748-756. (26) Anderson, R. F.; Shinde, S. S.; Hay, M. P.; Gamage, S. A.; Denny, W. A., Radical properties governing the hypoxia-selective cytotoxicity of antitumor 3-amino-1,2,4benzotriazine 1,4-dioxides. Organic \& biomolecular chemistry 2005, 3 (11), 2167-2174.

(27) Chin, D.-H.; Goldberg, I. H., Sources of hydrogen abstraction by activated neocarzinostatin chromophore. Biochemistry 1993, 32, 3611-3616.

(28) Štefane, B.; Polanc, S., CAN-Mediated Oxidation of Electron-Deficient Aryl and Heteroaryl Hydrazines and Hydrazides. Synlett 2008, (9), 1279-1282.

(29) Fitzsimmons, S. A.; Lewis, A. D.; Riley, R. J.; Workman, P., Reduction of 3amino-1,2,4-benzotriazine-1,4,-di- $N$-oxide to a DNA-damaging species: a direct role for NADPH:cytochrome P450 oxidoreductase. Carcinogenesis 1994, 15 (8), 1503-1510.

(30) Doyle, M. P.; Dellaria, J. F. J.; Siegfried, B.; Bishop, W. W., Reductive amination of arylamine by alkyl nitries in $\mathrm{N}, \mathrm{N}$-dimethylformamide. A direct conversion of arylamines to aromatic hydrocarbons. Journal of Organic Chemistry 1977, 42, 43943498.

(31) Fuchs, T.; Chowdhary, G.; Barnes, C. L.; Gates, K. S., 3-Amino-1,2,4benzotriazine 4-Oxide: Characterization of a New Metabolite Arising From Bioreductive Processing of the Antitumor Agent 3-Amino-1,2,4-benzotriazine 1,4-Dioxide (Tirapazamine). Journal of Organic Chemistry 2001, 66, 107-114. 
(32) Jonson, P. H.; Grossman, L. I., Electrophoresis of DNA in agarose gels. Optimizing separations of conformational isomers of double and single-stranded DNAs. Biochemistry 1977, 16, 4217-4224.

(33) Mirabelli, C. K.; Huang, C. H.; Fenwick, R. G.; Crooke, S. T., Quantitative measurement of single- and double-strand breakage of DNA in Escherichia coli by the antitumor antibiotics bleomycin and talisomycin. Antimicrobial Agents and Chemotherapy 1985, 27 (4), 460-467.

(34) Oppenheim, A., Separation of closed circular DNA from linear DNA by electrophoresis in two dimensions in agarose gels. Nucleic Acids Research 1981, 9 (24), 6805-6812.

(35) Hintermann, G.; Fischer, H. M.; Crameri, R.; Hutter, R., Simple procedure for distinguishing CCC, OC, and L forms of plasmid DNA by agarose gel electrophoresis. Plasmid 1981, 5 (3), 371-373.

(36) Delahoussaye, Y. M.; Evans, J. M.; Brown, J. M., Metabolism of tirapazamine by multiple reductases in the nucleus. Biochemical Pharmacology 2001, 62, 1201-1209.

(37) Patterson, A. V.; Saunders, M. P.; Chinje, E. C.; Patterson, L. H.; Stratford, I. J., Enzymology of tirapazamine metabolism: a review. Anti-Cancer Drug Design 1998, 13, 541-573.

(38) Walton, M. I.; Wolf, C. R.; Workman, P., The role of cytochrome P450 and cytochrome $\mathrm{P} 450$ reductase in the reductive activation of the novel benzotriazine di- $N$ oxide hypoxic cytotoxin 3-amino-1,2,4-benzotriazine 1,4-dioxide (SR 4233, WIN 59075) by mouse liver. Biochemical Pharmacology 1992, 44 (2), 251-259. 
(39) Halliwell, B.; Gutteridge, J. M. C., Role of free radicals and catalytic metal ions in human disease: an overview. Methods in Enzymology 1990, 186, 1-85.

(40) Fuchs, T.; Barnes, C. L.; Gates, K. S., Crystal Structure of 3-Amino-5-methyl1,2,4-benzotriazine 1-Oxide: Evidence for Formation of a Covalent Attachment Between a Carbon-Centered Radical and the Antitumor Agent Tirapazamine. Journal of Chemical Crystallography 2001, 31 (78), 387-391.

(41) Markgraf, J. H.; Chang, R.; Cort, J. R.; Durant, J. L. J.; Finkelstein, M.; Gross, A. W.; Lavyne, M. H.; Peterson, R. C.; Ross, S. D., Protodediazoniation of aryldiazonium fluoroborates by dimethylformamide. Tetrahedron 1997, 53 (29), 10009-10018.

(42) Jodkowski, J. T.; Rayez, M.-T.; Rayez, J.-C.; Bérces, T.; Dóbé, S., Theoretical Study of the Kinetics of the Hydrogen Abstraction from Methanol. 3. Reaction of Methanol with Hydrogen Atom, Methyl, and Hydroxyl Radicals. The Journal of Physical Chemistry A 1999, 103, 3750-3765.

(43) McCaulley, J. A.; Kelly, N.; Golde, M. F.; Kaufman, F., Kinetic studies of the reactions of F and HO with methanol. The Journal of Physical Chemistry 1989, 93, 10141018.

(44) Hess, W. P.; Tully, F. P., Hydrogen atom abstraction from methanol by hydroxyl radical. The Journal of Physical Chemistry 1989, 93, 1944-1947.

(45) Chowdhury, G.; Kotandeniya, D.; Barnes, C. L.; Gates, K. S., Enzyme-activated, hypoxia-selective DNA damage by 3-amino-2-quinoxalinecarbonitrile 1,4-di- $\mathrm{N}$-oxide. Chemical Research in Toxicology 2004, 17 (11), 1399-1405.

(46) Chowdhury, G.; Sarkar, U.; Pullen, S.; Wilson, W. R.; Rajapakse, A.; FuchsKnotts, T.; Gates, K. S., DNA strand cleavage by the phenazine di- $N$-oxide natural 
product myxin under both aerobic and anaerobic conditions. Chemical Research in Toxicology 2012, 25, 197-206.

(47) Bender, M. L.; Clement, G. E.; Kézdy, F. J.; Heck, H. D. A., The Correlation of the $\mathrm{pH}(\mathrm{pD})$ Dependence and the Stepwise Mechanism of $\alpha$-Chymotrypsin-Catalyzed Reactions. Journal of the American Chemical Society 1964, 86 (18), 3680-3690.

(48) Walde, P.; Peng, Q.; W., F. N.; Battistel, E.; Luisi, P. L., Structure and activity of trypsin in reverse micelles. European Journal of Biochemistry 1988, 173 (2), 401-409.

(49) Mason, J. C.; Tennant, G., Heterocyclic N-oxides. Part VI. Synthesis and Nuclear Magnetic Resonance Spectra of 3-Aminobenzo-1,2,4-triazines and their mono and di-N-oxides. Journal of the Chemical Society B: Physical Organic 1970, 911-916.

(50) Boyd, M.; Hay, M. P.; Boyd, P. D. W., Complete 1H, 13C, and 15N NMR assignment of tirapazamine and related 1,2,4-benzotriazine $N$-oxides. Magnetic Resonance in Chemistry 2006, 44, 948-954. 


\section{Chapter 3. TPZ mono- $N$-oxides as the pro-fluorescent substrates for bioredcutive enzymes}

\subsection{Introduction}

Hypoxia, which means low oxygen concentration, is one of the unique characteristics for most tumor cells. ${ }^{1}$ Generally, tumor hypoxia is associated with poor prognosis and is viewed as a therapeutic disadvantage. ${ }^{2}$ However, hypoxia-selective DNA-damaging agents can turn hypoxia into a therapeutic advantage. ${ }^{3-6}$ These prodrugs can be activated by one-electron reductive enzymes such as NADPH:cytochrome P450 reductase (CYPOR) and xanthine oxidase (XO) to generate oxygen-sensitive drug radicals. ${ }^{7,8}$ In aerobic conditions, the oxygen-sensitive radicals can be readily oxidized back to the starting prodrug, while under hypoxic conditions, the lifetime of the radicals is significantly elongated and the radicals can undergo further reduction to generate cellkilling reactive species. ${ }^{9-13}$

At least two conditions are required for successful use of hypoxia-selective prodrugs: i. the target tumor tissues must be hypoxic and ii. appropriate enzymes involved in bioactivation of the drug must be expressed in the tissue. In this regard, it will be necessary to develop diagnostic probes to assess the expression of these enzymes for the successful clinical applications of hypoxia-selective cytotoxins.

Here we described the development of tirapazamine (1a) analogs as profluorescent substrates of enzymes that catalyze the bioreductive activation of hypoxiaselective antitumor prodrugs. As described in the previous chapters, 1a and its analogs can undergo hypoxia-selective one-electron reduction to generate hydroxyl radical that damages cellular DNA. And it is important that the mono- $N$-oxide (3a) is the major 
product in the hypoxia-selective enzymatic metabolism. ${ }^{14}$ Fortuitously, the mono- $\mathrm{N}$ oxide metabolite is modestly fluorescent, while the di- $\mathrm{N}$-oxide form is non-fluorescent (Scheme 3.1) ${ }^{15,16}$ This observation provided the possibility of developing 1,2,4benzotriazine-1,4-di- $N$-oxides as pro-fluorescent probes that detect drug-related bioreductive enzymes. That is, the mono- $N$-oxide metabolites generated by one-electron enzymatic reduction under hypoxic conditions are highly fluorescent, while the parent compounds di- $N$-oxides are non-fluorescent.

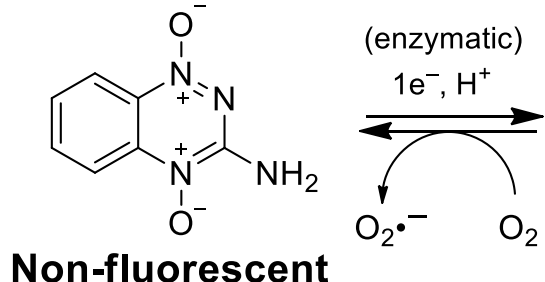

$1 \mathrm{a}$<smiles></smiles>

$2 a$

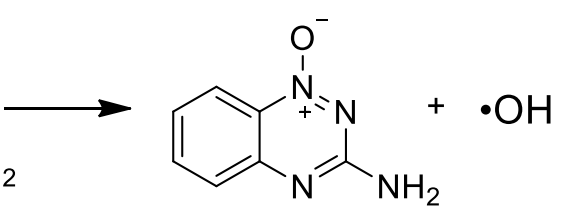

Fluorescent

Scheme 3.1. Hypoxic metabolism of tirapazamine (1a) and the generation of fluorescent mono- $N$-oxide (3a).

In this chapter, we synthesized and evaluated a small library of thirty-one 1,2,4benzotriazine 1-oxides for better photophysical properties than 3a. Two analogs (3d and 3e) with superior fluorescence properties were identified and characterized. The photophysical properties, such as the fluorescence quantum yields, the extinction coefficients and the absorption-emission spectra were determined. Fluorimetic assays and LC-MS were employed to characterize the in vitro enzymatic metabolism under hypoxic conditions of $\mathbf{3 d}$ and $\mathbf{3 e}$. Continuous time fluorimetic assays and cell extract assays shed light on the potential application of the probes in tumor tissue biopsies. The results showed that the fluorinated analog $\mathbf{1 d}$ could serve as a useful fluorescent probe in detecting one electron reductases involved in the bioactivation of hypoxia-selective 
antitumor prodrugs.

\subsection{Synthesis and preliminary screening of 1,2,4-benzotriazine 1- oxides by fluorescence properties}

A small library of thirty-one 1,2,4-benzotriazine 1-oxides (Scheme 3.2) were synthesized according to published methods by Dr. Ujjal Sarkar, Dr. Kevin M. Johnson and me. Then a preliminary screening of photophysical properties such as quantum yields $(\Phi)$, extinction coefficients $(\varepsilon)$, brightness values $(\Phi \bullet \varepsilon)$, Stokes shifts (the difference between emission maximum and absorption maximum), and emission maximum $\left(\lambda_{\max }\right)$ was carried out to identify the 1-oxides compounds superior to the parent mono- $N$-oxide compound 3a.
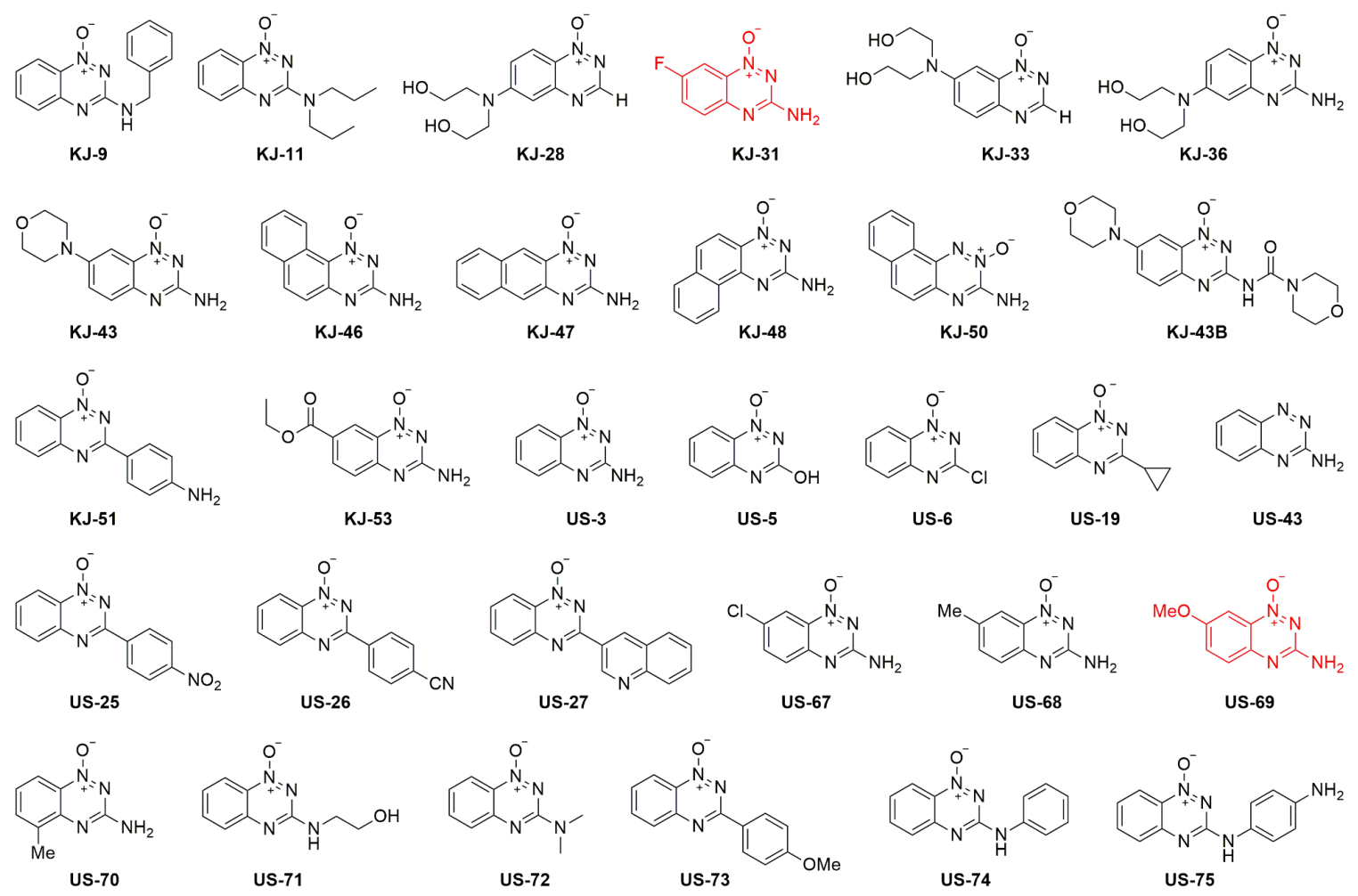

Scheme 3.2. The thirty-one compound library of 1,2-4-benzotriazine 1-oxides. 
Table 3.1. Preliminary Photophysical properties for benzotriazine 1-oxides. ${ }^{a}$

\begin{tabular}{|c|c|c|c|c|c|}
\hline Compound & $\lambda_{\mathrm{abs}} / \mathrm{nm}$ & $\varepsilon^{\mathrm{b}}$ & $\lambda_{\mathrm{em}} / \mathrm{nm}$ & $\Phi_{\mathrm{fl}}^{\mathrm{c}}$ & $\begin{array}{l}\text { Brightness } \\
(\varepsilon \times \Phi)\end{array}$ \\
\hline KJ-9 & 421 & 4700 & $507^{d}$ & 0.070 & 330 \\
\hline KJ-11 & 447 & 3900 & 550 & 0.005 & 20 \\
\hline KJ-28 & 437 & 1100 & 552 & 0.010 & 10 \\
\hline KJ-31 & 413 & 6300 & 485 & 0.210 & 1350 \\
\hline KJJ-33 & 465 & 17000 & 565 & 0.072 & 1200 \\
\hline KJ-36 & 412 & 16000 & 540 & 0.013 & 210 \\
\hline KJ-43 & 466 & 5400 & 588 & 0.212 & 1150 \\
\hline KJ-43B & 456 & 4400 & 589 & 0.081 & 358 \\
\hline KJ-46 & 413 & 4800 & none $e^{\mathrm{e}}$ & - & - \\
\hline KJ-47 & 375 & 2300 & 603 & 0.026 & 59 \\
\hline KJ-48 & 423 & 5500 & 466 & 0.210 & 1150 \\
\hline KJ-50 & 416 & 13000 & 468 & 0.019 & 270 \\
\hline KJ-51 & 407 & 3200 & 608 & $<0.001$ & $<3$ \\
\hline KJ-53 & 406 & 4900 & 495 & 0.170 & 831 \\
\hline US-3 & 405 & 3868 & 478 & 0.12 & 460 \\
\hline US-5 & 394 & 2354 & 490 & 0.004 & 10 \\
\hline US-6 & 356 & 5600 & none & - & - \\
\hline US-19 & 358 & 5270 & none & - & - \\
\hline US-25 & 333 & 9000 & none & - & - \\
\hline US-26 & 333 & 10000 & none & - & - \\
\hline US-27 & 333 & 10000 & none & - & - \\
\hline
\end{tabular}


Table 3.1. (Continued) Preliminary Photophysical properties for benzotriazine 1-oxides. ${ }^{a}$

\begin{tabular}{llllll}
\hline Compound & $\lambda_{\mathrm{abs}} / \mathrm{nm}$ & $\varepsilon^{\mathrm{b}}$ & $\lambda_{\mathrm{em}} / \mathrm{nm}$ & $\Phi_{\mathrm{fl}}^{\mathrm{c}}$ & $\begin{array}{c}\text { Brightness } \\
(\varepsilon \times)\end{array}$ \\
\hline US-43 & 388 & 3981 & 460 & 0.013 & 52 \\
US-67 & 413 & 4400 & 500 & 0.22 & 968 \\
US-68 & 413 & 5395 & 500 & 0.18 & 971 \\
US-69 & 430 & 5100 & 512 & 0.46 & 2346 \\
US-70 & 410 & 4846 & 490 & 0.08 & 387 \\
US-71 & 420 & 4596 & 518 & 0.08 & 367 \\
US-72 & 441 & 3470 & none & - & - \\
US-73 & 378 & 6000 & 542 & 0.013 & 78 \\
US-74 & 430 & 3100 & 532 & 0.0005 & 1.6 \\
US-75 & 442 & 3000 & none & - & - \\
\hline
\end{tabular}

${ }^{a}$ Data obtained from thesis of Ujjal Sarkar and Kevin M. Johnson. ${ }^{17,18}$ Absorbance and fluorescence measurements were taken in acetonitrile $(20 \mathrm{uM})$.

${ }^{\mathrm{b}}$ Molar absorptivity coefficients were calculated using Beer's law $(\mathrm{A}=\varepsilon \mathrm{bc})$.

${ }^{c}$ Fluorescence quantum yields were estimated using the equation $\Phi_{\mathrm{fl}}=\Phi_{\mathrm{A}}\left(\mathrm{A}_{\mathrm{R}} / \mathrm{A}\right)\left(\mathrm{I} / \mathrm{I}_{\mathrm{R}}\right)$ $\left(\mathrm{n} / \mathrm{n}_{\mathrm{R}}\right)^{2}$, where compound US-3 was used as a fluorescent standard with known quantum yield $\left(\Phi_{\mathrm{R}}\right), \mathrm{A}$ is absorbance at a given excitation wavelength and $\mathrm{I}$ is the integration of the fluorescent peak. The refractive index (n) is only needed when using different solvents for comparison.

${ }^{\mathrm{d}}$ Measurements taken in $\mathrm{CH}_{2} \mathrm{Cl}_{2}$.

${ }^{\mathrm{e}}$ None, the compound has no observable emission peak.

According to the preliminary screening data in Table 3.1, most of the 1-oxides showed the fluorescence brightness lower than that of 3a. However, we did identify a few compounds (KJ-31, US-69, KJ-33, KJ-43, KJ-48, KJ-53, US-67 and US-68) that have photophysical properties superior to 3a. Among these, 3d and 3e (KJ-31 and US-69 in Scheme 3.2) were selected for further evaluations as potential pro-fluorescent probes for 
the detection of drug-related bioreductive enzymes. Besides $\mathbf{3 d}$ and $\mathbf{3 e}$, the reasons why other 1-oxides that are brighter than 3a were not selected were listed below. Compound $\mathbf{K J}-\mathbf{4 3}$ was not selected because of the low yield in the synthesis of the corresponding di$N$-oxide. Compound KJ-33 was not selected because the fluorescence is completely quenched by water. Compound KJ-48 was not selected because the internal hydrogen bond of its di- $N$-oxide form may prevent the hypoxic metabolism. Compound $\mathbf{K J - 5 3}$ was not selected because the ester group may get hydrolyzed when used as a probe in cellular conditions. Compounds US-67 and US-68 were not selected because they were mimics of 3d and 3c, respectively, but have weaker fluorescence brightness.

\subsection{Static photophysical properties of $1,2,4$-benzotriazine oxides}

After the preliminary screening of the 1,2,4-benzotriazine 1-oxide library, we carried out careful static photophysical properties for compounds $\mathbf{3 d}$ and $\mathbf{3 e}$ and their corresponding di-N-oxides $\mathbf{1 d}$ and $\mathbf{1 e}$, in comparison with the parent compounds TPZ (1a) and TPZ mono- $N$-oxide (3a). The mono- $N$-oxides $(\mathbf{1 a}, \mathbf{1 d}, \mathbf{1 e})$ were synthesized by the reaction of substituted nitroaniline and cyanamide, and the di- $N$-oxides (3a, 3d, 3e) were prepared by the oxidation of mono- $N$-oxides with trifluoroacetic acid and hydrogen peroxide. ${ }^{19-21}$ (Scheme 3.3)

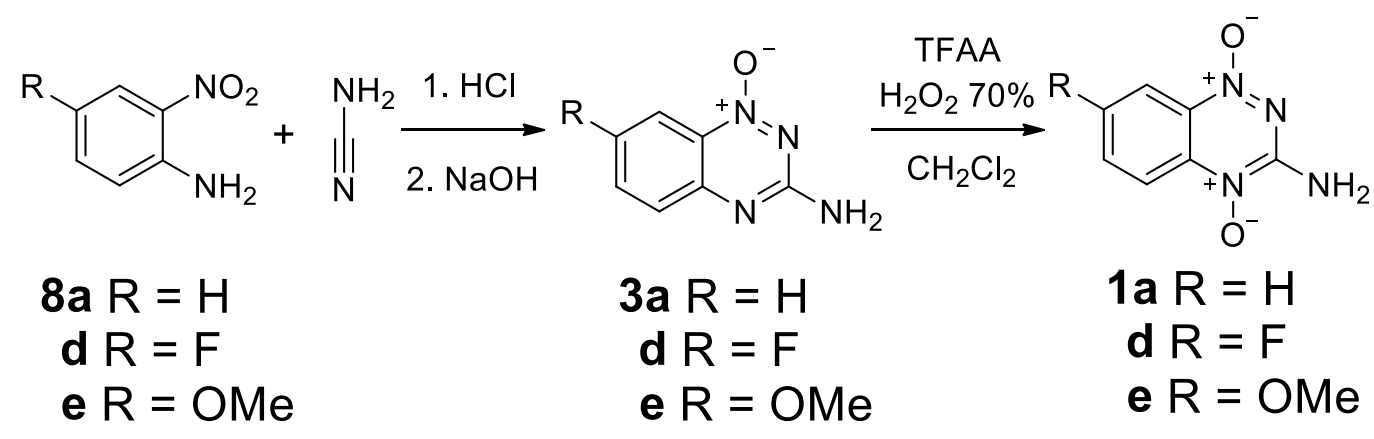

Scheme 3.3. The synthesis of 1,2,4-benzotriazine-1,4-di- $N$-oxides and 1-oxides. 
For the dioxides, 1a had absorption maximum at $457 \mathrm{~nm}$ and emission maximum at $545 \mathrm{~nm}$ with the quantum yield $0.33 \%$ in water; while in acetonitrile, the absorption maximum occurred at $477 \mathrm{~nm}$ and the emission maximum was $505 \mathrm{~nm}$ with the quantum yield $0.60 \%$ (Table 3.2 ). Similarly, $\mathbf{1 d}$ and $1 \mathrm{e}$ had very low quantum yields $(<3 \%)$ either in water or in organic solvent, ethyl acetate. There is no substantial fluorescence of the dioxides in all twelve solvents we tested.

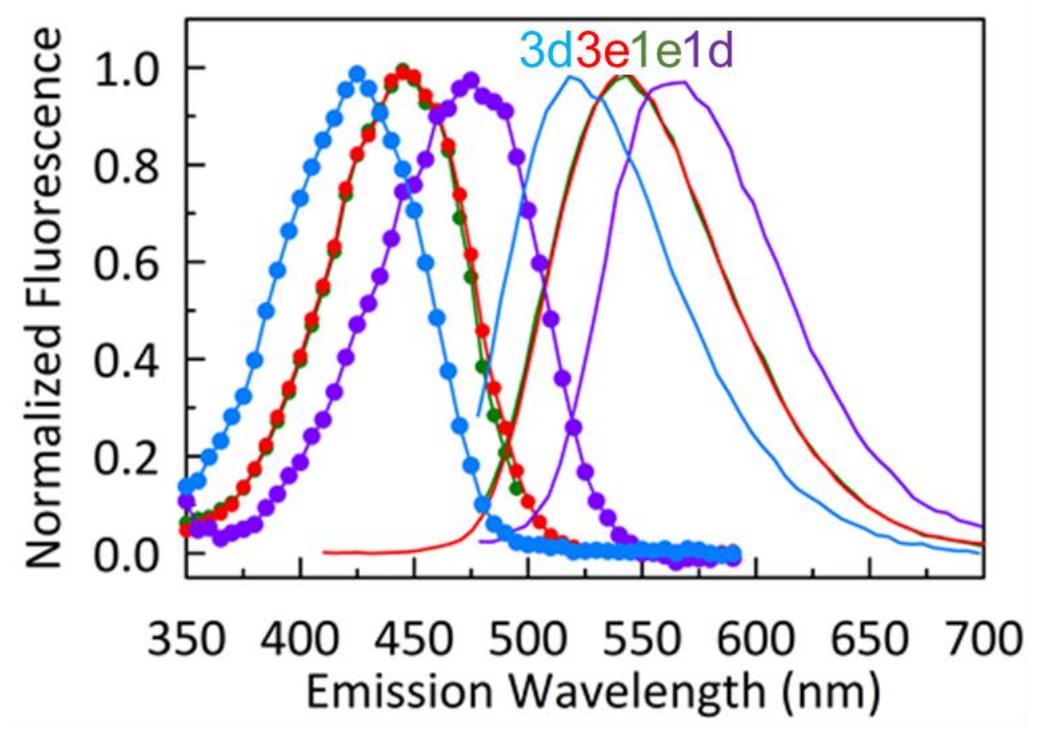

Figure 3.1. Normalized excitation and emission spectra of BTO dioxides (1d-1e) and mono- $N$-oxides (3d-3e) in $18 \mathrm{M} \Omega \mathrm{H}_{2} \mathrm{O}$. The solid line curves represent emission spectra when excited at $470 \mathrm{~nm}$ and dotted profiles represent associated excitation spectra. Data obtained by Charles H. Laber in Dr. Gary A. Baker lab.

In contrast, the mono- $N$-oxides are fluorescent. The tirapazamine mono- $N$-oxide metabolite 3a displayed absorption maximum at $407 \mathrm{~nm}$ and emission maximum at 478 $\mathrm{nm}$ with the quantum yield $16.86 \%$ in acetonitrile; while in water, the absorption maximum was $415 \mathrm{~nm}$ and the emission maximum was $521 \mathrm{~nm}$ with the quantum yield $3.67 \%$. The mono- $N$-oxides $3 \mathbf{d}$ and 3e showed the absorption maximum at $416 \mathrm{~nm}$ and 
$428 \mathrm{~nm}$, and emission maximum at $492 \mathrm{~nm}$ and $501 \mathrm{~nm}$, respectively, in ethyl acetate. It is notable that the quantum yields for $\mathbf{3 d}(24.77 \%)$ and $3 \mathbf{e}(42.56 \%)$ were higher than that of 1a. In addition, Figure 3.1 showed that the Stokes shifts of $\mathbf{3 d}$ and $\mathbf{3 e}$ were around 70 $\mathrm{nm}$, suggesting the potentials as fluorescent markers.

Table 3.2. Static photophysical properties of 1,2,4-benzotriazine oxides. ${ }^{\text {a }}$

\begin{tabular}{ccccc}
\hline Compound & $\lambda_{\mathrm{abs}} / \mathrm{nm}$ & $\log _{10} \varepsilon^{\mathrm{b}}$ & $\lambda_{\mathrm{em}} / \mathrm{nm}^{\mathrm{c}}$ & $\Phi_{\mathrm{fl}} / \%^{\mathrm{d}}$ \\
\hline $\mathbf{3 a}^{\mathrm{e}}$ & 407 & 3.747 & 478 & $16.86 \pm 1.40$ \\
$\mathbf{3 d}^{\mathrm{f}}$ & 416 & 3.775 & 492 & $24.77 \pm 2.88$ \\
\hline $\mathbf{3 e}^{\mathrm{f}}$ & 428 & 3.612 & 501 & $42.56 \pm 5.41$ \\
\hline $\mathbf{3 a}^{\mathrm{g}}$ & 415 & 3.751 & 521 & $3.67 \pm 0.21$ \\
$\mathbf{3 d}^{\mathrm{g}}$ & 422 & 3.749 & 526 & $2.44 \pm 0.21$ \\
$\mathbf{3 e}^{\mathrm{g}}$ & 441 & 3.655 & 547 & $8.68 \pm 1.00$ \\
\hline $\mathbf{1 a}^{\mathrm{e}}$ & 477 & 3.867 & 505 & $0.60 \pm 0.01$ \\
$\mathbf{1 d}^{\mathrm{f}}$ & 497 & 3.818 & 563 & $1.73 \pm 0.11$ \\
$\mathbf{1 e}^{\mathrm{f}}$ & 428 & 3.532 & 499 & $2.77 \pm 0.57$ \\
\hline $\mathbf{1 a}^{\mathrm{g}}$ & 457 & 3.786 & 545 & $0.33 \pm 0.01$ \\
$\mathbf{1 d}^{\mathrm{g}}$ & 468 & 3.807 & 562 & $0.30 \pm 0.01$ \\
$\mathbf{1 e}^{\mathrm{g}}$ & 440 & 3.765 & 542 & $1.24 \pm 0.16$ \\
\hline
\end{tabular}

${ }^{a}$ Data obtained by Charles H. Laber in Dr. Gary A. Baker lab. ${ }^{\mathrm{b} \varepsilon}$ in units $\mathrm{of} \mathrm{L} \cdot \mathrm{mol}^{-1} \cdot \mathrm{cm}^{-1}$. ${ }^{\mathrm{c}}$ For excitation at $421 \mathrm{~nm}$. ${ }^{\mathrm{d}}$ Determined using coumarin $153(\mathrm{C} 153)$ in ethanol $\left(\Phi_{\mathrm{ref}}=38 \%\right)$ as the fluorescence quantum yield standard. ${ }^{\mathrm{e}}$ Measured in acetonitrile. ${ }^{\mathrm{f}}$ Measured in ethyl acetate. ${ }^{\mathrm{g}}$ Measured in water. 
Similar to $\mathbf{3 a}$, the emission of $\mathbf{3 d}$ and $\mathbf{3 e}$ are strongly solvent dependent (Figure 3.2 and 3.3). $\mathrm{E}_{\mathrm{T}}(30)$ is the solvent polarity parameter, which more polar solvents have larger values. And $\mathrm{E}_{\mathrm{T}}(30)$-emission maximum curve showed the emission shift occurred from the various electron donation processes between the probe and solvent system. For 3d, the emission maximum changed between $480 \mathrm{~nm}$ to $520 \mathrm{~nm}$, from less polar solvents such as toluene to more polar solvents such as water, indicating a slight bathochromic shift with the increase in solvent polarity. Moreover, $\mathbf{3 e}$ underwent a larger bathochromic shift when exposed to more polar solvents in comparison to $\mathbf{3 d}$, with the emission maximum ranging from $490 \mathrm{~nm}$ to $550 \mathrm{~nm}$.

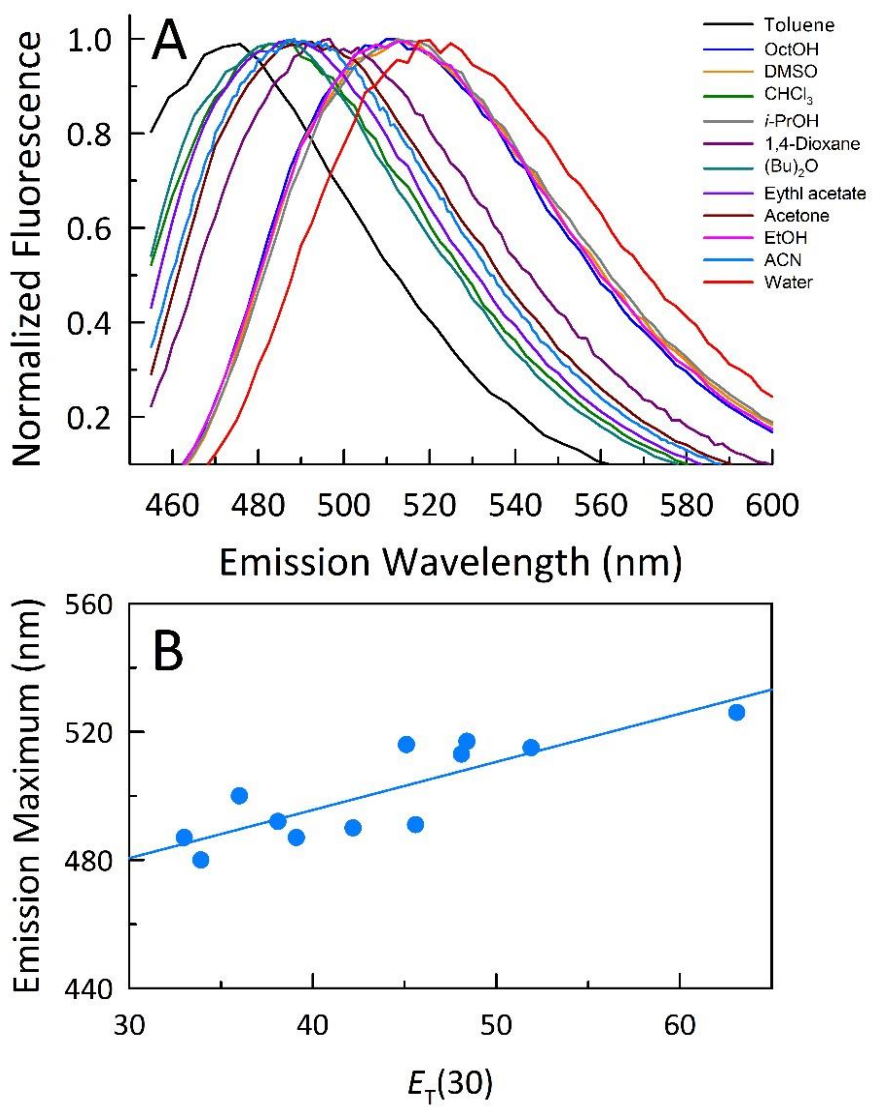

Figure 3.2. A. Solvent dependent emission spectra of $\mathbf{3 d}$ at an exication of $450 \mathrm{~nm}$. B. $\mathrm{E}_{\mathrm{T}}(30)$-Emission maximum curve of $\mathbf{3 d}$ in twelve solvents. Data obtained by Charles $\mathrm{H}$. Laber in Dr. Gary A. Baker lab. 

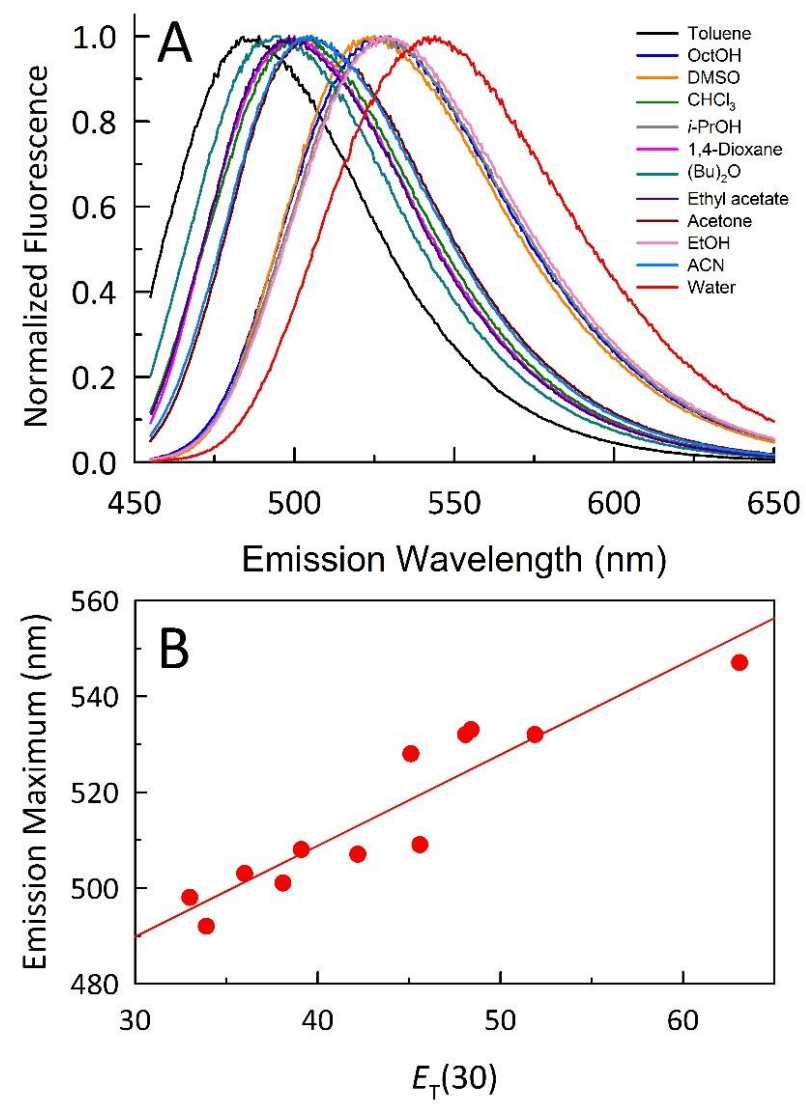

Figure 3.3. A. Solvent dependent emission spectra of 3e at an exication of $450 \mathrm{~nm}$. B. $\mathrm{E}_{\mathrm{T}}(30)$-Emission maximum curve of $\mathbf{3 e}$ in twelve solvents. Data obtained by Charles $\mathrm{H}$. Laber in Dr. Gary A. Baker lab.

\subsection{LC-MS analysis of hypoxia-selective in vitro metabolic conversion of dioxides (1d-e) to the corresponding mono- $N$-oxides (3d-e).}

After the screening of better fluorophores, it is important to examine the efficiency of the conversion of pro-fluorescent dioxides 1d and 1e into fluorescent mono$N$-oxides 3d and 3e under hypoxic condition with one-electron reductive enzymes. NADPH/NADPH:cytochrome P450 reductase (NADPH/CYPOR) and xanthine/xanthine oxidase $(\mathrm{X} / \mathrm{XO})$ enzyme systems were used to catalyze the reactions because these enzymes were involved in the bioreductive activation of hypoxia-selective antitumor 
prodrugs in vitro and in vivo. We used LC-MS to identify the structures of the metabolites and used HPLC calibration curves to estimate the yield of the mono- $N$-oxides for $1 \mathrm{a}, 1 \mathrm{~d}$ and $1 \mathrm{e}$.

Hypoxic assays were carried out in a glove bag filled with argon and all solutions except the enzyme were degassed prior use. In the assay, 1a, 1d and 1e (500 uM) was incubated with CYPOR (0.13 units/mL) and NADPH (2 mM, 4 equiv) in $50 \mathrm{mM} \mathrm{pH}=$ 7.0 sodium phosphate buffer at $25^{\circ} \mathrm{C}$ for $4 \mathrm{~h}$.

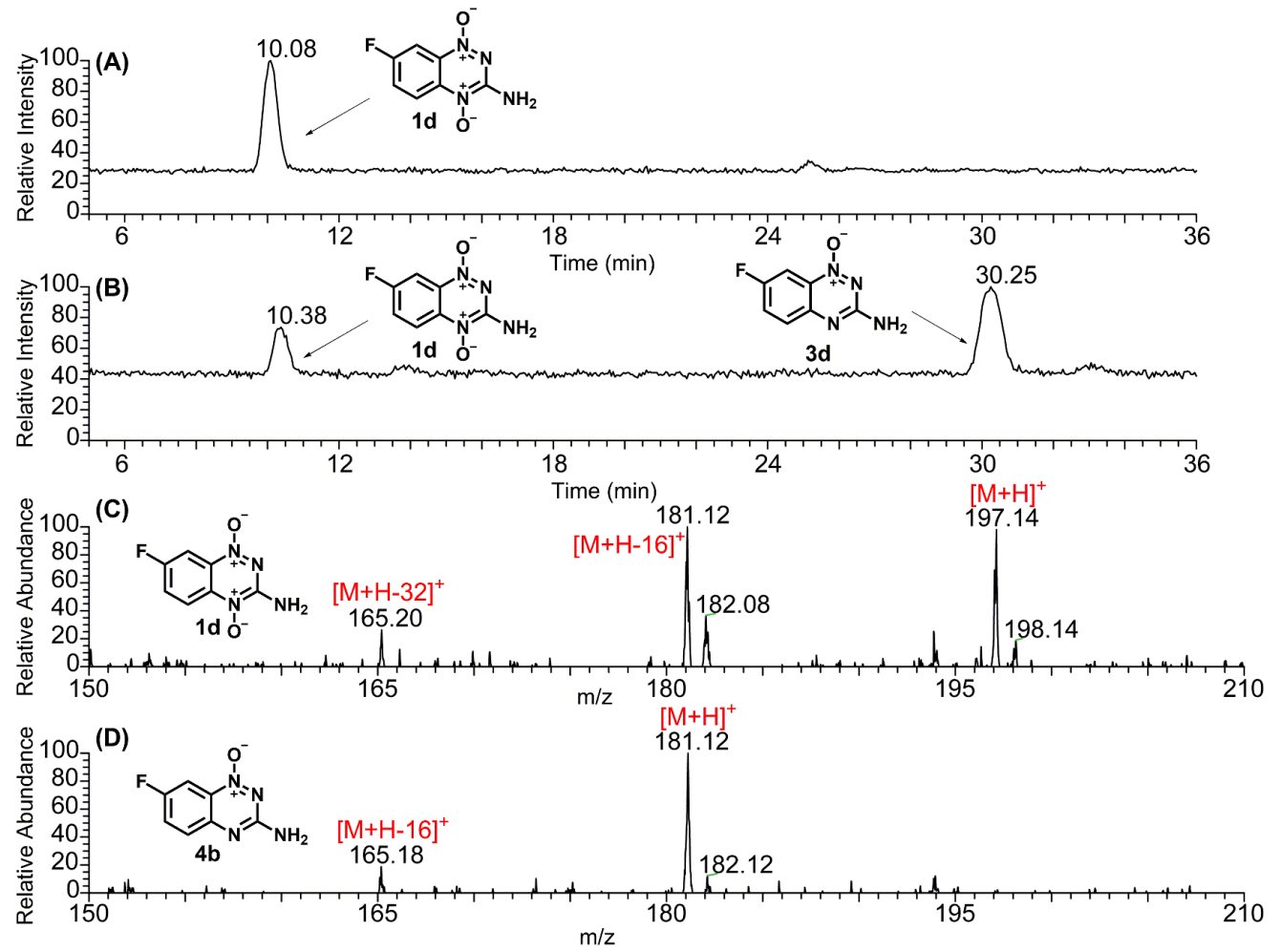

Figure 3.4. LC-MS analysis of the in vitro hypoxic metabolism of $1 \mathbf{d}$ in NADPH/CYPOR. (A) Chromatogram of the aerobic assay (elution time $10.08 \mathrm{~min}$ ); (B) Chromatogram of the hypoxic assay (elution time 10.38, $30.25 \mathrm{~min}$ ); (C) MS data for $\mathbf{1 d}$ (found molecular ion at 197); (D) MS data for 3d (found molecular ion at 181). 

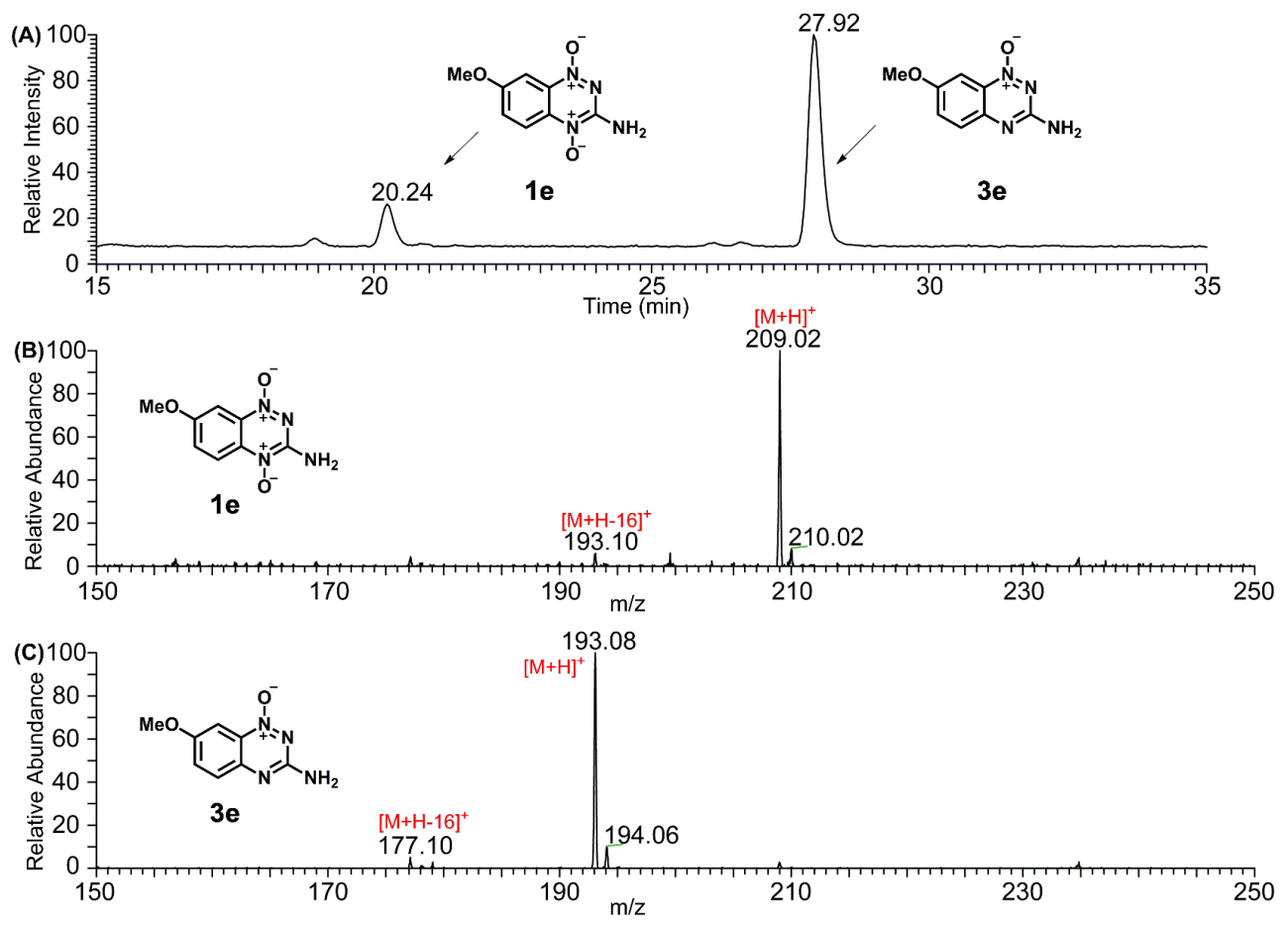

Figure 3.5. LC-MS analysis of the in vitro hypoxic metabolism of 1e in NADPH/CYPOR. (A) Chromatogram of the assay (elution time $20.24 \mathrm{~min}, 27.92 \mathrm{~min}$ ); (B) MS data for 1e (found molecular ion at 209); (C) MS data for 3e (found molecular ion at 193).
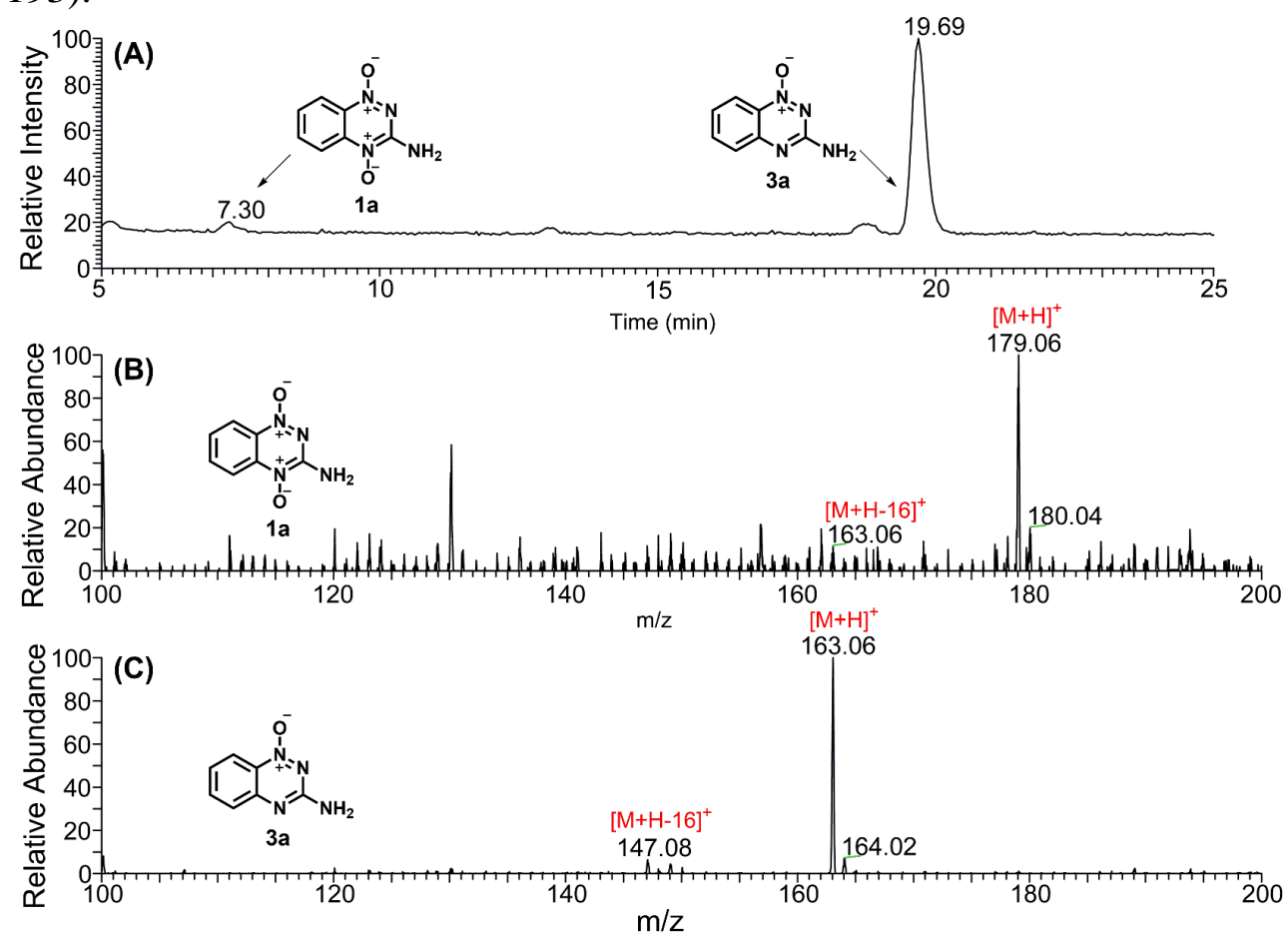

Figure 3.6. LC-MS analysis of the in vitro hypoxic metabolism of 1a in NADPH/CYPOR. (A) Chromatogram of the assay (elution time $7.30 \mathrm{~min}, 19.69 \mathrm{~min}$ ); (B) MS data for 1a (found molecular ion at 179); (C) MS data for the 3a (found molecular ion at 163). 
As shown in Figure 3.4, 3.5 and 3.6, the major metabolites of the hypoxiaselective in vitro metabolic metabolism of benzotriazine-1,4-di- $N$-oxides were indeed the corresponding mono- $N$-oxides (mono- $N$-oxide metabolite was found at $\mathrm{m} / \mathrm{z}=181,193$ and 163 for 3d, 3e and 3a, respectively). In contrast, the identical asssay, except conducted under aerobic conditions of $\mathbf{1 d}$ generated not observble amount of $\mathbf{3 d}$, further suggestion that the in vitro enzymatic reduction only happened under hypoxic conditions.

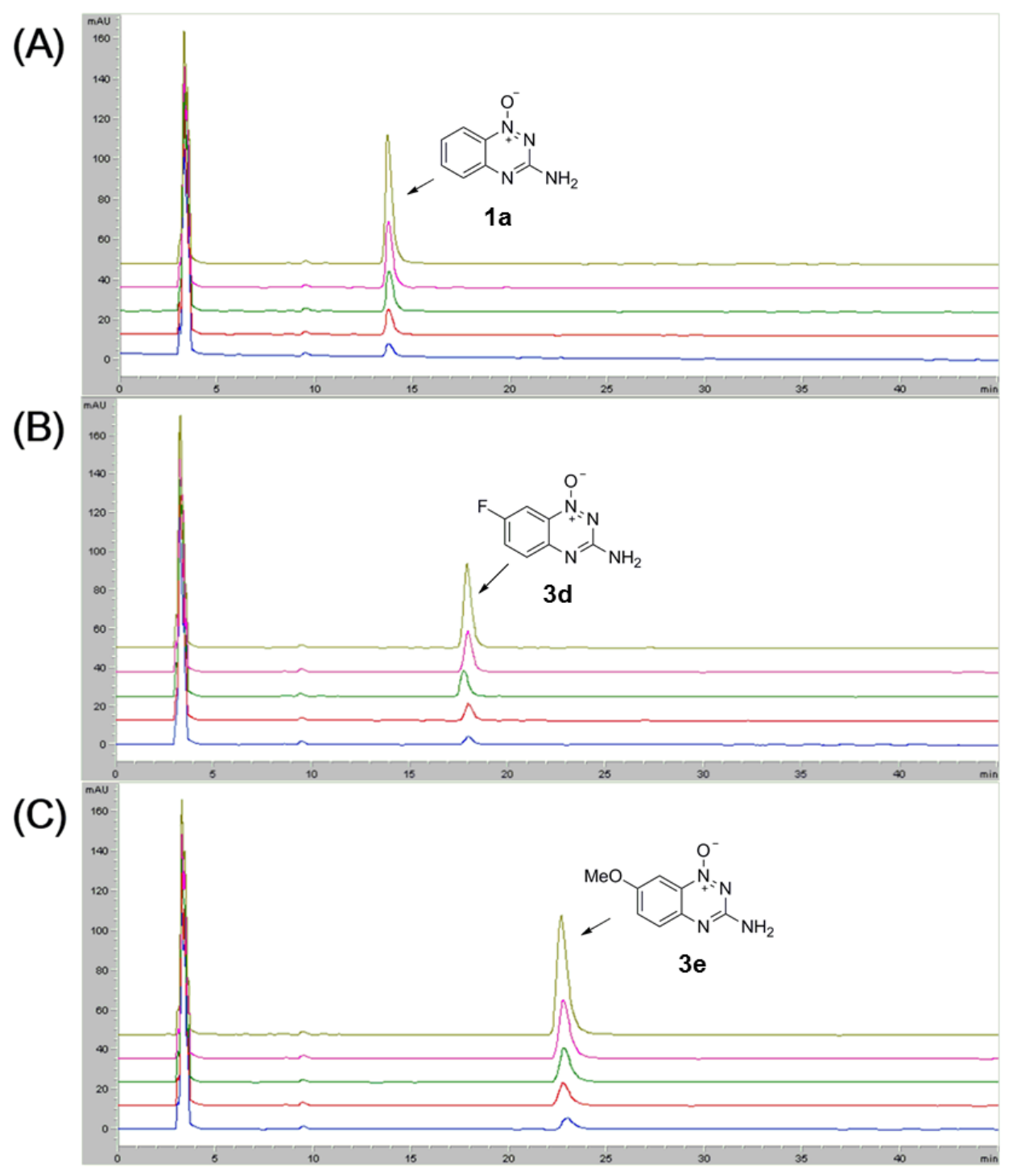

Figure 3.7. HPLC calibration curves of BTO mono- $N$-oxides with different concentrations. (10 $\mu \mathrm{M}, 20 \mu \mathrm{M}, 30 \mu \mathrm{M}, 50 \mu \mathrm{M}, 100 \mu \mathrm{M})$ (A) 1a eluted at $13.7 \mathrm{~min}$; (B) 3d eluted at $17.9 \mathrm{~min}$; (C) 3e eluted at $22.9 \mathrm{~min}$. 
Table 3.3. Generation of mono- $N$-oxide via in vitro metabolism of $1 \mathrm{a}, 1 \mathrm{~d}$, and $1 \mathrm{e}$.

\begin{tabular}{|c|c|c|c|c|}
\hline & & $\mathbf{3 a}$ & 3d & $3 \mathbf{e}$ \\
\hline & Aero $^{a}$ & $0.8(0.2)$ & $2.9(0.4)$ & $4.5(0.1)$ \\
\hline \multirow[t]{2}{*}{$\mathrm{X} / \mathrm{XO}$} & Hypox $^{a}$ & $12.2(0.6)$ & $20.6(2.6)$ & $10.4(1.0)$ \\
\hline & Ratio $^{b}$ & 15.3 & 7.1 & 2.3 \\
\hline \multirow{3}{*}{ NADPH/CYPOR } & Aero & $0.6(0.4)$ & $2.9(0.2)$ & $6.0(0.1)$ \\
\hline & Нурох & $10.8(1.9)$ & $22.0(0.5)$ & $9.4(1.4)$ \\
\hline & Ratio & 18.0 & 7.6 & 1.6 \\
\hline \multirow{3}{*}{ No enzyme } & Aero & 0 & $2.1(0.22)$ & $4.8(0.63)$ \\
\hline & Нурох & $0.4(0.27)$ & $2.6(0.64)$ & $6.3(0.64)$ \\
\hline & Ratio & $-{ }^{c}$ & 1.2 & 1.3 \\
\hline \multirow{3}{*}{$\begin{array}{c}\text { NADPH } \\
\text { DT-Diaphorase }\end{array}$} & Aero & $0.5(0.19)$ & $5.4(0.02)$ & $10.6(0)$ \\
\hline & Нурох & $1.0(0.16)$ & $4.3(0.02)$ & $9.7(0)$ \\
\hline & Ratio & 2.0 & 0.8 & 0.9 \\
\hline
\end{tabular}

${ }^{a}$ The percent yield (\%) is calculated on the basis of benzotriazine mono- $N$-oxide. Aero: aerobic assay; Hypox: hypoxic assay. The number in parenthesis is the standard deviation calculated by two replicate experiments. ${ }^{\mathrm{b}}$ Ratio $=$ yield ratio of hypoxic/aerobic. ${ }^{\mathrm{c}}$ Not Applicable.

HPLC calibration curves were established by the linear regression of the peak integration of different concentrations $(10 \mu \mathrm{M}, 20 \mu \mathrm{M}, 30 \mu \mathrm{M}, 50 \mu \mathrm{M}, 100 \mu \mathrm{M})$ of the authentic 3d, 3e and 3a, respectively (Figure 3.7). As illustrated in Table 3.3, both $\mathbf{1 d}$ and the parent compound 1a showed high yields of mono- $N$-oxides under hypoxic conditions (20.6\% and $12.2 \%$ in $\mathrm{X} / \mathrm{XO} ; 22.0 \%$ and $10.8 \%$ in NADPH/CYPOR) and low yields under aerobic conditions (2.9\% and $0.8 \%$ in $\mathrm{X} / \mathrm{XO} ; 2.9 \%$ and $0.6 \%$ in NADPH/CYPOR), 
indicating that effective conversion only occurred under hypoxic conditions. However, 1e also displayed high percentage of metabolism under aerobic conditions $(4.5 \%$ in $\mathrm{X} / \mathrm{XO}$ and $6.0 \%$ in NADPH/CYPOR), suggesting that its redox potential allowed the aerobic metabolism, thus losing the hypoxia selectivity.

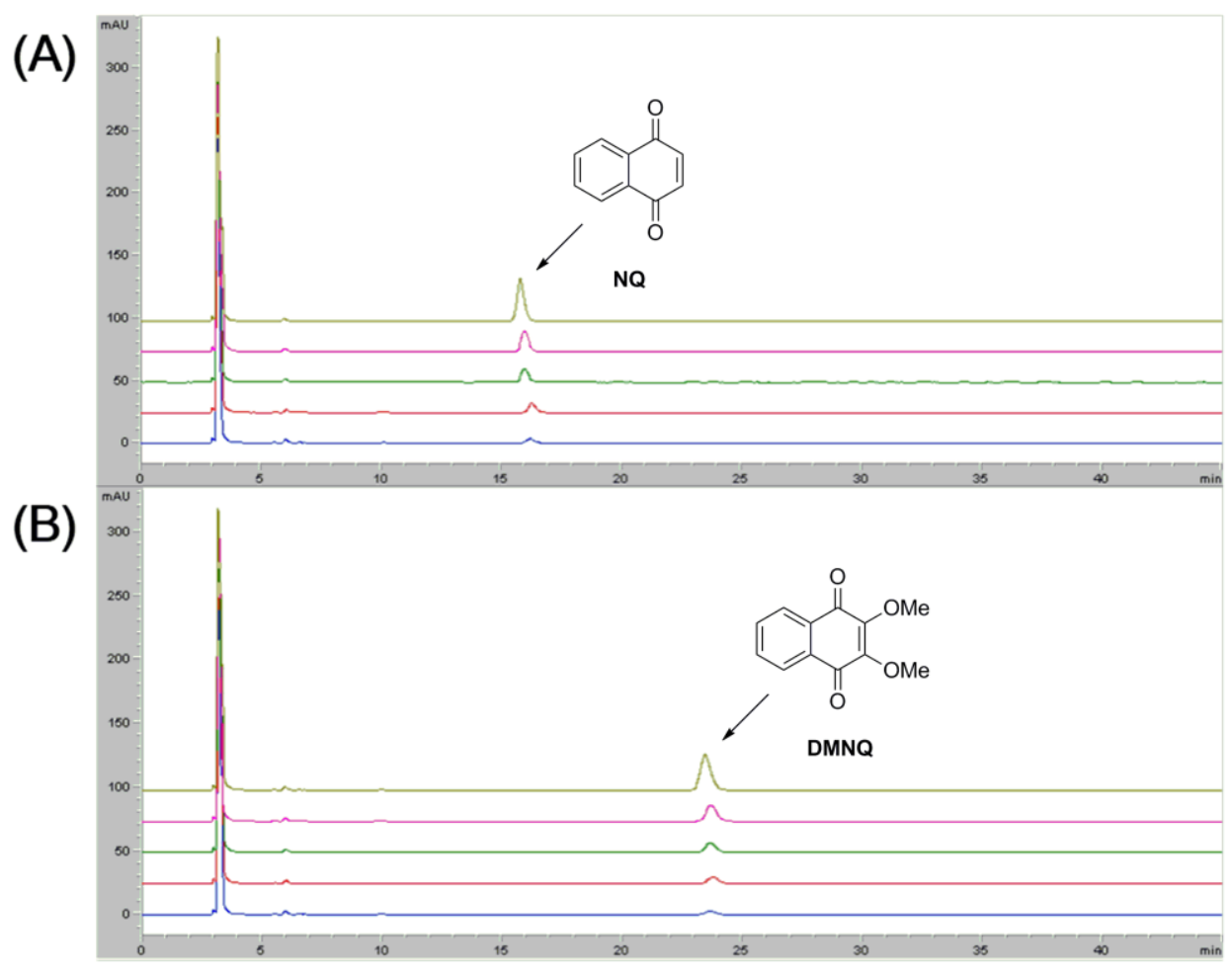

Figure 3.8. HPLC calibration curves of quinones with different concentration. $(10 \mu \mathrm{M}$, $20 \mu \mathrm{M}, 30 \mu \mathrm{M}, 50 \mu \mathrm{M}, 100 \mu \mathrm{M}$ ) (A) 1,4-Naphthoquinone (NQ) eluted at $16.1 \mathrm{~min}$; (B) 2,3-Dimethyl-1,4-naphthoquinone (DMNQ) eluted at $23.5 \mathrm{~min}$.

We also checked whether two-electron reductase DT-diaphorase could catalyze the in vitro hypoxic metabolism of the dioxides or not. If so, the enzymatic metabolism would generate the two-electron reducing metabolite, mono- $N$-oxide directly, bypassing the oxygen-sensitive radical and losing the hypoxia selectivity. We found that $\mathbf{1 d}$ and $\mathbf{1 a}$ were not reduced by DT-diaphorase, either under hypoxic or aerobic conditions. Interestingly, we found that 1e can be metabolized by DT-diaphorase in the same manner in one electron reductase CYPOR and XO (Figure 3.8, Table 3.3). Positive controls were 
performed by the enzymatic conversion of natural substrates of DT-diaphorase, 1,4naphthoquinone (NQ) and 2,3-dimethyl-1,4-naphthoquinone (DMNQ) into the corresponding hydroquinones. The results showed the oxygen independent conversion of NQ and DMNQ by NADPH/DT-diaphorase, suggesting that the enzyme system was active (Figure 3.9). In addition, the no enzyme control also showed low metabolism of 1d and 1a, indicating that the conversion was due to the one-electron reductive enzymes.<smiles>O=C1C=CC(=O)c2ccccc21</smiles>

NQ<smiles>Oc1ccc(O)c2ccccc12</smiles>

hydroNQ<smiles>COC1=C(OC)C(=O)c2ccccc2C1=O</smiles>

DMNQ<smiles>COc1c(OC)c(O)c2ccccc2c1O</smiles>

hydroDMNQ

\begin{tabular}{c|ccc}
\hline & & HydroNQ & HydroDMNQ \\
& & & \\
\hline & Aero & $62.9(0.2)$ & $17.1(2.2)$ \\
NADPH & Hypox & $56.1(6.0)$ & $19.3(4.0)$ \\
DT-Diaphorase & Ratio & 0.9 & 1.1 \\
& & & \\
\hline
\end{tabular}

Figure 3.9. 1,4-Naphthoquinone (NQ) and 2,3-Dimethyl-1,4-naphthoquinone (DMNQ) as the positive control of the enzymatic function of DT-Diaphorase. The assays were operated as the in-vitro enzymatic assay procedure described in materials and methods. The yield of 1,4-hydroxyl-naphthoquinone (hydroNQ) and 2,3-Dimethyl-1,4-hydroxylnaphthoquinone (hydroDMNQ) were calculated from the consumption of the starting material NQ and DMNQ. Aero: aerobic assay; Hypox: hypoxic degassed assay. The number in parenthesis is the standard deviation calculated by two replicate experiments. 


\subsection{Fluorimetric analysis of hypoxia-selective in vitro metabolic conversion of $1 d$-e into $3 d-e$.}

The fluorescence intensity was measured from the ethyl acetate extract in the assays which 1a, 1d and 1e were incubated with NADPH/CYPOR and X/XO enzyme systems under hypoxic or aerobic conditions at the emission maximum of the corresponding mono- $N$-oxides.

Among the three dioxides, hypoxic metabolism of compounds 1d gave the highest fluorescence enhancements of 24 and 16 folds between anaerobic and aerobic assays, in $\mathrm{NADPH} / \mathrm{CYPOR}$ and $\mathrm{X} / \mathrm{XO}$, respectively (Figure 3.10). The parent compound 1a showed high fluorescence enhancement but the intensity is lower than that of $\mathbf{1 d}$, while 1e showed poor enhancement, though it displayed high intensity. In addition, in the control assays, the fluorescence enhancements became 0.7 and 1.9 in NADPH/DTdiaphorase and no enzyme assays, respectively, further validating the potential of $\mathbf{1 d}$ as fluorescent markers to detect bioreductive enzymes. As expected from Table 3.3, the 7methoxy derivative 1e showed high metabolism in both hypoxic and aerobic assays in NADPH/DT-diaphorase and no enzyme assays.

In addition, fluorescence intensity without ethyl acetate extract was also measured in the above assays. As shown in Figure 3.11, the fluorescence intensity was lower than in ethyl acetate because water quenched the fluorescence. Anyway, 1d still displayed favorable fluorescence enhancement between the hypoxic and aerobic assays in NADPH/CYPOR and X/XO, and showed no significant fluorescence in the NADPH/DTdiaphorase and no enzyme controls. 

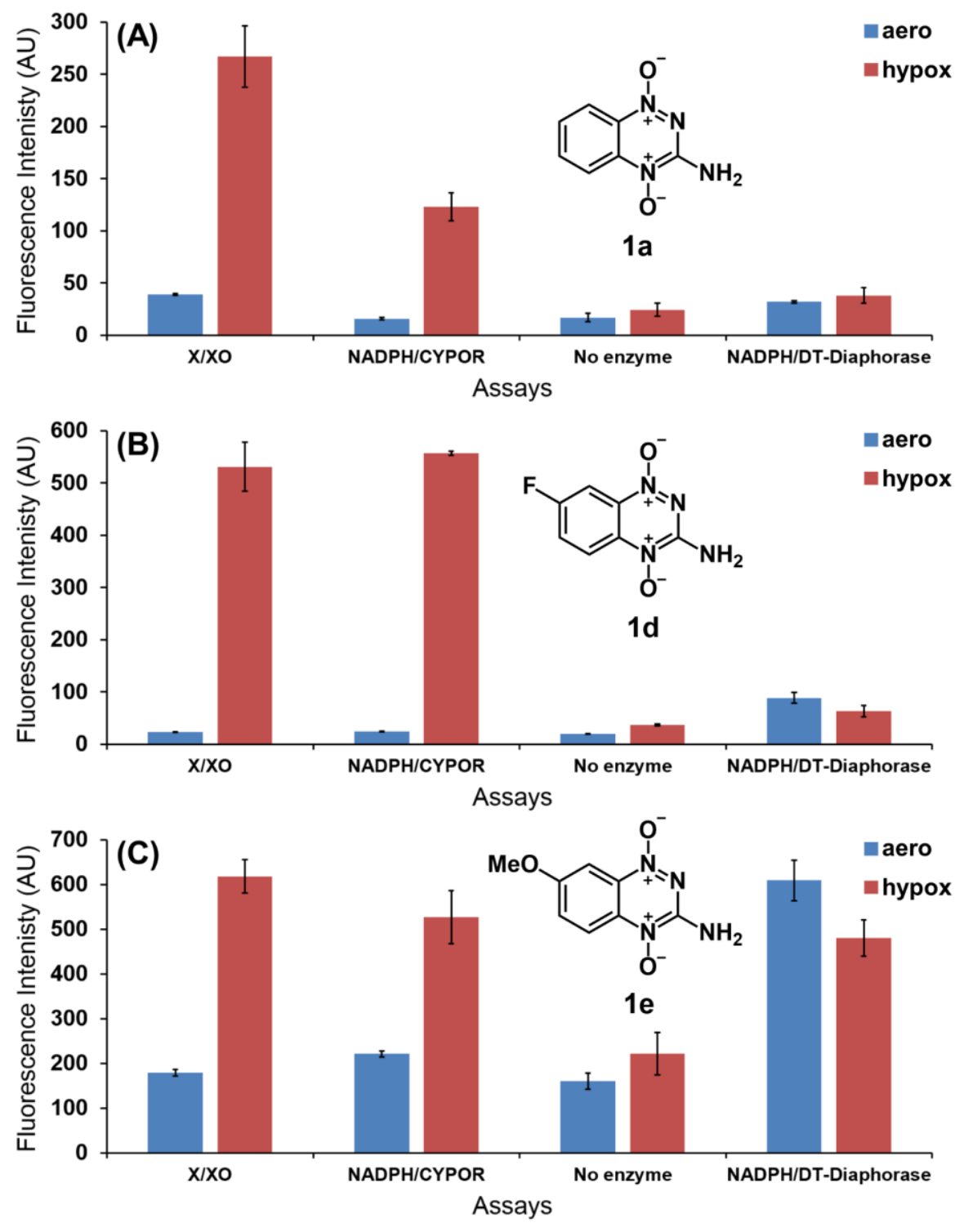

Figure 3.10. Fluorimetric analysis of metabolites in ethyl acetate extract generated in the aerobic and hypoxic metabolism of 1a, 1d, and 1e by X/XO, NADPH/CYPOR and NADPH/DT-Diaphorase. The aerobic assay represents in blue bars; the hypoxic assay represents in red bars. (A) Enzymatic assays for 1a; (B) Enzymatic assays for 1d; (C) Enzymatic assays for 1e. X/XO: enzymatic assay in xanthine/xanthine oxidase, BTO dioxides $(500 \mu \mathrm{M})$, xanthine $(2 \mathrm{mM})$, xanthine oxidase $(0.04 \mathrm{U} / \mathrm{mL})$, sodium phosphate buffer (50 mM, pH 7.0); NADPH/CYPOR: enzymatic assay in NADPH/cytochrome P450 reductase, BTO dioxides $(500 \mu \mathrm{M})$, NADPH $(2 \mathrm{mM})$, cytochrome P450 reductase $(0.13 \mathrm{U} / \mathrm{mL})$, sodium phosphate buffer $(50 \mathrm{mM}, \mathrm{pH} 7.0)$; No enzyme: enzymatic assay in NADPH only, BTO dioxides $(500 \mu \mathrm{M})$, NADPH $(2 \mathrm{mM})$, sodium phosphate buffer (50 $\mathrm{mM}, \mathrm{pH}$ 7.0); NADPH/DT-Diaphorase: enzymatic assay in NADPH/DT-diaphorase, BTO dioxides $(500 \mu \mathrm{M})$, NADPH $(2 \mathrm{mM})$, DT-diaphorase $(0.01 \mathrm{U} / \mathrm{mL})$, sodium phosphate buffer $(50 \mathrm{mM}, \mathrm{pH} 7.0)$. The fluorescence was measured in a volume of $1 \mathrm{~mL}$ from a dilution of $200 \mu \mathrm{L}$ assay. The standard deviation is calculated from two replicates. 

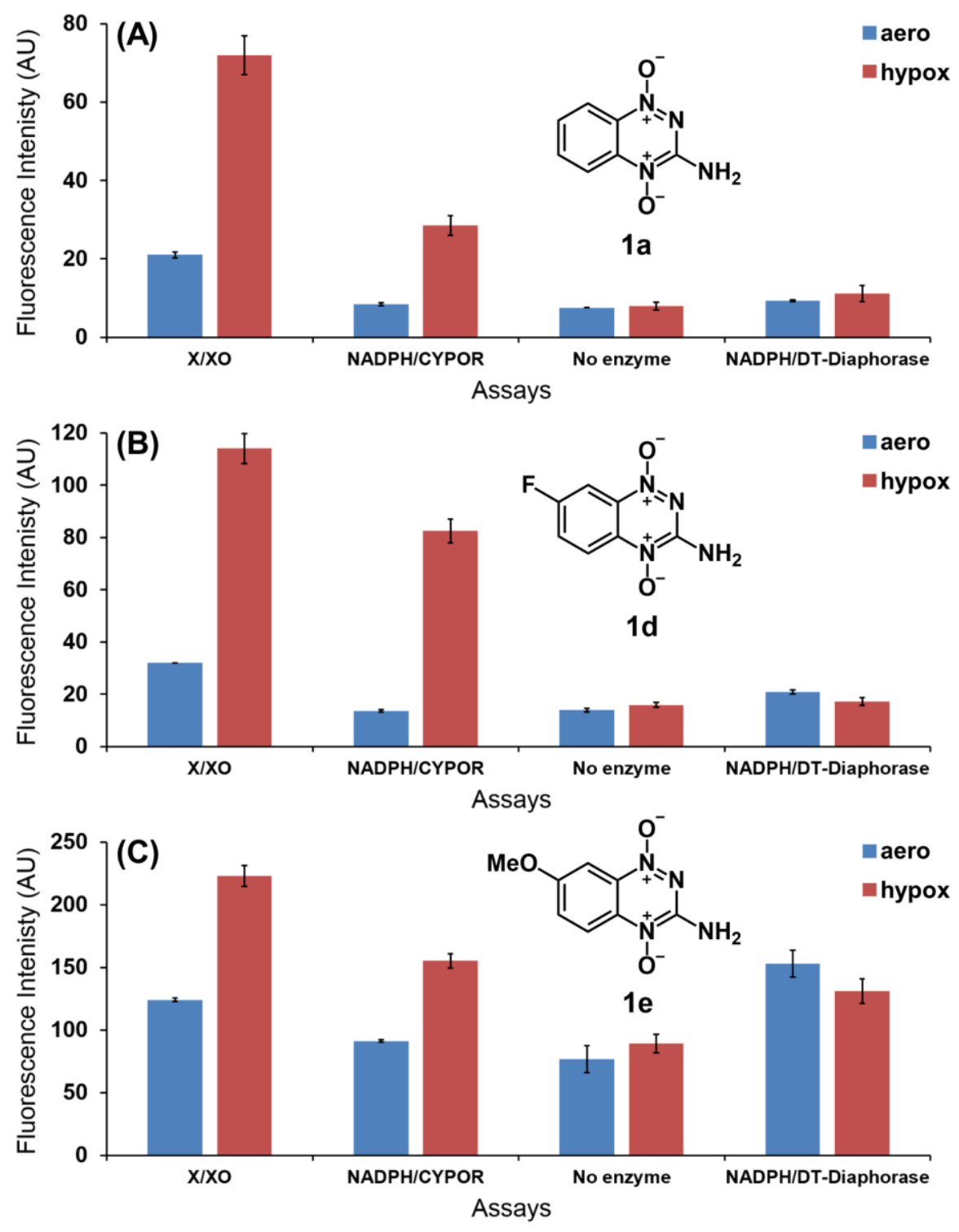

Figure 3.11. Fluorescence intensity of enzymatic assays in water. The aerobic assay represents in blue bars; the hypoxic assay represents in red bars. (A) Enzymatic assays for 1a; (B) Enzymatic assays for 1d; (C) Enzymatic assays for 1e. X/XO: enzymatic assay in xanthine/xanthine oxidase, BTO dioxides $(500 \mu \mathrm{M})$, xanthine $(2 \mathrm{mM})$, xanthine oxidase $(0.04 \mathrm{U} / \mathrm{mL})$, sodium phosphate buffer $(50 \mathrm{mM}, \mathrm{pH} 7.0)$; NADPH/CYPOR: enzymatic assay in NADPH/cytochrome P450 reductase, BTO dioxides $(500 \mu \mathrm{M})$, NADPH ( $2 \mathrm{mM})$, cytochrome $\mathrm{P} 450$ reductase $(0.13 \mathrm{U} / \mathrm{mL})$, sodium phosphate buffer $(50$ mM, pH 7.0); No enzyme: enzymatic assay in NADPH only, BTO dioxides $(500 \mu \mathrm{M})$, NADPH (2 mM), sodium phosphate buffer (50 mM, pH 7.0); NDAPH/DT-Diaphorase: enzymatic assay in NADPH/DT-diaphorase, BTO dioxides $(500 \mu \mathrm{M})$, NADPH $(2 \mathrm{mM})$, DT-diaphorase $(0.01 \mathrm{U} / \mathrm{mL})$, sodium phosphate buffer $(50 \mathrm{mM}, \mathrm{pH} 7.0)$. The fluorescence was measured in a volume of $1 \mathrm{~mL}$ from a dilution of $200 \mu \mathrm{L}$ assay. The standard deviation is calculated from two replicates. 


\subsection{Effects of exogenous protein and cell extracts on the potential}

\section{applications of the probes}

Given the intended application with biochemical and biological systems, we tested the effects of added bovine serum albumin (BSA) on the photophysical properties of $\mathbf{3 d}$ and $3 \mathbf{e}$ such as quantum yield and emission maximum. As shown in Figure 3.12, there is no significant change in quantum yield and emission maximum of $\mathbf{3 d}$ and $\mathbf{3 e}$ in the presence of $0-50 \mathrm{mg} / \mathrm{mL} \mathrm{BSA}$.

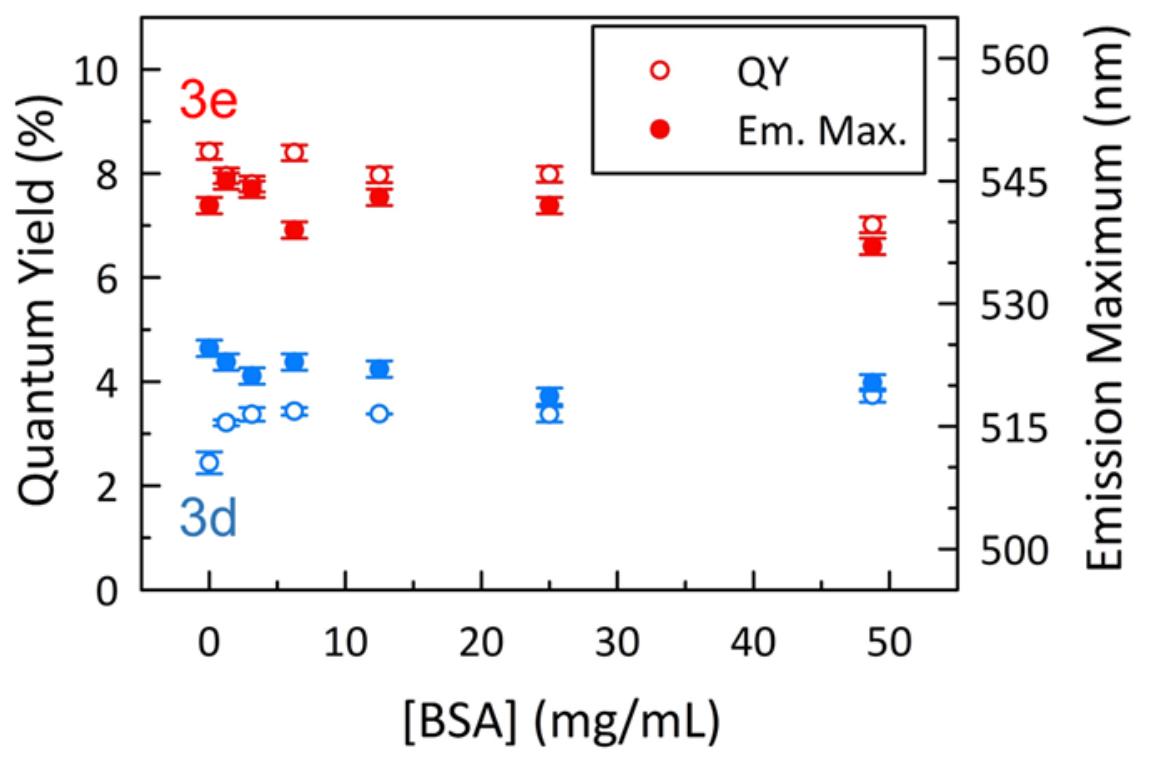

Figure 3.12. Fluorescence quantum yield (QY) and emission maximum (Em. Max.) of $\mathbf{3 d}$ and $\mathbf{3 e}$ in water with various concentrations of bovine serum albumin (BSA).

In addition, we also tested the effect of cancer cell extract to the fluorescence enhancement between hypoxic and aerobic assays of $\mathbf{1 d}$. The cell extract was made from human prostate cancer (PC-3) cell lines by disrupting the cells with detergent based RIPA buffer and centrifuging to remove the cell membranes. The cell extract was prepared by Hang Xu in Dr. Linxin Ma lab. The fluorescence intensity was not drastically decreased 
in the presence of $0-10^{6}$ cells $/ \mathrm{ml}$ cell extract, not losing the fluorescence enhancement (Figure 3.13). The possible reason for the slight decrease of fluorescence intensity with increasing amount of cell extract is that the detergent based buffer in the cell extract would affect the enzyme activity of added xanthine oxidase.

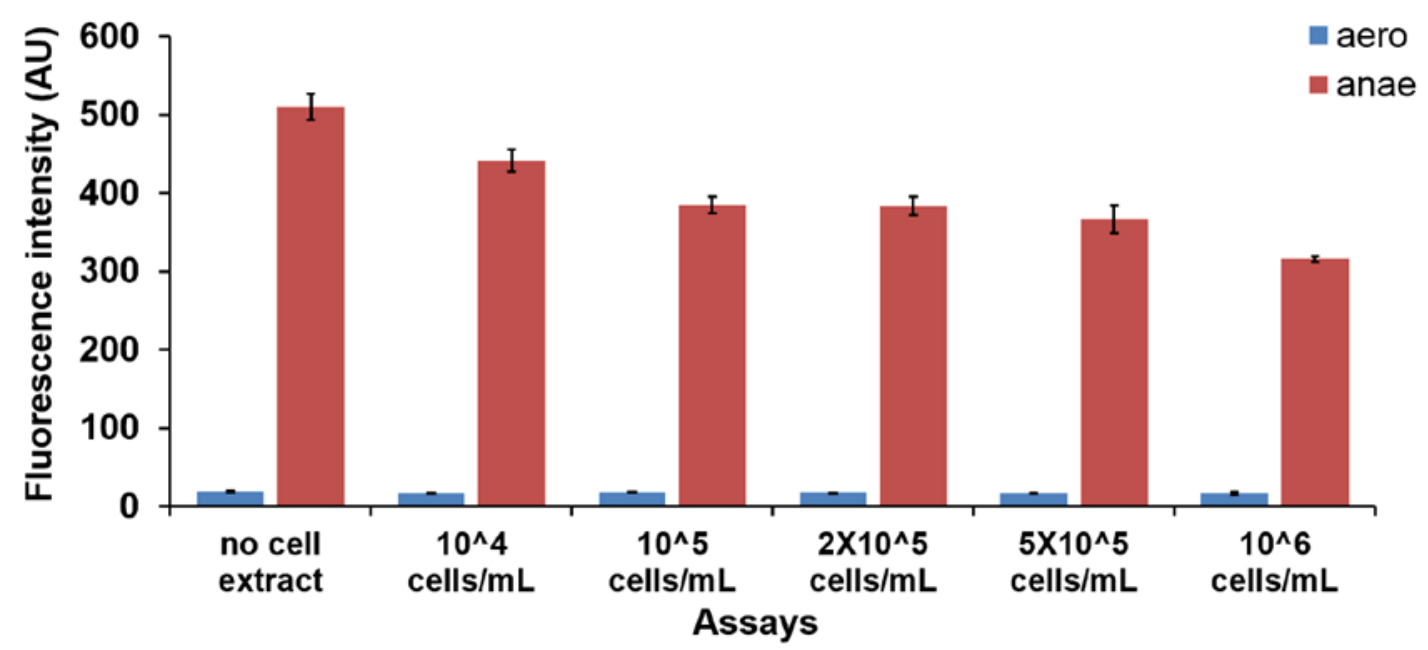

Figure 3.13. Fluorescence intensity of enzymatic assays in ethyl acetate with $\mathrm{X} / \mathrm{XO}$ and human prostate cancer (PC-3) cell extract. The aerobic assay represents in blue bars; the anaerobic assay represents in red bars. In the assay, 1d $(500 \mu \mathrm{M})$, xanthine $(2 \mathrm{mM})$, xanthine oxidase $(0.04 \mathrm{U} / \mathrm{mL})$, sodium phosphate buffer $(50 \mathrm{mM}, \mathrm{pH} 7.0)$ and PC-3 cell extract $\left(0,10^{4}, 10^{5}, 2 \times 10^{5}, 5 \times 10^{5}\right.$ and $10^{6}$ cells $\left./ \mathrm{mL}\right)$ were incubated for 4 hours with aluminum foil. The fluorescence was measured in a volume of $1 \mathrm{~mL}$ from a dilution of $200 \mu \mathrm{L}$ assay. The standard deviation is calculated from two replicates.

\subsection{Potential quantitative application of $1 \mathrm{~d}$ as pro-fluorescent probes to}

\section{measure the total reductive enzyme activity}

Besides detecting the presence of reductive enzymes involved in bioreductive activation of hypoxia-selective antitumor prodrugs, the probes also have the potential to quantitatively determine the total reductive enzyme concentration relative to xanthine oxidase. In a hypoxia-selective in vitro metabolism of $\mathbf{1 d}$ with various concentrations ( 0 $0.04 \mathrm{U} / \mathrm{mL}$ ) of the enzyme xanthine oxidase, the fluorescence intensity is proportional to 
the enzyme concentration $\left(\mathrm{R}^{2}=0.999\right.$ in a linear regression, Figure 3.14), indicating the potential to determine the total reductive enzyme concentration in vitro.

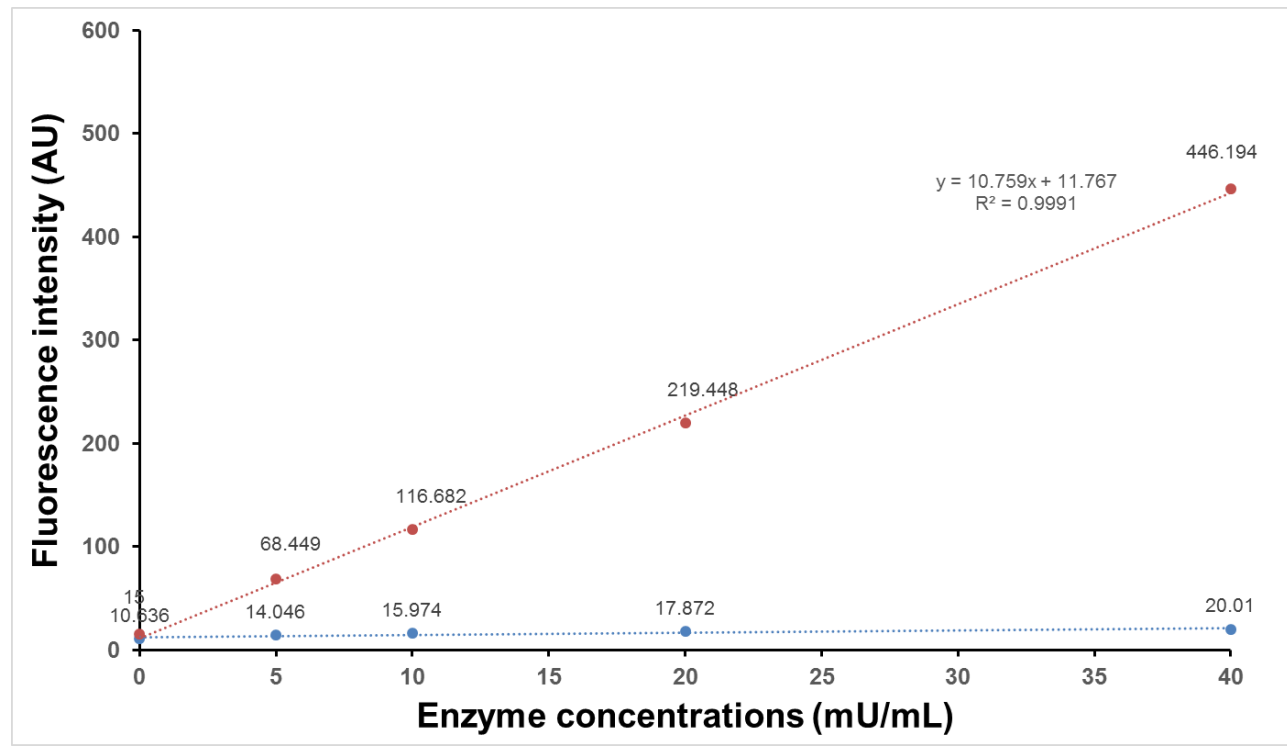

Figure 3.14. Fluorescence intensity of enzymatic assays in ethyl acetate with xanthine/xanthine oxidase. The aerobic assay represents in blue dots; the anaerobic assay represents in red dots. In the assay, $1 \mathbf{d}(500 \mu \mathrm{M})$, xanthine $(2 \mathrm{mM})$, xanthine oxidase $(0$ $0.04 \mathrm{U} / \mathrm{mL})$, sodium phosphate buffer $(50 \mathrm{mM}, \mathrm{pH} 7.0)$ were incubated for $4 \mathrm{~h}$ with aluminum foil. The fluorescence was measured in a volume of $1 \mathrm{~mL}$ from a dilution of $200 \mu \mathrm{L}$ assay. The standard deviation is calculated from two replicates.

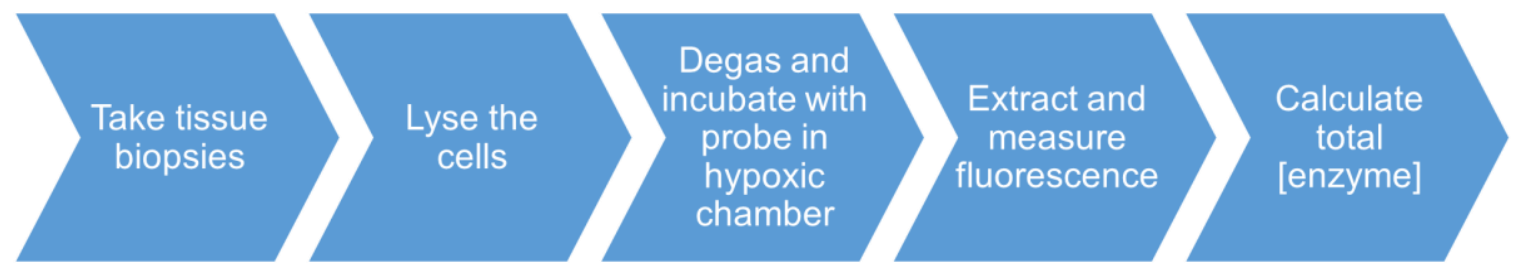

Scheme 3.4. Schematic procedure for the quantitative application of the probe $\mathbf{1 d}$.

Therefore, the procedure of the potential diagnostic tool by $\mathbf{1 d}$ was proposed in Scheme 3.4. In this proposed application, the tumor tissue biopsies would be taken from the patients and cell extracts prepared using RIPA buffer and ultrasonication. Then the cell lysate would be incubated in a hypoxic chamber with the probe $\mathbf{1 d}$ for 4 hours. Then fluorescence intensity would be measured from the ethyl acetate extract and the total 
reductive enzyme concentration calculated from the calibration curve. Assays under aerobic conditions should be performed and the background fluorescence should be subtracted if there is a low metabolism. If there is a high metabolism under aerobic conditions, the drugs would not be hypoxia selective. Further work needs to be done to determine the threshold amounts of reductive enzymes required for the activation of prodrugs. Evaluating the total reductive enzyme concentration may be necessary for the successful implementation of hypoxia-selective antitumor prodrugs in cancer chemotherapy.

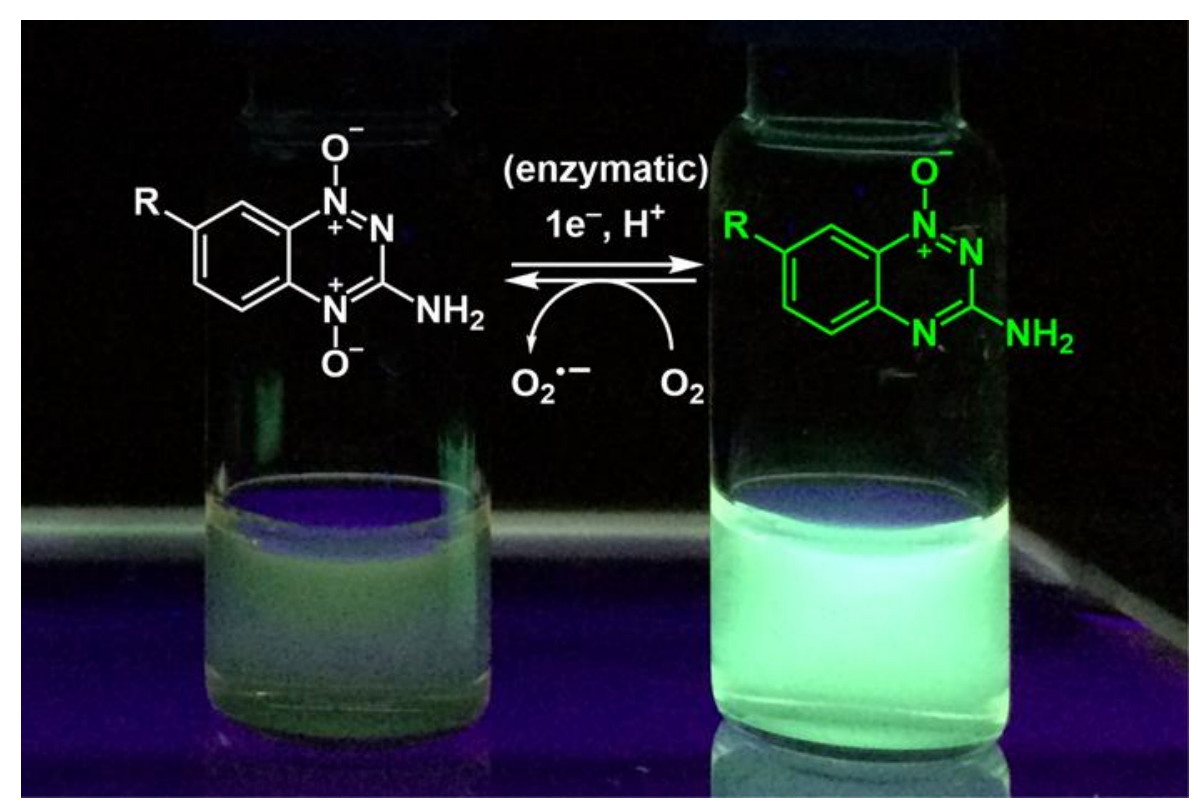

Figure 3.15. Compound 1d as fluorescence probe for the detection of drug-related bioreductive enzymes. Left vial: enzymatic assays under aerobic condition; right vial: enzymatic assays under hypoxic conditions. Fluorescence intensity was determined at emission maximum in ethyl acetate extract.

\subsection{Conclusions}

The hypoxia-selective enzymatic metabolism of tirapazamine (1a) generated mono- $N$-oxide metabolite (3a) with modest fluorescence properties. Here we identified 
two benzotriazine mono- $N$-oxides, $\mathbf{3 d}$ and $\mathbf{3 e}$, with improved photophysical properties such as high fluorescence quantum yield and large Stokes shift. The fluorinated analog 1d exhibited hypoxia-selective metabolism by one-electron reductases involved in hypoxia-selective antitumor prodrugs and produced good amounts of the fluorescent mono- $N$-oxide 3d (Figure 3.15). In addition, 1d is not a substrate for the two-electron reductase DT-diaphorase. The fluorinated analog $\mathbf{1 d}$ has the potential to serve as a useful pro-fluorescent probe to detect global reductive enzymes involved in the bioreductive activation of hypoxia-selective antitumor prodrugs.

\subsection{Experimental section}

Materials. Materials were of the highest purity available and were obtained from the following sources: cytochrome P450 reductase, DT-diaphorase, NADPH, xanthine, 1,4-naphthoquinone (NQ), 2,3-dimethoxy-1,4-naphthoquinone (DMNQ), sodium phosphate, DMSO, silica gel (0.04-0.063 mm pore size) for column chromatography, and silica gel plates for thin layer chromatography from Sigma Chemical Co. (St. Louis, MO); xanthine oxidase from Roche Applied Science; HPLC grade solvents (acetonitrile, methanol, ethyl acetate, hexane, trifluoroacetic acid and acetic acid) from Fischer (Pittsburgh, PA); deuterated NMR solvents were from Cambridge Isotope Laboratories (Andover, MA). Human prostate cancer (PC-3) cell-lines were bought from American Type Culture Collection (ATCC, Manassas, VA) and maintained by the Cell and Immunobiology Core Facility at University of Missouri. RPMI 1640 was bought from Thermo Fisher Scientific (Waltham, MA) with 10\% fetal bovine serum (FBS) from Sigma-Aldrich (St. Louis, MO) and 1\% penicillin from Invitrogen (Carlsbad, CA) as the 
culture medium. Trypsin was purchased from Invitrogen (Carlsbad, CA), with $0.25 \%$ EDTA as the agent to suspend cells. Forma water-jacketed incubator from Fisher Scientific (Waltham, MA) offered proper growing environment $\left(37^{\circ} \mathrm{C}\right.$ and $\left.5 \% \mathrm{CO}_{2}\right)$ for PC-3 cells. PBS was bought from Leinco Technologies (St. Louis, MO), and RIPA buffer was bought from Fisher Scientific (Waltham, MA).

General methods for synthesis. Compounds KJ-31, KJ-53 were prepared following the methods of Suzuki, H. ${ }^{21}$ Compounds KJ-28, KJ-33 and KJ-36 were prepared following the methods of Johnson K. M. ${ }^{22}$ Compounds US-25, US-26, US-27, US-73 and KJ-51 were prepared following the methods of Sarkar U. ${ }^{23}$ Compounds KJ9, KJ-11, US-69, US-71, US-72, US-74 and US-75 were prepared following the methods of Jiang F. ${ }^{24}$ Compounds US-67, US-68 and US-70 were prepared following the methods of Hay, M. P. ${ }^{20}$ Compounds US-3, US-5, US-6 and US-43 were prepared following the methods of Robbins, R. F. ${ }^{25}$ Compounds KJ-43, KJ-43B, KJ-46, KJ-47, KJ-48, KJ-50 were prepared following the methods of Johnson K. M. ${ }^{18,26-29}$ Compound US-19 was prepared following the methods of Sarkar U. ${ }^{30}$

General procedure for in-vitro enzymatic assays. In an anaerobic assay, BTO dioxides $(500 \mu \mathrm{M})$ were incubated with NADPH $(2 \mathrm{mM})$ or xanthine $(2 \mathrm{mM})$, cytochrome P450 reductase $(0.13 \mathrm{U} / \mathrm{mL}$, where one unit is defined as the amount of enzyme required to reduce $1.0 \mu$ mole of cytochrome $c$ by NADPH per minute at $\mathrm{pH} 7.4$ at $\left.37^{\circ} \mathrm{C}\right)$ or xanthine oxidase $(0.04 \mathrm{U} / \mathrm{mL}$, where one unit is defined as the amount of enzyme required to oxidize approximately $1 \mathrm{mg}$ xanthine at $25{ }^{\circ} \mathrm{C}$ ) or DT-Diaphorase $(0.005 \mathrm{U} / \mathrm{mL}$, where one unit is defined as the amount of enzyme required to reduce 1.0 
$\mu$ mole of cytochrome $c$ by NADPH per minute in the presence of menadione substrate at $\left.37^{\circ} \mathrm{C}\right)$ or no enzyme or cell extract solution $\left(10^{4}-10^{6} \mathrm{cells} / \mathrm{mL}\right)$, sodium phosphate buffer (50 mM, pH 7.0), DMSO (5.0 \% v/v, stock solution of BTO dioxides), and HPLC grade water to obtain the final solution $(0.2 \mathrm{~mL}$ final volume) under anaerobic conditions at $25{ }^{\circ} \mathrm{C}$ for $4 \mathrm{~h}$. All components of the reactions except enzymes and NADPH were degassed by three freeze-pump-thaw cycles. Enzymes and NADPH were diluted with degassed water in an argon-filled glovebag to prepare stock solutions. Reactions were initiated by the addition of enzymes, wrapped in aluminum foil to prevent exposure to light, and incubated in an argon-filled glovebag. The aerobic controls were performed with the same recipe with aerobic stock solutions and solvents. Following incubation, the reactions were opened to air and diluted to $1 \mathrm{~mL}$ with aerobic sodium phosphate buffer (50 mM, pH 7.0), and the fluorescence measurements were then carried out in a cuvette open to air. The assay in ethyl acetate for fluorescence and HPLC analysis were performed by extracting the assay with $1 \mathrm{~mL}$ ethyl acetate, freezing the solution in $-20{ }^{\circ} \mathrm{C}$ freezer, and taking the organic layer by pipet.

Cell extract protocol. 35 million PC-3 cells were suspended with ice-cold culture medium and trypsin. The cell suspension was then rinsed with ice cold 1X PBS three times to remove culture medium. Cell pellets were precipitated via centrifugation by Sorvall Legend XFR centrifuge (Fisher Scientific, Waltham, MA), suspended in $1.75 \mathrm{ml}$ RIPA buffer, and kept on ice for 30 min with vortex every 10 min. Subsequently, the sample was treated with sonication for cell extract at a power of 180 watts for $1 \mathrm{~min}$ in rounds of 10 second sonication/10 seconds rest for each cycle on ice using model 100 Sonic Dismembrator (Fisher Scientific, Waltham, MA) to break cells further and shear 
DNA. The resulting mixture was centrifuged at $10,000 \mathrm{x}$ g for $20 \mathrm{~min}$ at $4^{\circ} \mathrm{C}$ by a Sorvall Discovery 100 SE Ultracentrifuge (Fisher Scientific, Waltham, MA). Finally, supernatant was gently transferred to a tube for each sample. Samples (20 million lysed cells $/ \mathrm{mL}$ ) were diluted with DI water and used for immediate in-vitro enzymatic assays and were frozen at $-20^{\circ} \mathrm{C}$ for long-term storage.

LC-MS analysis for the enzymatic reduction of BTO dioxides. LC-MS were performed with the samples in anaerobic assays with NADPH/CYPOR enzyme system. For xanthine/Xanthine Oxidase and NADPH/DT-diaphorase systems, the chromatograms were almost the same according to HPLC study for the estimated yield of mono- $N$-oxide. Following incubation, the samples were dried with speed vacuum under room temperature and dissolved in $1 \mathrm{~mL}$ DMSO, and analyzed by Beckman Coulter HPLC employing a C18 reverse phase Betabasic column ( $5 \mu \mathrm{m}$ particle size, $150 \AA$ A pore size, 25 cm length, and $4.6 \mathrm{~mm}$ i.d.) eluted with gradient starting from 5\% B (0.1\% trifluoacetic acid in acetonitrile) and 95\% A (0.1\% trifluoacetic acid in water) for 5 min followed by linear increase to $35 \% \mathrm{~B}$ in another $60 \mathrm{~min}$, then the gradient was increased linearly to $80 \%$ of B within in $5 \mathrm{~min}$, and finally $80 \%$ of B was used to wash the column for $10 \mathrm{~min}$. A flow rate of $1.0 \mathrm{~mL} / \mathrm{min}$ was used, and the products were monitored by their UVabsorbance at $254 \mathrm{~nm}$. LC/ESI-MS experiments were carried out using an ion trap mass analyzer, on a LCQ FLEET instrument (Thermo Fisher Scientific). Positive ion electrospray was used as the means of ionization. The heated inlet capillary temperature was $375^{\circ} \mathrm{C}$, and electrospray needle voltage was $5 \mathrm{kV}$. Nitrogen sheath gas was supplied at $45 \mathrm{psi}$, and the LC/ESI-MS analysis was done in the positive ion mode. 
Quantum yield determination. The quantum yield determinations for the tirapazamine mono- $N$-oxides fluorophore compounds, $\Phi_{u}$, were calculated by the Parker-Rees method ${ }^{31}$ :

$$
\Phi_{u}=\Phi_{r}\left(\frac{\mathrm{A}_{r}}{\mathrm{~L}_{r}}\right)\left(\frac{\mathrm{L}_{u}}{\mathrm{~A}_{u}}\right)\left(\frac{n_{u}^{2}}{n_{r}^{2}}\right)
$$

In the expression above, $\Phi_{r}$ denotes the quantum yield of a well-known fluorophore; which in this case was Coumarine $153\left(\Phi_{r}=38 \%\right.$ in ethanol). $A_{u}$ represents the absorbance of the unknown sample at the desired excitation wavelength, $A_{r}$ is the reference fluorophore's absorbance at the same excitation wavelength, $\mathrm{L}_{u}$ designates the total integrated luminescence intensity of the unknown sample when excited at the same excitation wavelength and $\mathrm{L}_{r}$ references the total integrated luminescence intensity of the reference fluorophore when excited at the same excitation wavelength. The refractive indices of the solvents in which the unknown sample along with the reference fluorophore are measured in are denoted as $\mathrm{n}_{u}$ and $\mathrm{n}_{r}$, respectively. ${ }^{32}$

HPLC calibration curves. Calibration curves were achieved by an Agilent 1100 series HPLC equipped with autosampler using external standard method. Standard solutions $(10,20,30,50,100 \mu \mathrm{M}$ in DMSO) were prepared using serial dilution from their higher concentration standard solutions. All the mono- $N$-oxide compounds were detected by UV-absorbance at $254 \mathrm{~nm}$ with the isocratic eluent (Water: Methanol: Acetic Acid $=74: 25: 1)$ in 45 min. Quinone compounds were detected by UV-absorbance at 254 nm with the isocratic eluent (Water: Methanol: Acetic Acid = 59:40:1) in 45 min. 


\subsection{References}

(1) Mottram, J., A factor of importance in the radio sensitivity of tumours. The British Journal of Radiology 1936, 9 (105), 606-614.

(2) Brown, J. M.; Giaccia, A. J., The unique physiology of solid tumors: opportunities (and problems) for cancer therapy. Cancer research 1998, 58 (7), 14081416.

(3) Kizaka-Kondoh, S.; Inoue, M.; Harada, H.; Hiraoka, M., Tumor hypoxia: a target for selective cancer therapy. Cancer science 2003, 94 (12), 1021-1028.

(4) Brown, J. M.; Wilson, W. R., Exploiting tumour hypoxia in cancer treatment. Nature Reviews Cancer 2004, 4 (6), 437-447.

(5) Mulcahy, R. T.; Gipp, J. J.; Schmidt, J. P.; Joswig, C.; Borch, R. F., Nitrobenzyl phosphorodiamidates as potential hypoxia-selective alkylating agents. Journal of Medicinal Chemistry 1994, 37 (11), 1610-1615.

(6) Wilson, W. R.; Hay, M. P., Targeting hypoxia in cancer therapy. Nature Reviews Cancer 2011, 11 (6), 393-410.

(7) Lin, A. J.; Cosby, L. A.; Shansky, C. W.; Sartorelli, A. C., Potential bioreductive alkylating agents. 1. Benzoquinone derivatives. Journal of Medicinal Chemistry 1972, 15 (12), 1247-1252.

(8) Mason, R. P.; Holtzman, J. L., The role of catalytic superoxide formation in the $\mathrm{O}_{2}$ inhibition of nitroreductase. Biochemical and biophysical research communications 1975, 67 (4), 1267-1274. 
(9) Priyadarsini, K. I.; Tracy, M.; Wardman, P., The one-electron reduction potential of 3-amino-1,2,4-benzotriazine 1,4-dioxide (tirapazamine): A hypoxia-selective bioreductive drug. Free radical research 1996, 25 (5), 393-399.

(10) Lloyd, R. V.; Duling, D. R.; Rumyantseva, G. V.; Mason, R. P.; Bridson, P. K., Microsomal reduction of 3-amino-1,2,4-benzotriazine 1,4-dioxide to a free radical. Molecular Pharmacology 1991, 40 (3), 440-445.

(11) Wardman, P.; Priyadarsini, K.; Dennis, M.; Everett, S.; Naylor, M.; Patel, K.; Stratford, I.; Stratford, M.; Tracy, M., Chemical properties which control selectivity and efficacy of aromatic N-oxide bioreductive drugs. The British Journal of Cancer. Supplement 1996, 27, S70.

(12) Laderoute, K.; Wardman, P.; Rauth, A. M., Molecular mechanisms for the hypoxiadependent activation of 3-amino-1, 2, 4-benzotriazine-1, 4-dioxide (SR 4233). Biochemical Pharmacology 1988, 37 (8), 1487-1495.

(13) Silva, J.; O'Brien, P., Molecular mechanisms of SR 4233-induced hepatocyte toxicity under aerobic versus hypoxic conditions. British Journal of Cancer 1993, 68 (3), 484.

(14) Laderoute, K. R.; Rauth, A. M., Identification of two major reduction products of the hypoxic cell toxin 3-amino-1,2,4-benzotriazine-1,4-dioxide. Biochemical Pharmacology 1986, 35 (19), 3417-3420.

(15) Shi, X.; Poole, J. S.; Emenike, I.; Burdzinski, G.; Platz, M. S., Time-resolved spectroscopy of the excited singlet states of tirapazamine and desoxytirapazamine. The Journal of Physical Chemistry A 2005, 109 (8), 1491-1496. 
Poole, J. S.; Hadad, C. M.; Platz, M. S.; Fredin, Z. P.; Pickard, L.; Levya Guerrero, E.; Kessler, M.; Chowdhury, G.; Kotandeniya, D.; Gates, K. S., Photochemical electron transfer reactions of tirapazamine. Photochemistry and Photobiology 2002, 75 (4), 339-345.

(17) Sarkar, U. Ph. D. thesis. University of Missouri-Columbia, 2009.

(18) Johnson, K. M. Ph. D. thesis. University of Missouri-Columbia, 2014.

(19) Mason, J.; Tennant, G., Heterocyclic N-oxides. Part VI. Synthesis and nuclear magnetic resonance spectra of 3-aminobenzo-1,2,4-triazines and their mono-and di- $\mathrm{N}$ oxides. Journal of the Chemical Society B: Physical Organic 1970, 911-916.

(20) Hay, M. P.; Gamage, S. A.; Kovacs, M. S.; Pruijn, F. B.; Anderson, R. F.; Patterson, A. V.; Wilson, W. R.; Brown, J. M.; Denny, W. A., Structure-activity relationships of 1,2,4-benzotriazine 1,4-dioxides as hypoxia-selective analogues of tirapazamine. Journal of Medicinal Chemistry 2003, 46 (1), 169-182.

(21) Suzuki, H.; Kawakami, T., A convenient synthesis of 3-amino-1,2,4-benzotriazine 1,4-dioxide (SR 4233) and related compounds via nucleophilic aromatic substitution between nitroarenes and guanidine base. Synthesis 1997, 1997 (08), 855-857.

(22) Johnson, K. M.; Parsons, Z. D.; Barnes, C. L.; Gates, K. S., Toward hypoxiaselective DNA-alkylating agents built by grafting nitrogen mustards onto the bioreductively activated, hypoxia-selective DNA-oxidizing agent 3-amino-1,2,4benzotriazine 1,4-dioxide (tirapazamine). The Journal of Organic Chemistry 2014, 79 (16), 7520-7531.

(23) Sarkar, U.; Hillebrand, R.; Johnson, K. M.; Cummings, A. H.; Phung, N. L.; Rajapakse, A.; Zhou, H.; Willis, J. R.; Barnes, C. L.; Gates, K. S., Application of Suzuki- 
Miyaura and Buchwald-Hartwig Cross-coupling Reactions to the Preparation of Substituted 1,2,4-Benzotriazine 1-Oxides Related to the Antitumor Agent Tirapazamine. Journal of Heterocyclic Chemistry 2015.

(24) Jiang, F.; Yang, B.; Fan, L.; He, Q.; Hu, Y., Synthesis and hypoxic-cytotoxic activity of some 3-amino-1,2,4-benzotriazine-1,4-dioxide derivatives. Bioorganic \& Medicinal Chemistry Letters 2006, 16 (16), 4209-4213.

(25) Robbins, R.; Schofield, K., 623. Polyazabicyclic compounds. Part II. Further derivatives of benzo-1,2,4-triazine. Journal of the Chemical Society (Resumed) 1957, 3186-3194.

(26) Hodgson, H. H.; Kilner, E., II.-Preparation of 1-halogeno-2-nitronaphthalenes and 2-nitronaphthalene. Journal of the Chemical Society (Resumed) 1926, 129, 7-9.

(27) Katritzky, A. R.; Laurenzo, K. S., Alkylaminonitrobenzenes by vicarious nucleophilic amination with 4-(alkylamino)-1,2,4-triazoles. The Journal of Organic Chemistry 1988, 53 (17), 3978-3982.

(28) Suzuki, H.; Kawakami, T., Straightforward Synthesis of Some 2-or 3-substituted Naphtho-and Quinolino [1,2,4] triazines via the Cyclocondensation of Nitronaphthalenes and Nitroquinolines with Guanidine Base. The Journal of Organic Chemistry 1999, 64 (9), 3361-3363.

(29) Murray, R.; Singh, M., Synthesis of epoxides using dimethyldioxirane: transstilbene oxide:(dioxirane, dimethyl-and oxirane, 2, 3-diphenyl-, trans). Organic Syntheses 1997, 74, 91-100. 
(30) Sarkar, U.; Glaser, R.; Parsons, Z. D.; Barnes, C. L.; Gates, K. S., Synthesis, crystal structure, and rotational energy profile of 3-cyclopropyl-1, 2, 4-benzotriazine 1, 4di-N-oxide. Journal of Chemical Crystallography 2010, 40 (7), 624-629.

(31) Parker, C.; Rees, W., Fluorescence spectrometry, A review. Analyst 1962, 87 (1031), 83-111.

(32) Baker, G. A.; Bright, F. V.; Detty, M. R.; Pandey, S.; Stilts, C. E.; Yao, H., The influence of phenylethynyl linkers on the photo-physical properties of metal-free porphyrins. Journal of Porphyrins and Phthalocyanines 2000, 4 (07), 669-683. 


\section{Chapter 4. Mechanistic study of DNA strand cleavage by \\ ${ }^{18}$ O-labeled tirapazamine}

\subsection{Background}

In chapter 2, we utilized 1,2,4-benzotriazine-1,4-di- $N$-oxide (1b) as a template to elucidate the mechanism of DNA strand cleavage by tirapazamine (1a) and its analogs. And we provided evidence against the generation of benzotriazinyl radical (5), leaving hydroxyl radical the only viable alternative mechanism to explain the cytotoxicity. Following up with this isotopic labeling project, we want to provide direct evidence for the generation of hydroxyl radical as DNA damaging species upon the hypoxia-selective enzymatic reduction of tirapazamine (1a) and its analogs. The idea is to trap the isotope labeled hydroxyl radical or its derivatives generated by organic molecules and characterize the structure by mass spectrometry.

In this regard, we got the 4 -oxide ${ }^{18} \mathrm{O}$-labeled tirapazamine $\mathbf{1 f}$ from collaboration with Professor Shlomo Rozen in Isarel, by their published method in $2012 .{ }^{1}$ It was synthesized by the oxidation of the mono- $\mathrm{N}$-oxide $\mathbf{3 a}$ with the $\mathrm{HOF} \cdot \mathrm{CH}_{3} \mathrm{CN}$ complex (Scheme 4.1). The corresponding desamino form $1 \mathrm{~g}$ was synthesized by reductive deamination with tert-butyl nitrite, described in chapter $2 .^{2}$<smiles></smiles>

$3 a$

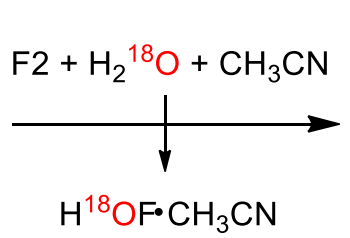

$\mathrm{H}^{18} \mathrm{OF} \cdot \mathrm{CH}_{3} \mathrm{CN}$

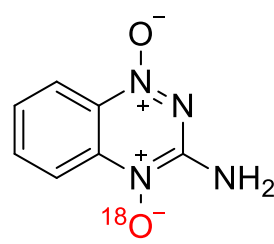

$1 f$

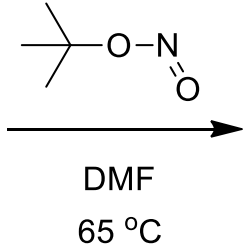

$65^{\circ} \mathrm{C}$

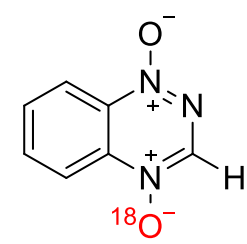

$1 \mathrm{~g}$

Scheme 4.1. Synthesis of ${ }^{18} \mathrm{O}$-lebaled TPZ (1f) and desamino TPZ (1g). 
With the compounds in hand, in vitro enzymatic metabolism can be performed and the metabolites can be analyzed by LC-MS/MS. As shown in Scheme $4.2,{ }^{18} \mathrm{O}-$ labeled hydroxyl radical will be generated if the mechanism is the release of hydroxyl radical, and ${ }^{18} \mathrm{O}$-labeled water will be generated if the mechanism is involved in benzotriazinyl radical (5).

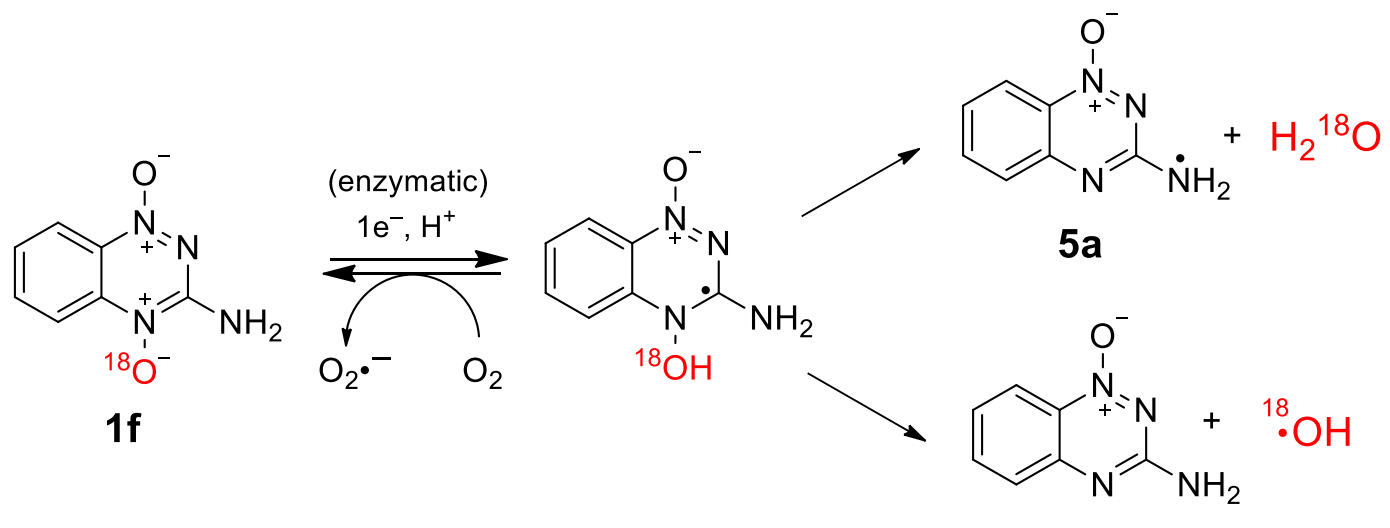

$3 a$

Scheme 4.2. In vitro enzymatic metabolism of ${ }^{18} \mathrm{O}$-lebaled TPZ (1f).

As reported in the previous literature, dimethyl sulfoxide (DMSO) can react with hydroxyl radical $\left(\mathrm{k}=7 \times 10^{9} \mathrm{M}^{-1} \mathrm{sec}^{-1}\right)^{3}$ and generate high yield of methanesulfinic acid (MSA, Scheme 4.3). ${ }^{4-7}$ Therefore, the ${ }^{18}$ O-labeled hydroxyl radical can be effectively trapped by DMSO to form ${ }^{18} \mathrm{O}$-labeled MSA (Scheme 4.3). We put extensive efforts to characterize MSA on LC-MS, but finally failed due to several reasons. First, MSA is not very stable under room temperature. According to Wudl and co-workers ${ }^{8}$, the decomposition was apparent within $48 \mathrm{~h}$ under $25{ }^{\circ} \mathrm{C}$ stored in nitrogen. Second, it is difficult to obtain the non-fragmented molecular ion of MSA (for $\mathrm{M}+, \mathrm{m} / \mathrm{z}=80$; for $\left.[\mathrm{M}+\mathrm{H}]^{+}, \mathrm{m} / \mathrm{z}=81\right)$ on MS, though there were established methods to detect MSA on HPLC electrochemically. ${ }^{9}$ 


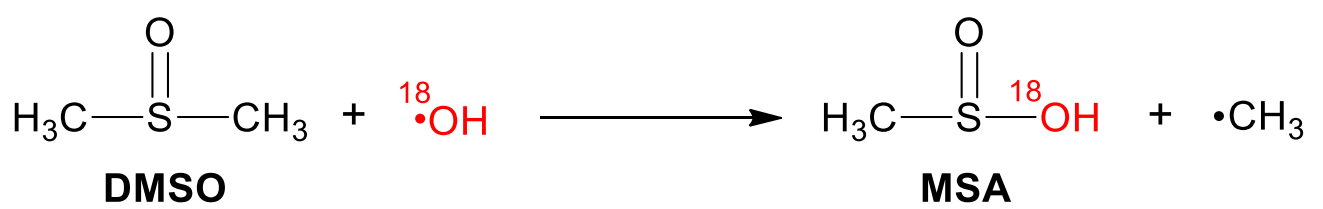

Scheme 4.3. Effective trapping of hydroxyl radical with DMSO that yields MSA.

Therefore, the ${ }^{18} \mathrm{O}$-labeled hydroxyl radical can be characterized with HPLC by derivatization of MSA with diazonium salts (9) to form stable diazosulfones (8) as described in Fukui S., et al. ${ }^{10-12}$ And mass spectrometry can be used to determine the structure of the ${ }^{18} \mathrm{O}$-labeled diazosulfone $(\mathbf{8})$ and quantify the yield.

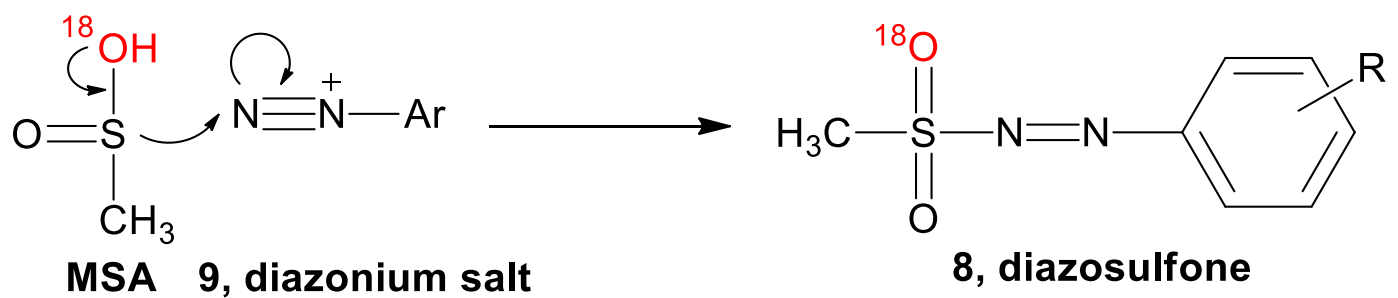

Scheme 4.4. The formation of diazosulfone by MSA and diazonium salts.

\subsection{Preliminary data}

\subsubsection{Synthesis of authentic diazosulfones 8a-b}

Diazosulfones are synthesized by mixing MSA and diazonium salts under room temperature. Therefore, a series of commercially available diazonium salts were collected and tested according to the stability and yield of the product, diazosulfones (8). Among them, fast red TR diazonium salt (9a) and fast blue BB diazonium salt $(\mathbf{9 b})$ were selected, with yields of diazosulfone $88 \%$ and $76 \%$, respectively (Scheme 4.5 ). 
<smiles>Cc1cc(Cl)ccc1N=NS(C)(=O)=O</smiles>

$8 a$<smiles>CCOc1cc(NC(=O)c2ccccc2)c(OCC)cc1N=NS(C)(=O)=O</smiles>

$8 b$<smiles>Cc1cc(Cl)ccc1[N+]#N</smiles>

9a, Fast red TR salt<smiles>CCOc1cc(NC(=O)c2ccccc2)c(OCC)cc1[N+]#N</smiles>

9b, Fast blue BB salt

Scheme 4.5. Diazosulfones (8a-b) and the corresponding diazonium salts (9a-b).

\subsubsection{HPLC detection of diazosulfone 8a}

UV absorption spectrum was recorded for 8a (Figure 4.1). The UV absorption maximum is $314 \mathrm{~nm}$ with an extinction coefficient $\varepsilon=9400 \mathrm{~L} \cdot \mathrm{mol}^{-1} \cdot \mathrm{cm}^{-1}$. Then HPLC was employed to detect 8a under $314 \mathrm{~nm}$. As shown in Figure 4.2, with an isocratic elution (water:acetonitrile $=60: 40$ ), the authentic diazosulfone 8a was eluted at $32.7 \mathrm{~min}$ with good peak shape.

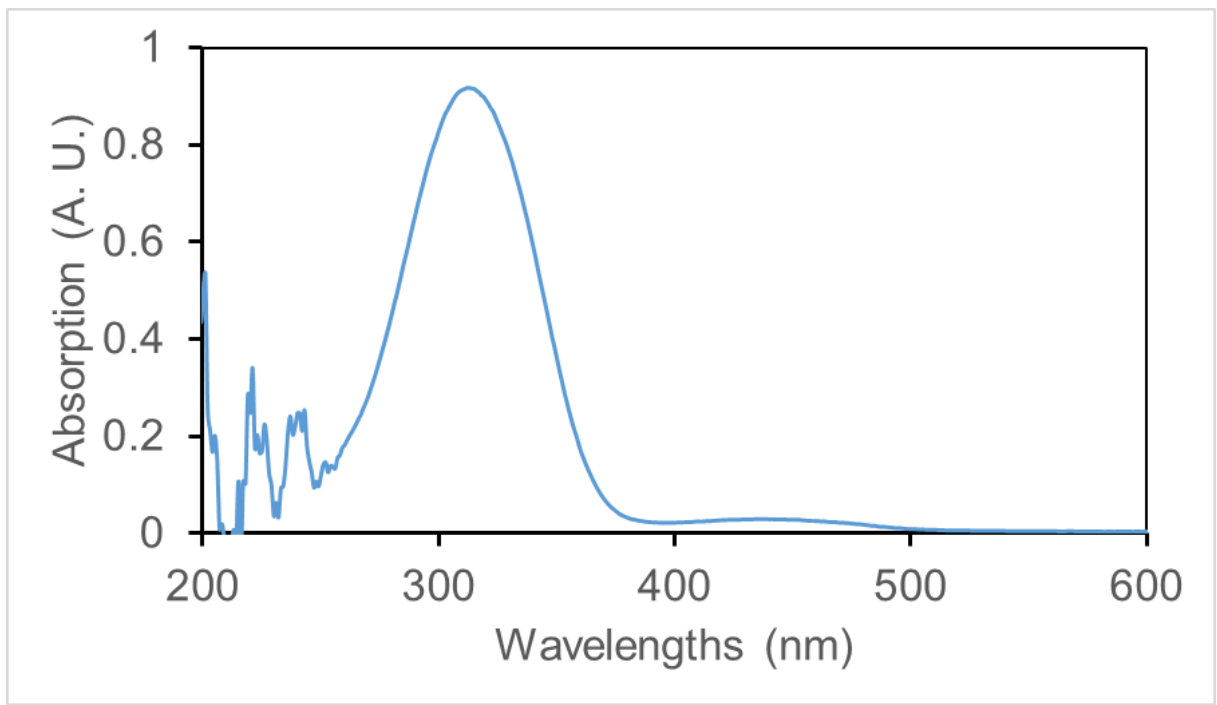

Figure 4.1. UV absorption spectrum of $100 \mu \mathrm{M}$ 8a in DMSO. 


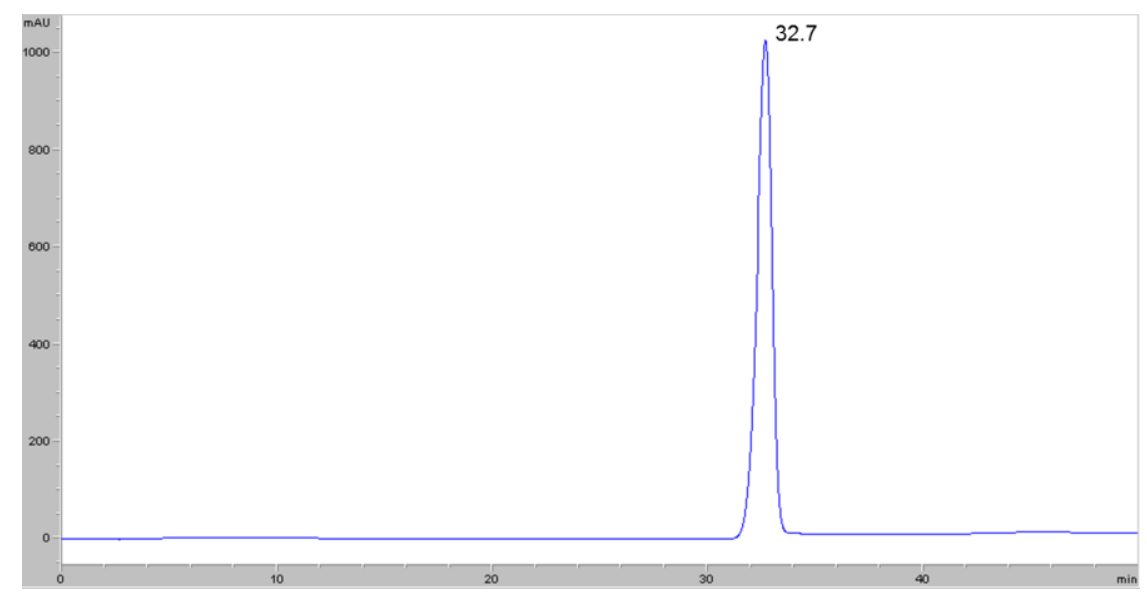

Figure 4.2. HPLC chromatogram of $10 \mathrm{mM}$ of 8a in DMSO.

\subsubsection{DMSO tolerance of in-vitro hypoxic enzymatic assays of 1a}

In order to use MS to analyze the isotopic ratio of $\mathbf{8 a}$, the mobility of hydroxyl radical in aqueous solution needs to be considered (Scheme 4.6). ${ }^{13,14}$ According to the study of Dubey, M. K.; et al. ${ }^{15}$, the isotope exchange rate of hydroxyl radical with water is very slow (time constant for exchange is about 350 years). Proper operations are still needed to maximize the reaction of hydroxyl radical with diazonium salts, minimizing the chance of the competitive isotope exchange reaction.

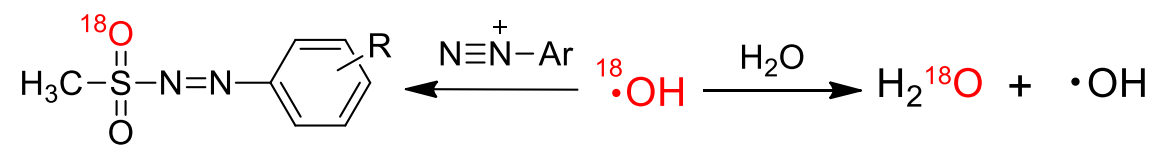

Scheme 4.6. The potential solvent exchange reaction of hydroxyl radical and water.

In this regard, $20 \%, 30 \% 40 \%, 50 \%, 60 \%$ and $76 \%$ volume ratio of DMSO were employed to determine the tolerance of DMSO in the hypoxic enzymatic assays of 1a. In a typical assay, $500 \mu \mathrm{M} 1 \mathrm{a}$ was mixed with degassed xanthine, xanthine oxidase, sodium phosphate buffer and DMSO and incubated under hypoxic conditions for 4 hours. Figure 4.3 showed that under as much as 50\% DMSO (volume ratio), the in-vitro metabolism is 
not affected and the parent compound 1a was totally reduced to 3a and $\mathbf{6}$. However, under $60 \%$ and $76 \%$ DMSO, almost no reactant $1 \mathrm{a}$ was metabolized into product.

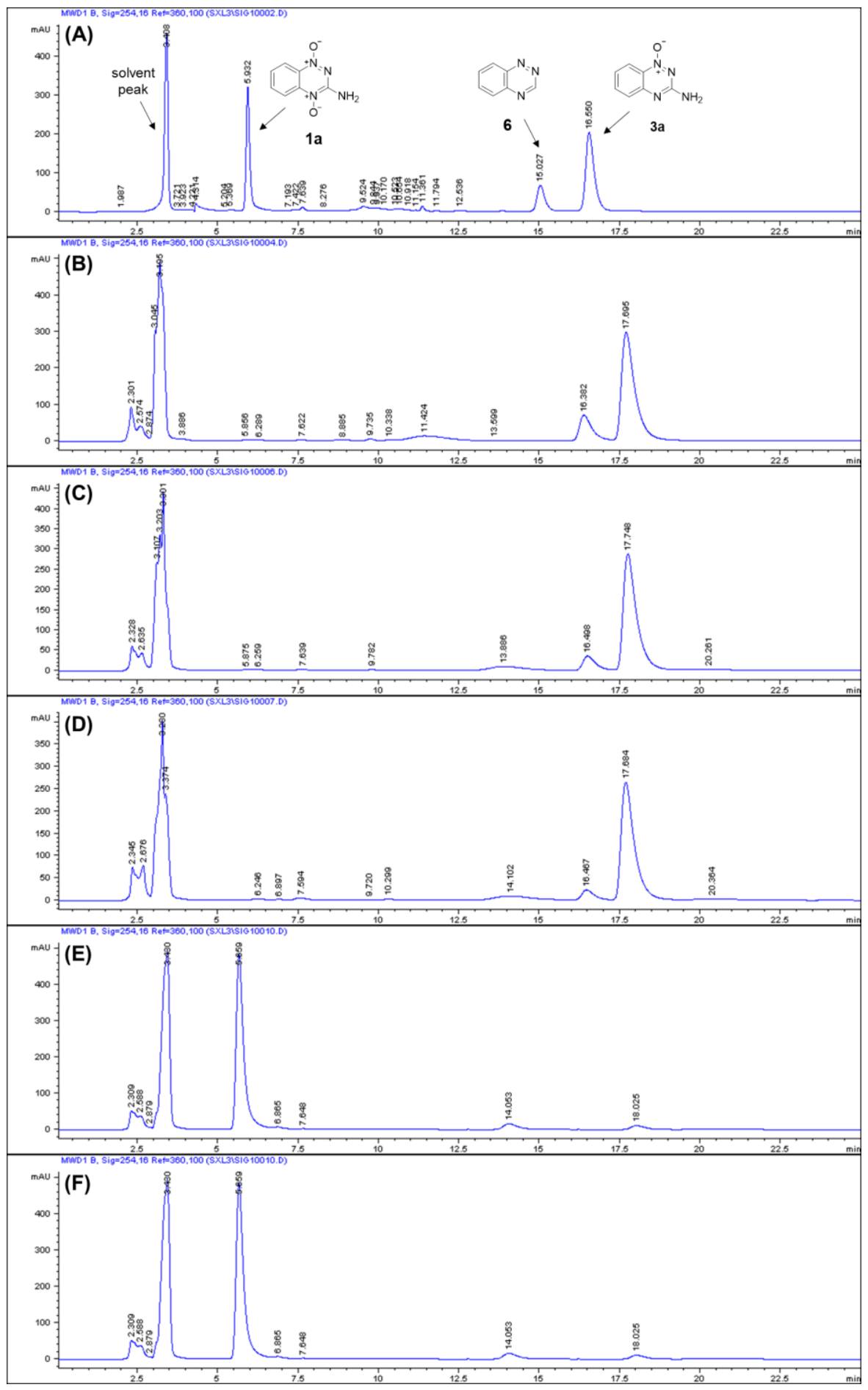

Figure 4.3. HPLC chromatogram of DMSO tolerance assay. (A) $20 \%$ DMSO (v/v); (B) 30\%; (C) 40\%; (D) 50\%; (E) 60\%; (F)76\%. 


\subsubsection{MS characterization of the authentic diazosulfones 8a-b}

Prior to the mass spectrometric analysis of the metabolites of in-vitro enzymatic assay under hypoxic conditions by 1f, MS for the authentic compounds 8a-b were analyzed by direct injection to MS. Fast red TR derived diazosulfone 8a was ionized by chemical ionization (CI) in positive ion mode and the MS spectra showed mass-to-charge ratio of the molecular ion $\left([\mathrm{M}+\mathrm{H}]^{+}\right)$as 233 and 235 with a 3:1 ratio (Figure 4.4), which is corresponding to the isotope of $\mathrm{Cl}$ atom $\left({ }^{35} \mathrm{Cl}\right.$ and $\left.{ }^{37} \mathrm{Cl}\right)$. It is expected that the isotopic ratio of peak 235 would increase significantly relative to 233 and 237 due to ${ }^{18} \mathrm{O}$ in enzymatic assay of $\mathbf{1 f}$ under hypoxic conditions. Similarly, $\mathbf{8 b}$ was also characterized with electrospray ionization (ESI) under positive ion mode with $\mathrm{m} / \mathrm{z}=392$ for the molecular ion (Figure 4.5 panel D).

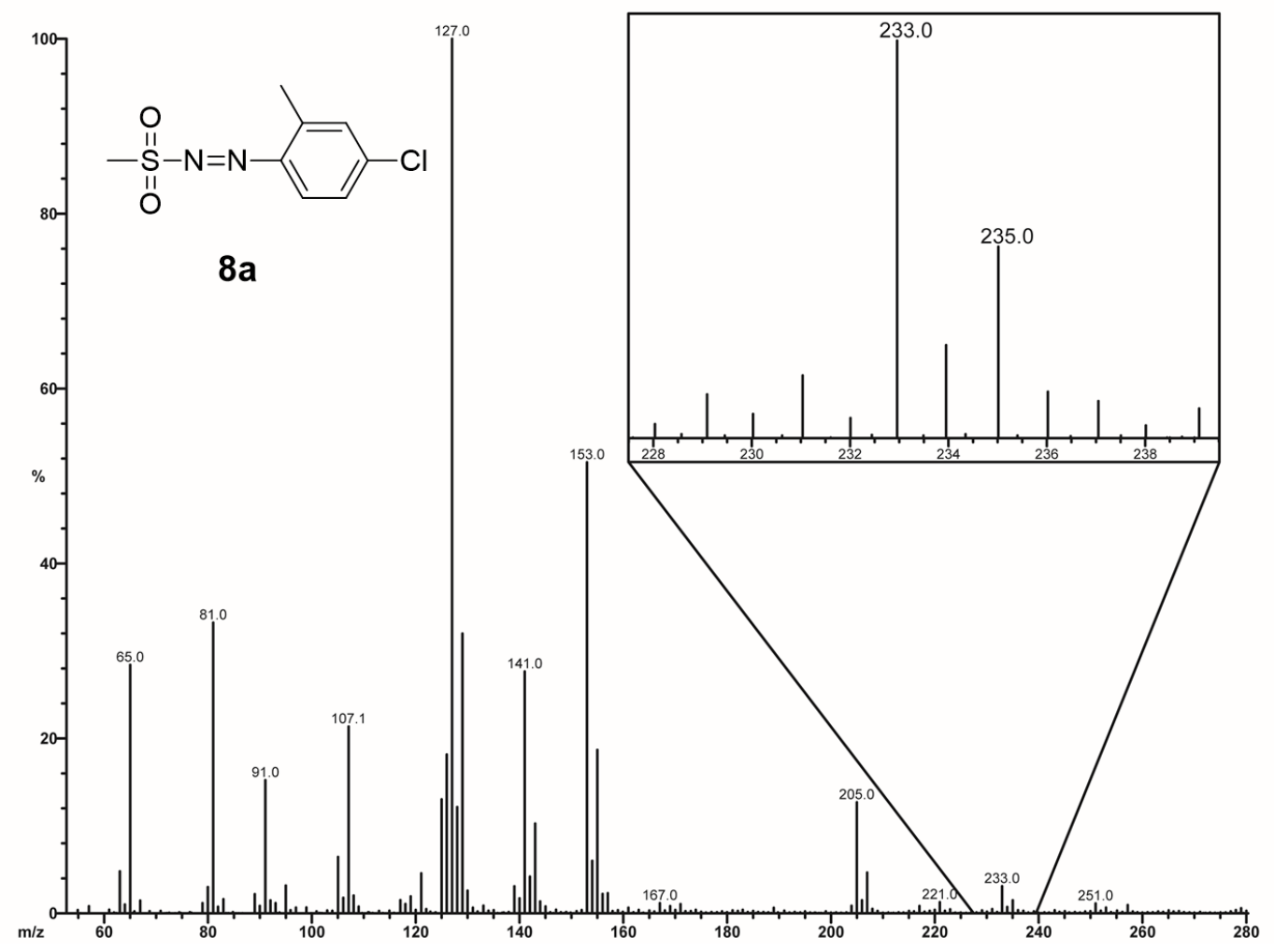

Figure 4.4. MS spectra of $8 \mathbf{a}$ with CI ionization in position ion mode. 
Before direct injection, efforts were devoted to analyzed the diazosulfones by LCMS. But finally we found that $\mathbf{8 a - b}$ decomposed rapidly to diazonium salt $\mathbf{9 a - b}$ under acidic condition prior to MS analysis. As shown in Figure 4.5, 8b was eluted at $15.27 \mathrm{~min}$ in $\mathrm{pH}$ neutral condition. However, $8 \mathbf{b}$ totally decomposed to the corresponding diazonium salt $9 \mathbf{b}$ (eluted at $8.88 \mathrm{~min}$ ) with co-injection of 1\% TFA (Figure 4.5).

(A)

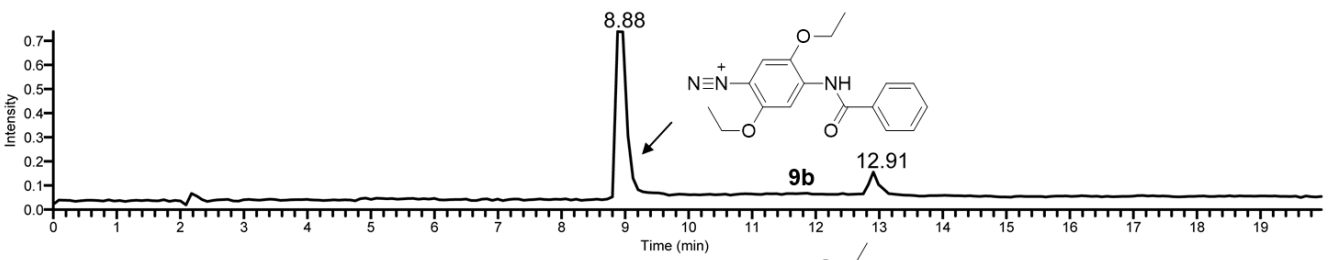

(B)

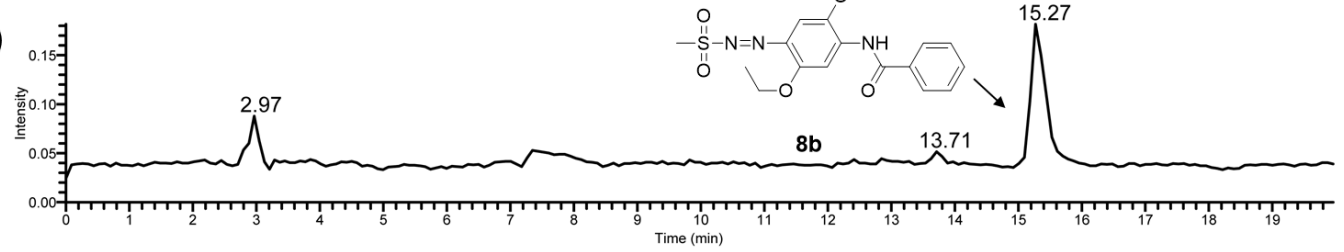

(C)

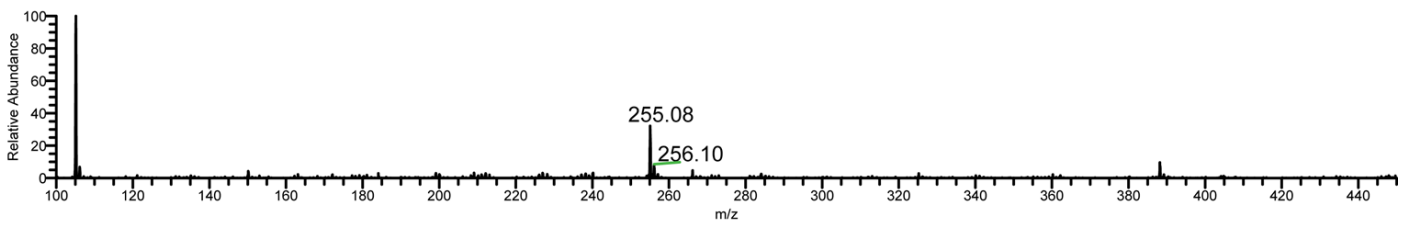

(D)

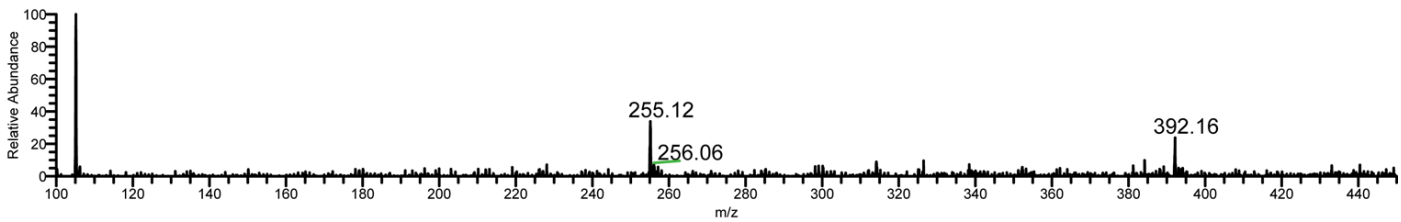

Figure 4.5. LC-MS spectra of 8a with ESI ionization in position ion mode. (A) sample was injected with $1 \%$ TFA; (B) samples was injected without TFA; (C) MS spectra of the peak at $8.88 \mathrm{~min}$; (D) MS spectra of the peak at $15.27 \mathrm{~min}$.

\subsection{Specific aims}

\subsubsection{Estimation of the yield of 8a-b in enzymatic metabolism of 1a}

As shown in section 3.4 and 4.2.2, calibration curves of $8 \mathbf{a}$ can be established with concentrations of $10 \mu \mathrm{M}, 20 \mu \mathrm{M}, 50 \mu \mathrm{M}, 100 \mu \mathrm{M}, 200 \mu \mathrm{M}$ and $500 \mu \mathrm{M}$ authentic 
compound. By comparing the HPLC peak integration in the enzymatic assay with the calibration curve, the estimated yield of $\mathbf{8 a}$ generated in the assay can be determined. It is expected that enzymatic assay of $\mathbf{1 a}$ and $\mathbf{1 f}$ generated high yield of ${ }^{18} \mathrm{O}$ labeled $\mathbf{8 a}$.

\subsubsection{MS analysis of the 8a-b generated in enzymatic assay of 1a and 1f}

MS analysis of 8a-b generated by non- ${ }^{18} \mathrm{O}$ labeled dioxide 1a was used to establish the methods of MS. Then the hypoxia-selective, enzymatically activated in-vitro metabolism of $\mathbf{1 f}$ with $50 \%$ DMSO can be performed and the isotopic ratio analysis can be done to estimate the amount of hydroxyl radical generated. If $\mathbf{8 a}$ is completely ${ }^{18} \mathrm{O}$ labeled, it is expected that mass-to-charge ratio would be: 235.01 (100.0\%), 237.01

(36.6\%), $238.01(10.2 \%)$. If $\mathbf{8 b}$ is partially ${ }^{18} \mathrm{O}$ labeled, it is expected that the ratio of $235: 237$ is lower than $3: 1$ and there would be substantial amount of peak that $\mathrm{m} / \mathrm{z}=233$.

\subsubsection{Controls}

Proper controls must be performed to elucidate that the diazosulfones are formed by the hydroxyl radical generated during the enzymatic metabolism of 1a and 1f. In that case, assays that lack the drug (1a and 1f), lack the enzyme system (X/XO), lack the enzyme (XO), lack the hydrogen donor (xanthine) must be tested.

In addition, A complementary assay that used non- ${ }^{18} \mathrm{O}$-labeled $\mathbf{1 a}$ with $\mathrm{H}_{2}{ }^{18} \mathrm{O}$ should also be performed. By varying DMSO concentration, the effect of isotope exchange of MSA with solvent can be evaluated. 


\subsection{Experimental section}

Materials. Materials were of the highest purity available and were obtained from the following sources: cytochrome P450 reductase, NADPH, xanthine, sodium phosphate, DMSO, fast red TR salt hemi(zinc chloride) salt, fast blue BB salt hemi(zinc chloride) salt, sodium methanesulfinate, silica gel (0.04-0.063 mm pore size) for column chromatography, and silica gel plates for thin layer chromatography from Sigma Chemical Co. (St. Louis, MO); xanthine oxidase from Roche Applied Science; HPLC grade solvents (acetonitrile, methanol, ethyl acetate, hexane, trifluoroacetic acid and acetic acid) from Fischer (Pittsburgh, PA); deuterated NMR solvents were from Cambridge Isotope Laboratories (Andover, MA).

Synthesis of 8a. In a $100 \mathrm{~mL}$ round-bottom flask, $210 \mathrm{mg}(0.81 \mathrm{mmol})$ of fast red TR salt hemi(zinc chloride) salt (9a) was dissolved in $20 \mathrm{~mL}$ water and the $\mathrm{pH}$ was adjusted to 4 using $1 \mathrm{M} \mathrm{HCl}$, then $20 \mathrm{~mL}$ solution of sodium methanesulfinate $(171 \mathrm{mg}$, $1.67 \mathrm{mmol}$ ) in water was added. The reaction was stirred with aluminum foil for $30 \mathrm{~min}$. Then column chromatography (ethyl acetate:hexane $=20: 80$ ) was used to purify the product. $162 \mathrm{mg}$ of yellow solid of $\mathbf{8 a}$ was obtained in 88\% yield: 1H NMR (500 MHz, DMSO-d $\left._{6}\right) \delta 7.71(\mathrm{~d}, \mathrm{~J}=2.0 \mathrm{~Hz}, 1 \mathrm{H}), 7.64(\mathrm{~d}, \mathrm{~J}=8.5 \mathrm{~Hz}, 1 \mathrm{H}), 7.48(\mathrm{dd}, \mathrm{J}=8.5,2.0 \mathrm{~Hz}$, $1 \mathrm{H}), 3.42(\mathrm{~s}, 3 \mathrm{H})$ and $2.64(\mathrm{~s}, 3 \mathrm{H}) ; 13 \mathrm{C}$ NMR (125 MHz, DMSO-d 6$) \delta$ 145.2, 143.6, $140.2,131.9,127.6,117.6,34.7,16.9$.

Synthesis of $8 \mathbf{b}$. In a $100 \mathrm{~mL}$ round-bottom flask, $166 \mathrm{mg}(0.4 \mathrm{mmol})$ of fast blue BB salt hemi(zinc chloride) salt (9b) was dissolved in $20 \mathrm{~mL}$ water and the $\mathrm{pH}$ was 
adjusted to 4 using $1 \mathrm{M} \mathrm{HCl}$, then $20 \mathrm{~mL}$ solution of sodium methanesulfinate $(204 \mathrm{mg}, 2$ mmol) was added. The reaction was stirred with aluminum foil for $30 \mathrm{~min}$. Then column chromatography (ethyl acetate:hexane $=30: 70$ ) was used to purify the product. $120 \mathrm{mg}$ of orange solid of $\mathbf{8 b}$ was obtained in $76 \%$ yield: $1 \mathrm{H} \mathrm{NMR}\left(500 \mathrm{MHz}, \mathrm{CD}_{3} \mathrm{CN}\right) \delta 9.13$ (s, 1 H), 8.57 (s, $1 \mathrm{H}), 7.96$ (d, J = 8.0 Hz, $2 \mathrm{H}), 7.68$ (dd, J = 7.0, 7.0 Hz, $1 \mathrm{H}), 7.60$ (dd, J = 8.0, 7.0 Hz, $2 \mathrm{H}), 7.32$ (s, $1 \mathrm{H}), 4.32$ (ddd, J = 7.0, 7.0, 7.0 Hz, $2 \mathrm{H}), 4.21(\mathrm{dd}, \mathrm{J}=7.0,7.0$ $\mathrm{Hz}, 2 \mathrm{H}), 3.18(\mathrm{~s}, 1 \mathrm{H})$ and $1.49(\mathrm{dd}, \mathrm{J}=7.0,7.0 \mathrm{~Hz}, 3 \mathrm{H}), 1.48(\mathrm{dd}, \mathrm{J}=7.0,7.0 \mathrm{~Hz}, 3$ $\mathrm{H})$; 13C NMR (125 MHz, CD $\left.{ }_{3} \mathrm{CN}\right) \delta$ 166.5, 157.3, 143.5, 139.2, 135.1, 133.9, 133.6, $130.0,128.3,105.8,99.1,66.8,66.3,35.7,15.0,14.8$.

HPLC analysis of 8a. HPLC analysis were achieved by an Agilent 1100 series HPLC equipped with autosampler using external standard method. Authentic solution of 8a was prepared in $10 \mathrm{mM}$ in DMSO and detected by UV-absorbance at $314 \mathrm{~nm}$ with the isocratic eluent (Water:Acetonitrile $=60: 40$ ) in $50 \mathrm{~min}$.

HPLC calibration curves. Calibration curves were achieved by an Agilent 1100 series HPLC equipped with autosampler using external standard method. Standard solutions of $\mathbf{8 a}(10,20,30,50,100,500 \mu \mathrm{M}$ in DMSO) were prepared using serial dilution from their higher concentration standard solutions and detected by UVabsorbance at $314 \mathrm{~nm}$ with the isocratic eluent (Water:Acetonitrile= 60:40) in $50 \mathrm{~min}$.

General procedure for in-vitro enzymatic assays. In an hypoxic assay, BTO dioxides (1a and 1f-g, $500 \mu \mathrm{M})$ were incubated with NADPH (2 mM) or xanthine (2 
$\mathrm{mM})$, cytochrome $\mathrm{P} 450$ reductase $(0.13 \mathrm{U} / \mathrm{mL}$, where one unit is defined as the amount of enzyme required to reduce $1.0 \mu$ mole of cytochrome $c$ by NADPH per minute at $\mathrm{pH}$ 7.4 at $\left.37^{\circ} \mathrm{C}\right)$ or xanthine oxidase $(0.04 \mathrm{U} / \mathrm{mL}$, where one unit is defined as the amount of enzyme required to oxidize approximately $1 \mathrm{mg}$ xanthine at $25^{\circ} \mathrm{C}$ ), sodium phosphate buffer (50 mM, pH 7.0), DMSO (20-50\% v/v), diazonium salts (9a-b, $10 \mathrm{mg} / \mathrm{mL})$ and HPLC grade $\mathrm{H}_{2} \mathrm{O}$ (or $\mathrm{H}_{2}{ }^{18} \mathrm{O}$ ) to obtain the final solution $(0.5 \mathrm{~mL}$ final volume) under anaerobic conditions at $25{ }^{\circ} \mathrm{C}$ for $4 \mathrm{~h}$. All components of the reactions except enzymes and NADPH were degassed by three freeze-pump-thaw cycles. Enzymes and NADPH were diluted with degassed water in an argon-filled glovebag to prepare stock solutions. Reactions were initiated by the addition of enzymes, wrapped in aluminum foil to prevent exposure to light, and incubated in an argon-filled glovebag.

Sample preparation for MS. Upon incubation, the assays were diluted with 0.5 $\mathrm{mL}$ sodium phosphate buffer (50 mM, pH 7.0). Two methods can be used to extract the diazosulfone with minimum amount of DMSO. One method involves the extraction with ethyl acetate, freeze the solution with dry ice (DMSO will freeze but ethyl acetate is not) then collect the top layer. Another method is to dilute the assay to $50 \mathrm{~mL}$ and extract with $50 \mathrm{~mL}$ ethyl acetate. Then the ethyl acetate extract can be dried with speed vacuum and the samples are analyzed by a LCQ FLEET instrument (the samples are coming through a short purification column, therefore compounds showed retention time in Figure 4.5) (Thermo Fisher Scientific) or a VG 70-VSE(B) instrument with positive ion mode. 


\section{${ }^{1} \mathrm{H}$ NMR of 8a (DMSO, $500 \mathrm{MHz}$ )}

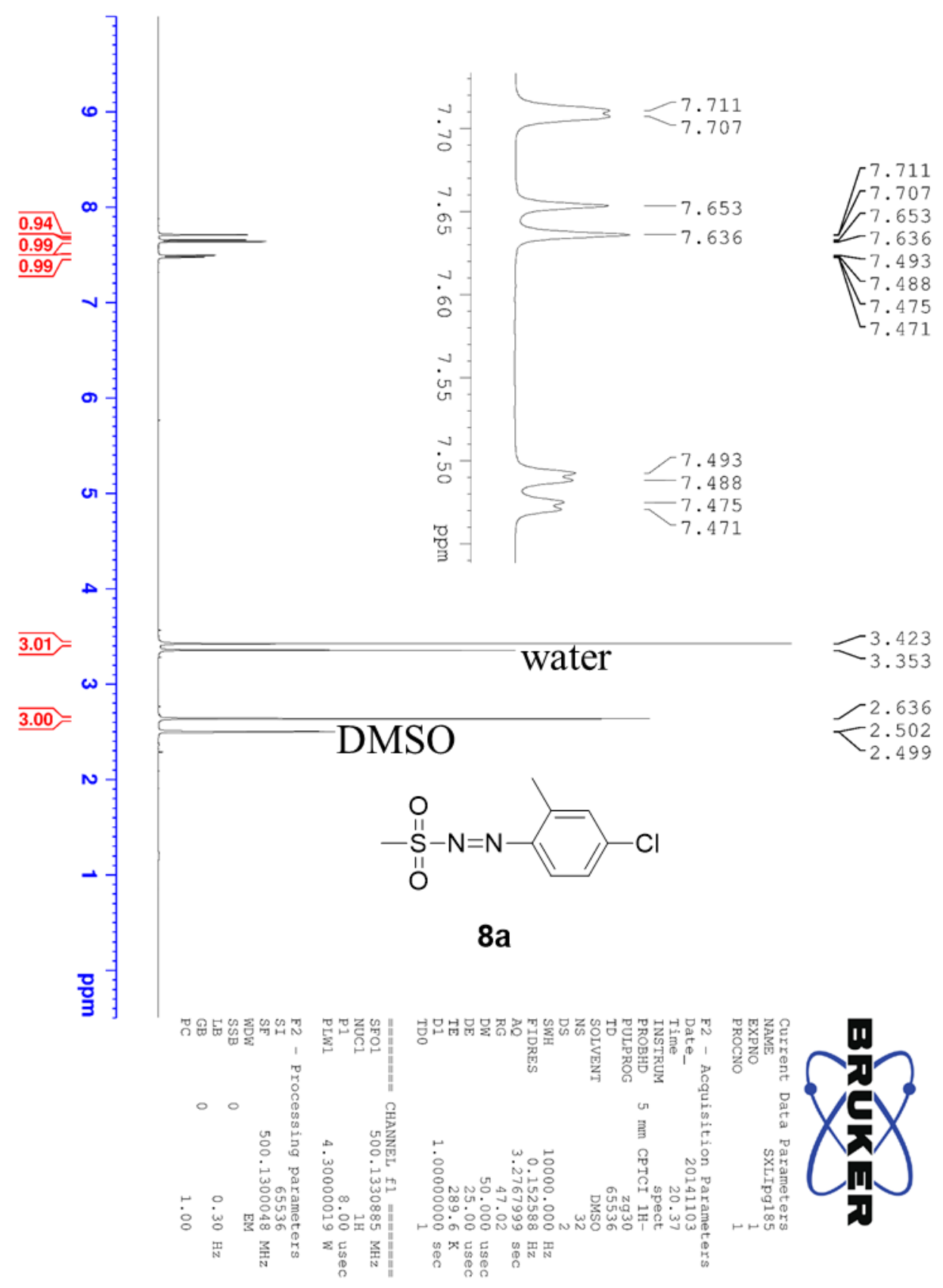




\section{${ }^{13} \mathrm{C}$ NMR of 8a (DMSO, $\left.125.8 \mathrm{MHz}\right)$}

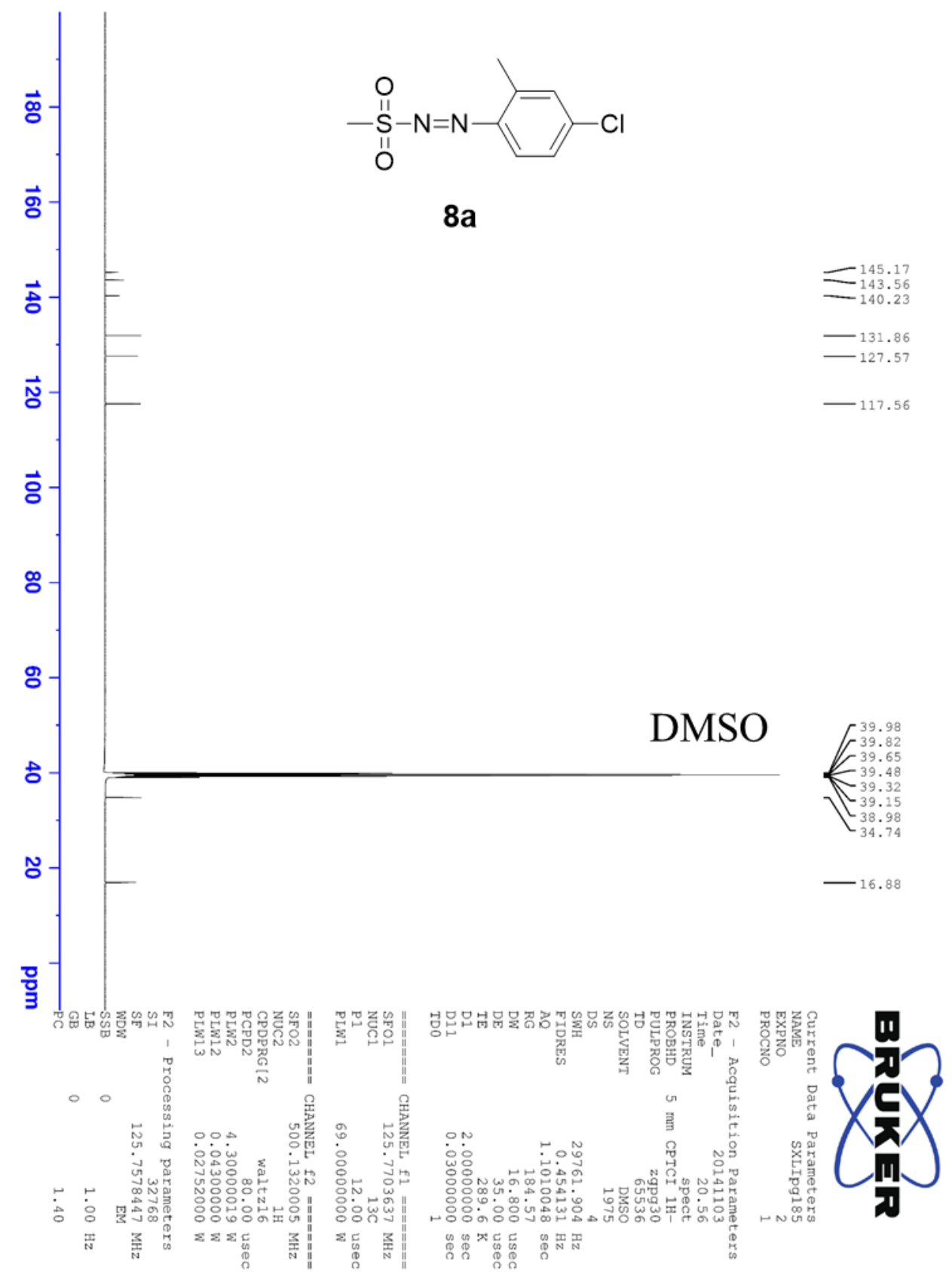




\section{${ }^{1} \mathrm{H}$ NMR of $8 \mathrm{~b}\left(\mathrm{CH}_{3} \mathrm{CN}, 500 \mathrm{MHz}\right)$}

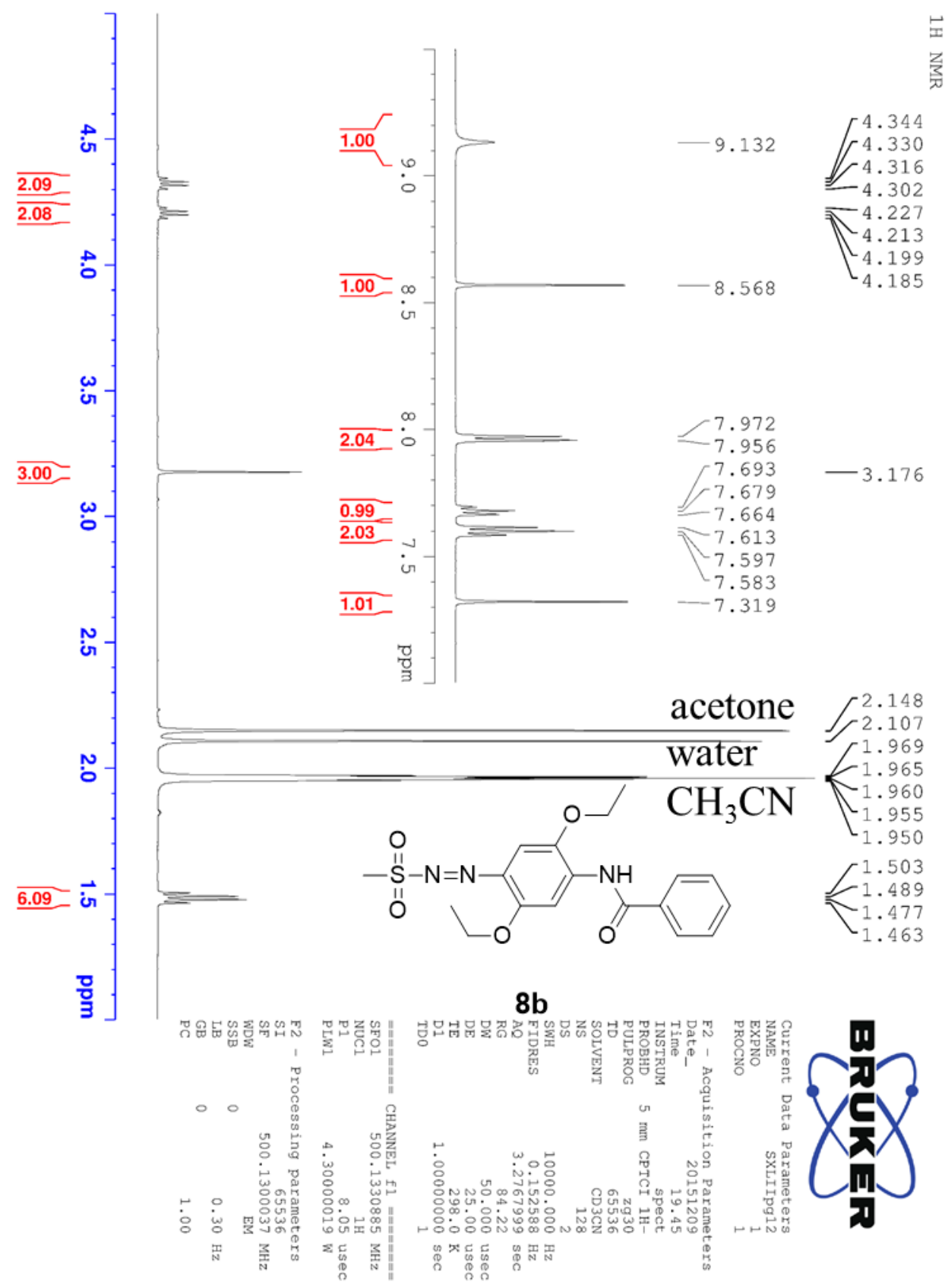




\section{${ }^{13} \mathrm{C} N M R$ of $8 \mathrm{~b}\left(\mathrm{CD}_{3} \mathrm{CN}, 125.8 \mathrm{MHz}\right)$}

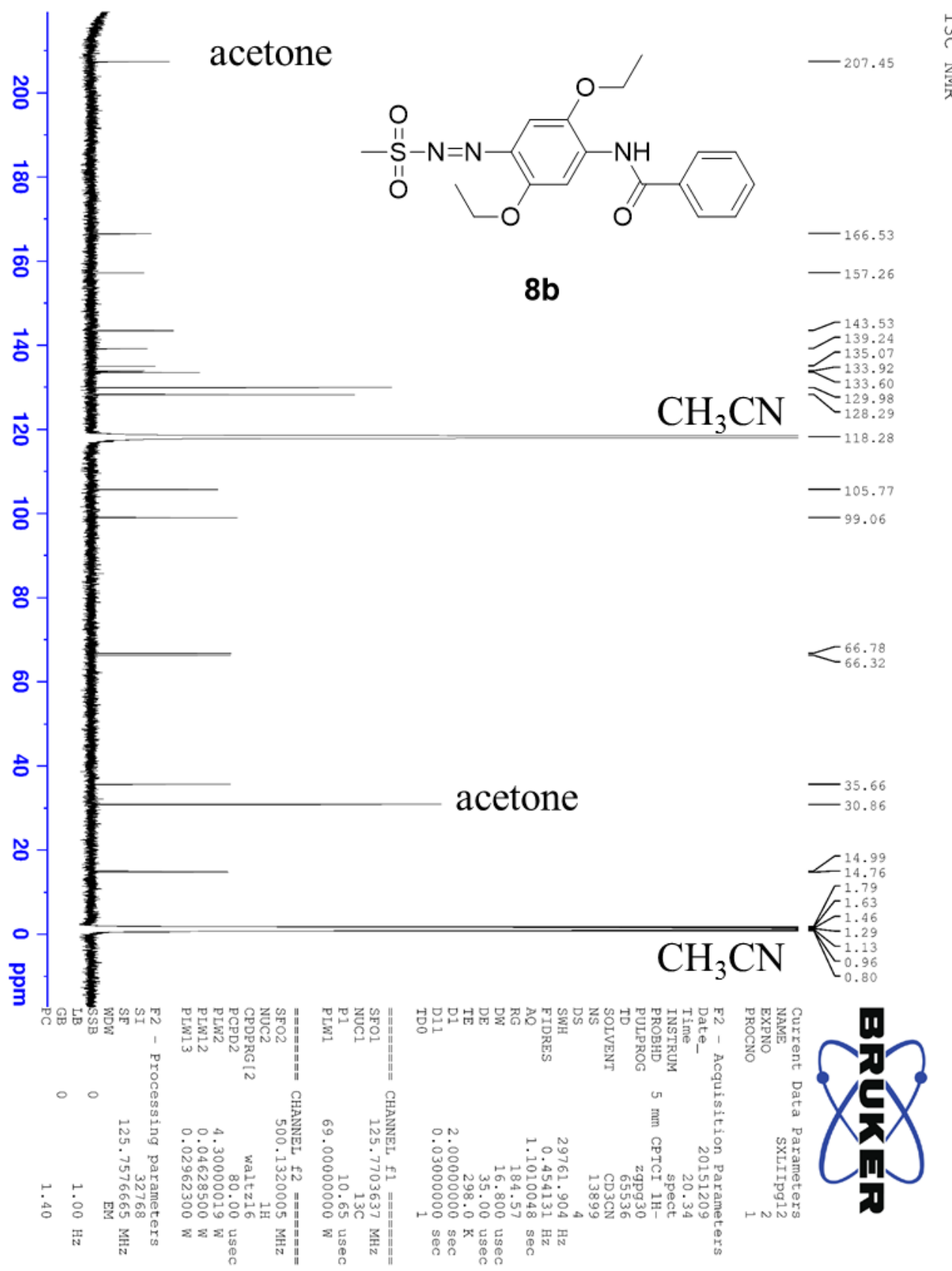




\subsection{References}

(1) Gatenyo, J.; Johnson, K.; Rajapakse, A.; Gates, K. S.; Rozen, S., Transferring oxygen isotopes to 1,2,4-benzotriazine 1-oxides forming the corresponding 1,4-dioxides by using the HOF. $\mathrm{CH}_{3} \mathrm{CN}$ complex. Tetrahedron 2012, 68 (43), 8942-8944.

(2) Doyle, M. P.; Dellaria Jr, J. F.; Siegfried, B.; Bishop, S. W., Reductive deamination of arylamines by alkyl nitrites in N,N-dimethylformamide. A direct conversion of arylamines to aromatic hydrocarbons. The Journal of Organic Chemistry 1977, 42 (22), 3494-3498.

(3) Dorfman, L. M.; Adams, G. E. Reactivity of the hydroxyl radical in aqueous solutions, DTIC Document, 1973.

(4) Dixon, W.; Norman, R.; Buley, A., 701. Electron spin resonance studies of oxidation. Part II. Aliphatic acids and substituted acids. Journal of the Chemical Society (Resumed) 1964, 3625-3634.

(5) Lagercrantz, C.; Forshult, S., Trapping of short-lived free radicals as nitroxide radicals detectable by ESR spectroscopy. The radicals formed in the reaction between OH-radicals and some sulphoxides and sulphones. Acta Chemica Scandinavica 1969, 23 (81), 1-817.

(6) Klein, S. M.; Cohen, G.; Cederbaum, A. I., Production of formaldehyde during metabolism of dimethyl sulfoxide by hydroxyl radical-generating systems. Biochemistry 1981, 20 (21), 6006-6012.

(7) Steiner, M. G.; Babbs, C. F., Quantitation of the hydroxyl radical by reaction with dimethyl sulfoxide. Archives of biochemistry and biophysics 1990, 278 (2), 478-481. 
(8) Wudl, F.; Lightner, D. A.; Cram, D. J., Methanesulfinic acid and its properties. Journal of the American Chemical Society 1967, 89 (16), 4099-4101.

(9) Jahnke, L. S., Measurement of hydroxyl radical-generated methane sulfinic acid by high-performance liquid chromatography and electrochemical detection. Analytical biochemistry 1999, 269 (2), 273-277.

(10) Fukui, S.; Hanasaki, Y.; Ogawa, S., High-performance liquid chromatographic determination of methanesulphinic acid as a method for the determination of hydroxyl radicals. Journal of Chromatography A 1993, 630 (1-2), 187-193.

(11) Daniels, J. S.; Gates, K. S., DNA cleavage by the antitumor agent 3-amino-1,2,4benzotriazine 1,4-dioxide (SR4233): Evidence for involvement of hydroxyl radical. Journal of the American Chemical Society 1996, 118 (14), 3380-3385.

(12) Junnotula, V.; Sarkar, U.; Sinha, S.; Gates, K. S., Initiation of DNA strand cleavage by 1,2,4-benzotriazine 1,4-dioxide antitumor agents: mechanistic insight from studies of 3-methyl-1,2,4-benzotriazine 1,4-dioxide. Journal of the American Chemical Society 2008, 131 (3), 1015-1024.

(13) Codorniu-Hernández, E.; Kusalik, P. G., Insights into the solvation and mobility of the hydroxyl radical in aqueous solution. Journal of Chemical Theory and Computation 2011, 7 (11), 3725-3732.

(14) Codorniu-Hernández, E.; Kusalik, P. G., Mobility mechanism of hydroxyl radicals in aqueous solution via hydrogen transfer. Journal of the American Chemical Society 2011, 134 (1), 532-538.

(15) Dubey, M. K.; Mohrschladt, R.; Donahue, N. M.; Anderson, J. G., Isotope specific kinetics of hydroxyl radical $(\mathrm{OH})$ with water $\left(\mathrm{H}_{2} \mathrm{O}\right)$ : Testing models of reactivity 
and atmospheric fractionation. The Journal of Physical Chemistry A 1997, 101 (8), 14941500. 
Xiulong Shen was born in Rizhao, China, the younger child of the two. He finished his Bachelor degree of Pharmaceutical Science and Technology from Tianjin University, China in May 2011. Then he started his graduate study in chemistry at the University of Missouri-Columbia in September 2011, where he joined in Dr. Kent S. Gates's research group in January 2012. He worked on elucidating the mechanism of hypoxia-selective antitumor prodrugs and the development of fluorescent probes for drug-related bioreductive enzymes. He graduated with a Ph.D. degree in chemistry from the University of Missouri-Columbia in December 2016. He will continue as a postdoctoral fellow in Dr. David R. Corey research group at the University of Texas Southwestern Medical Center in Dallas, TX. 